University of Louisville

ThinkIR: The University of Louisville's Institutional Repository

Electronic Theses and Dissertations

$12-2007$

\title{
Globalization and social work education : an initial international inquiry.
}

Elaine Rushmore Wright

University of Louisville

Follow this and additional works at: https://ir.library.louisville.edu/etd

\section{Recommended Citation}

Wright, Elaine Rushmore, "Globalization and social work education : an initial international inquiry." (2007). Electronic Theses and Dissertations. Paper 1594.

https://doi.org/10.18297/etd/1594

This Doctoral Dissertation is brought to you for free and open access by ThinkIR: The University of Louisville's Institutional Repository. It has been accepted for inclusion in Electronic Theses and Dissertations by an authorized administrator of ThinkIR: The University of Louisville's Institutional Repository. This title appears here courtesy of the author, who has retained all other copyrights. For more information, please contact thinkir@louisville.edu. 


\title{
GLOBALIZATION AND SOCIAL WORK EDUCATION:
}

\section{AN INITIAL INTERNATIONAL INQUIRY}

\author{
by
}

Elaine Rushmore Wright

B.S.W., Brescia University, 1995

M.S.S.W., University of Louisville, 1998

\author{
A Dissertation \\ Submitted to the Faculty of the \\ Graduate School of the University of Louisville \\ in Partial Fulfillment of the Requirements \\ for the Degree of \\ Doctor of Philosophy \\ Kent School of Social Work \\ University of Louisville \\ Louisville, Kentucky \\ and \\ College of Social Work \\ University of Kentucky \\ Lexington, Kentucky
}

December, 2007 

Copyright by Elaine R. Wright

All rights reserved 


\title{
GLOBALIZATION AND SOCIAL WORK EDUCATION:
}

AN INITIAL INTERNATIONAL INQUIRY

\author{
by
}

\author{
Elaine R. Wright \\ B.S.W., Brescia University, 1995 \\ M.S.S.W., University of Louisville, 1998 \\ A Dissertation Approved on
}

November 12, 2007

By the following Dissertation Committee:

Thomas R. Lawson, Ph.D., Chair

Joe H. Brown, Ph.D.

James J. Clark, Ph.D.

Ruth Huber, Ph.D.

Pam A. Yankeelov, Ph.D. 


\section{DEDICATION}

To my grandparents:

John \& Alice Wright.

Arlo \& Elaine Brown

To my parents:

John \& Brenda Wright

To my siblings and their families:

Jack \& Mary Lynn Wright ........................................ Andrew \& Meredith Wright

Kati, Jay, and Emma

Josephine

Thank you for all of your love and support.

Om namaha shivaya 


\section{ACKNOWLEDGMENTS}

To my chair: Dr. Tom Lawson

To my committee: Drs. Joe Brown, Jim Clark, Ruth Huber, and Pam Yankeelov

To the schools who participated in this study: China Civil Affairs College, Beijing, China; Chongqing City Management College, Chongqing, China; Wuhan Civil Affairs Vocational College, Wuhan, China; Katholischestiftungfachhochschule (KSFH), Munich, Germany; Belgorod State University, Belgorod, Russia; and Kent School of Social Work, Louisville, Kentucky USA

To the many supporters along the way: my translators, especially Inna Kaskova and Jakob Braun; the faculty and staff at the Kent School of Social Work, my cohort, my colleagues, and my friends near and far.

Thank you! 


\section{ABSTRACT \\ GLOBALIZATION AND SOCIAL WORK EDUCATION: \\ AN INITIAL INTERNATIONAL INQUIRY}

Elaine R. Wright

November 12, 2007

With an increasing awareness of a global-local reality, social work research and theorizing on globalization is limited but growing. From a multinational perspective, the purpose of this dissertation was to contribute to the emerging professional discourse through (a) an examination of definitions and dimensions of globalization and (b) and an exploration of the impact of globalization on social work education.

Perspectives on globalization were collected on a newly designed and translated survey from 46 social work educators from schools of social work in China, Germany, Russia, and the United States of America. Descriptive analysis and the coding of themes were used to develop a baseline of information about the social work educators' impressions and experiences with globalization.

Although there were many differences in the personal demographics and professional characteristics of the sample, the findings indicated that the social work educators had similar definitions, attitudes, and responses to globalization and its impact on social work education. The implication of these results is that 
globalization is a common reality for social work educators regardless of location or individual background. Overall, the social work educators found globalization to be a relevant topic for curricula and an influence on the future of social work education. The social work educators were more ambivalent about the effects of globalization on their teaching methods and on their roles within academic institutions. 


\section{TABLE OF CONTENTS}

PAGE

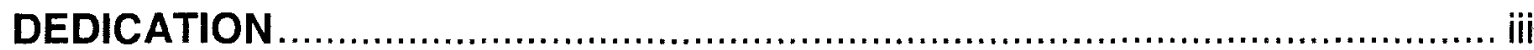

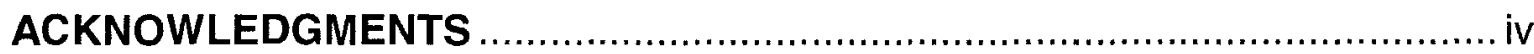

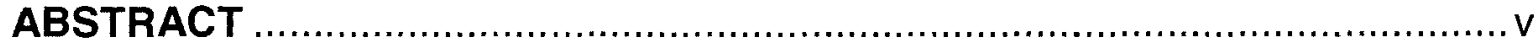

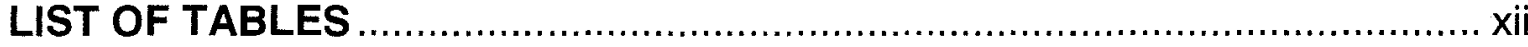

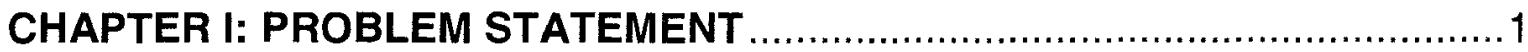

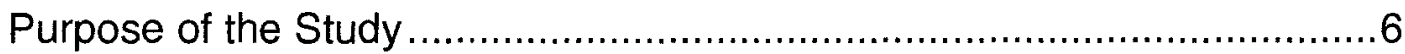

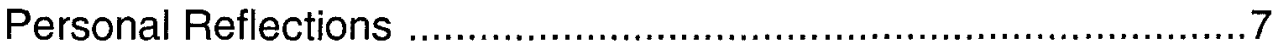

The Status of Social Work Education...........................................13

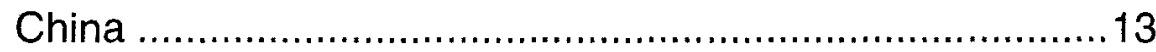

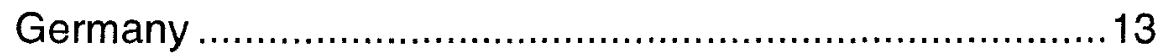

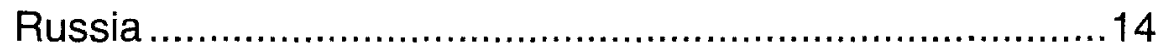

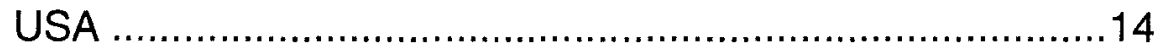

The Concept of Globalization …............................................15

Ubiquity of the Term .......................................................16

Complexity of the Concept ...........................................17

International Definitions of Globalization...................................21

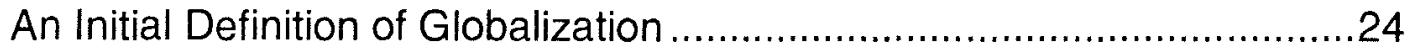

A Framework for Perspectives on Globalization ..........................25

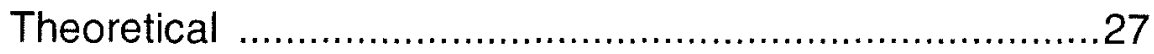

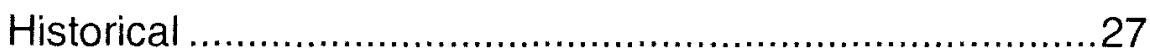




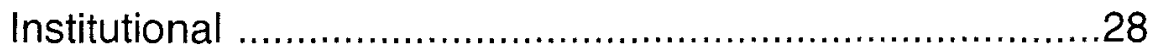

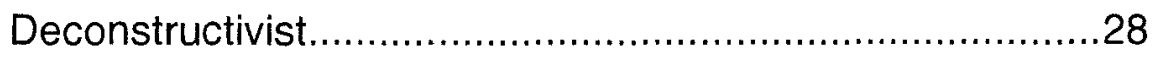

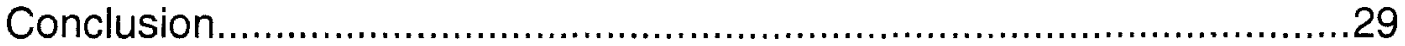

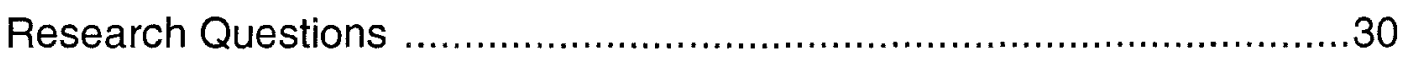

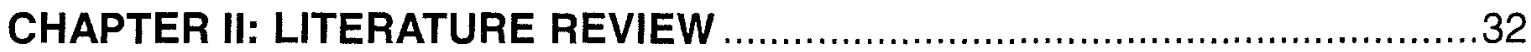

The Globalization of Higher Education ..............................................33

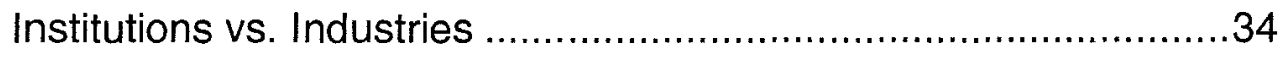

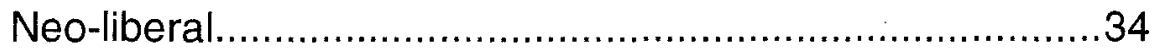

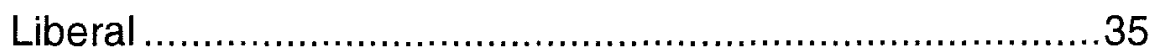

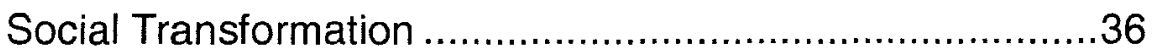

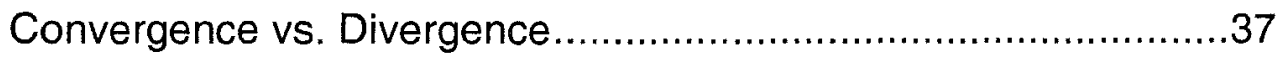

Social Work and Globalized Higher Education ......................................40

Social Work Education and Globalization ............................................42

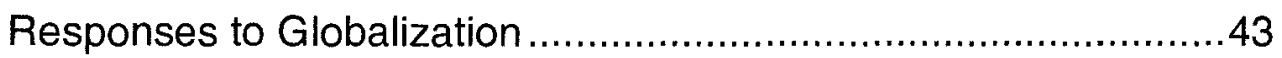

Curriculum Content ..................................................... 43

Policy Initiatives .............................................................

Homogenization and Internationalization .........................48

Social Work Research on Globalization ...............................................50

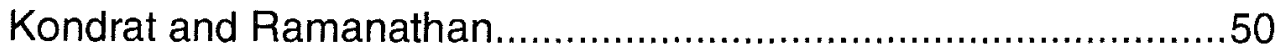

Rowe, Hanley, Repetur-Moreno, and Mould ................................53

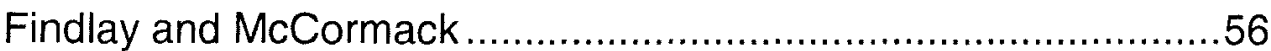

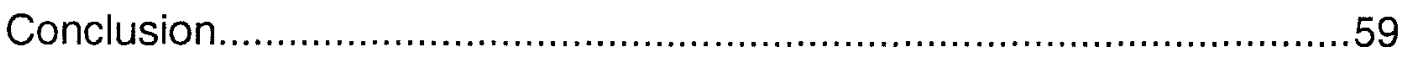

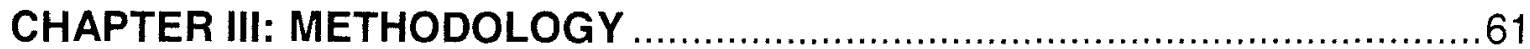




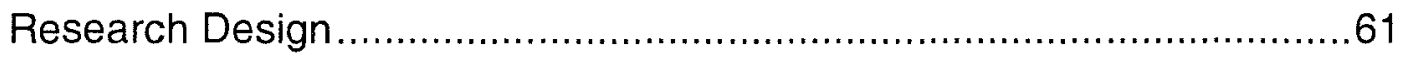

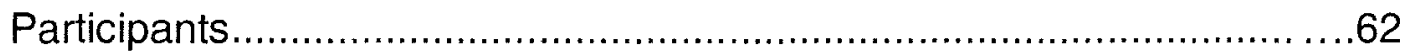

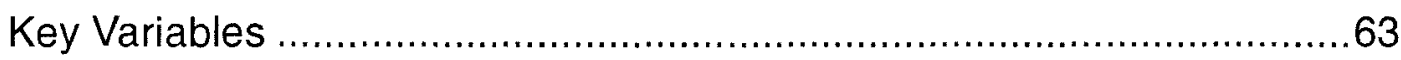

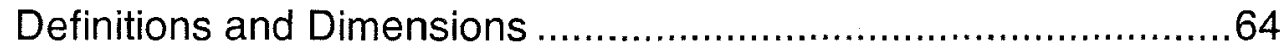

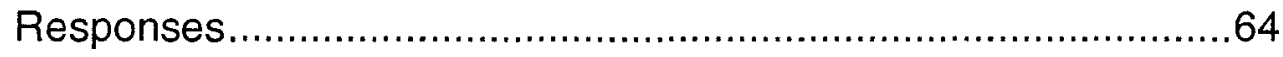

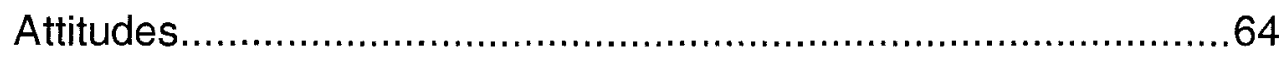

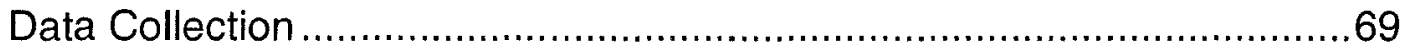

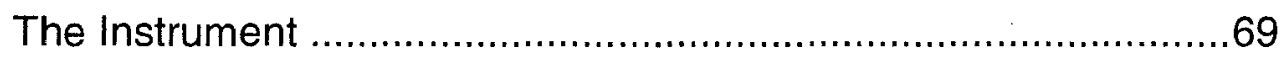

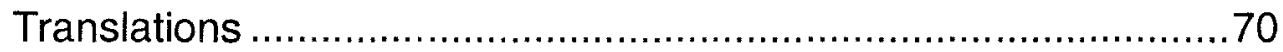

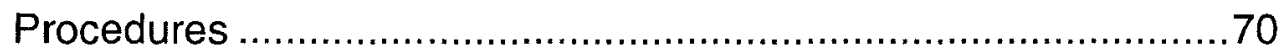

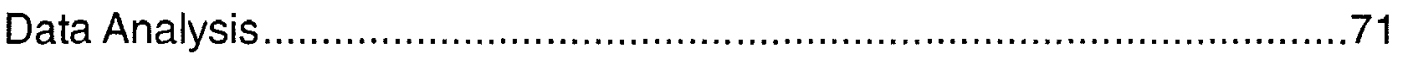

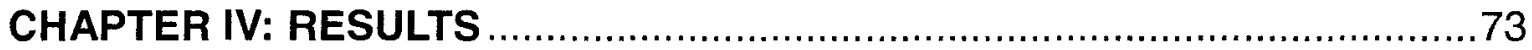

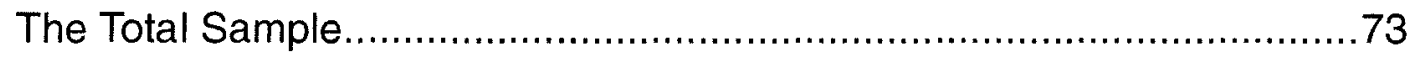

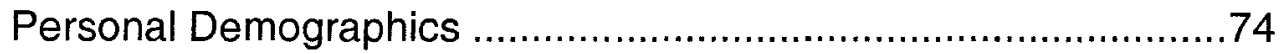

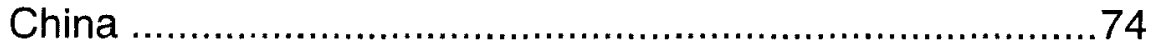

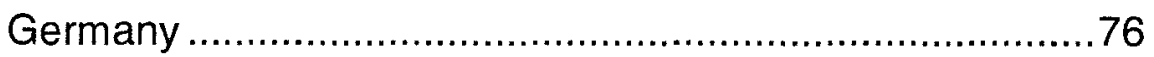

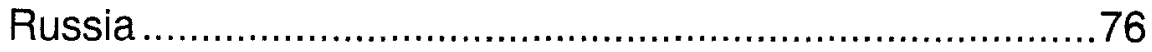

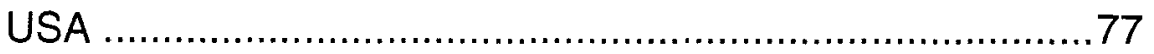

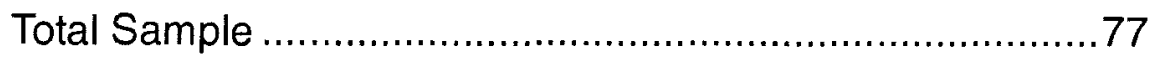

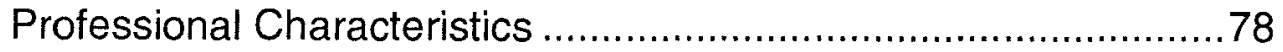

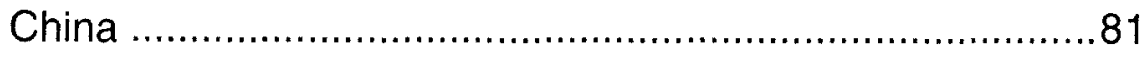

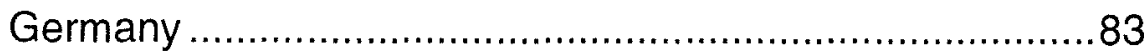

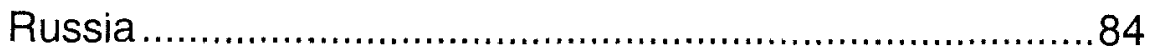


Definitions and Dimensions of Globalization ......................................93

Definitions of Globalization ........................................................93

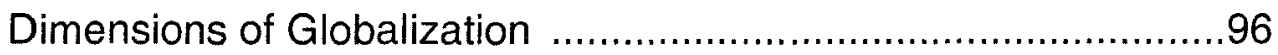

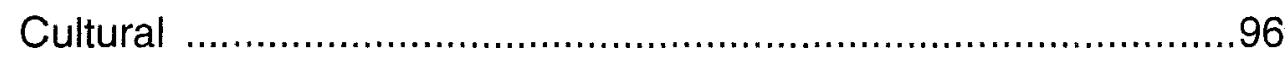

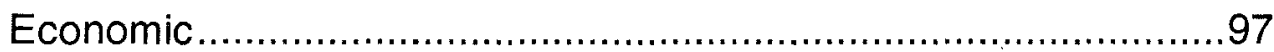

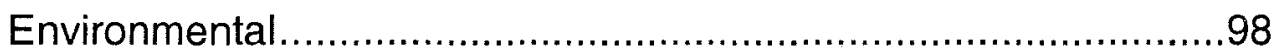

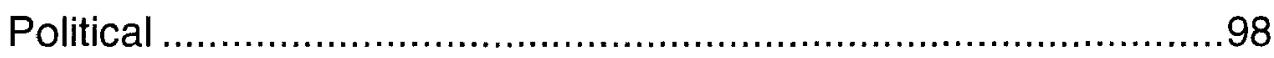

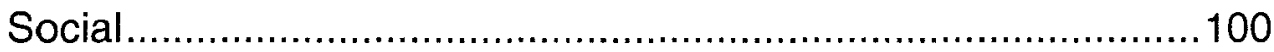

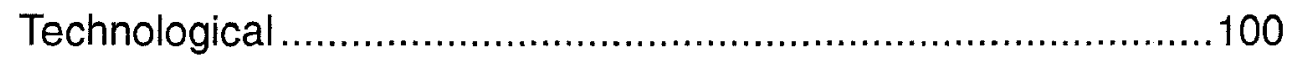

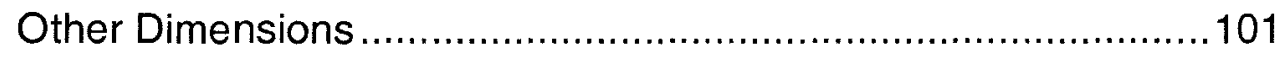

Perspectives on Globalization ................................................................102

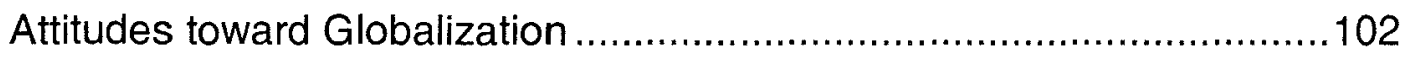

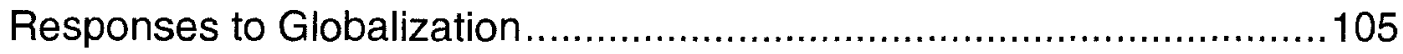

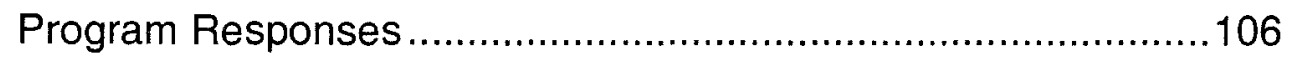

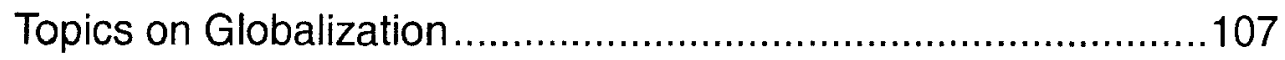

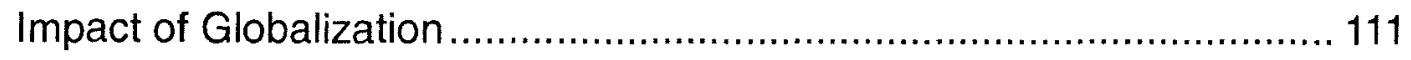

Challenges to Teaching about Globalization.............................. 111

Effects on Teaching Methods..................................................112

Influence on Future of Social Work Education ............................ 114

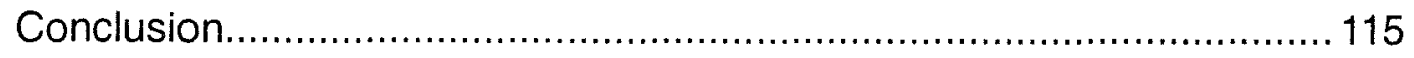

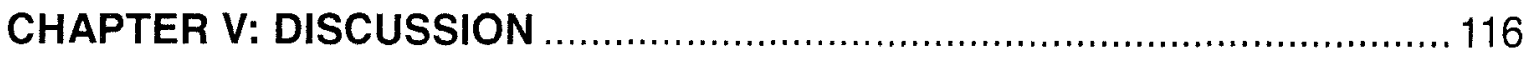




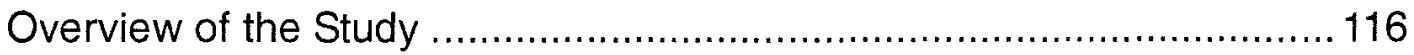

Background of the Social Work Educators ................................118

Personal Demographics..............................................118

Professional Characteristics..........................................120

Definitions of Globalization ..................................................122

Attitudes toward Globalization ...............................................124

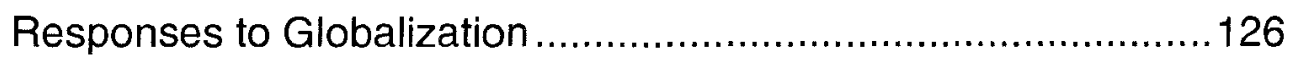

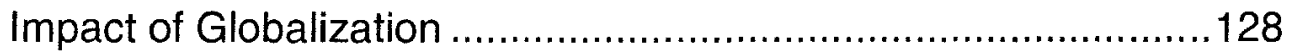

Implications for Social Work Education ........................................... 131

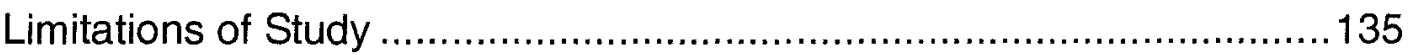

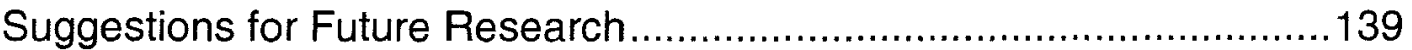

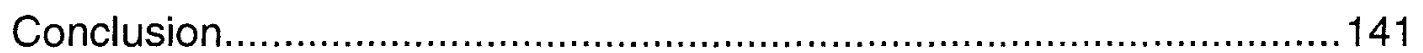

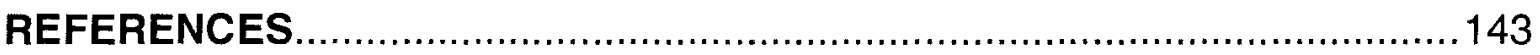

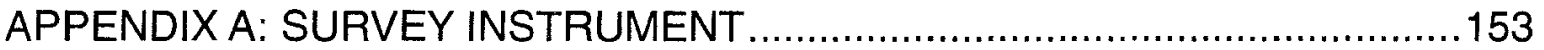

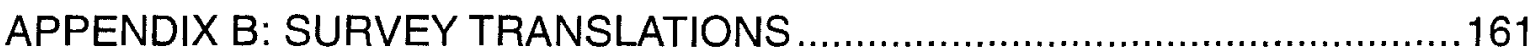

APPENDIX C: CONSENT PREAMBLE AND IRB APPROVAL .......................186

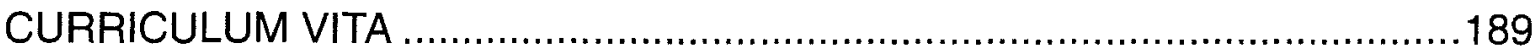




\section{LIST OF TABLES}

TABLE

PAGE

1. Variable Names, Data Levels, and Operational Definitions ....................65

2. Mean Age of Social Work Educators by Country..................................74

3. Frequencies and Percentages of Demographic Variables by Country......75

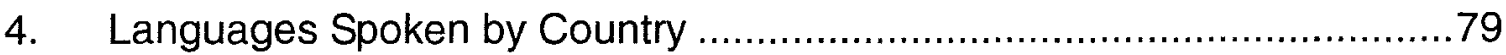

5. Mean Years of Teaching in Social Work by Country ..............................8

6. Mean Number of Social Work Classes Taught by Country .....................80

7. Mean Percentage of Time Spent Teaching by Country ..........................81

8. Frequencies and Percentages of Professional Characteristics ...............82 by Country

9. Frequencies and Percentages of Globalization Resources ....................89 by Country

10. Most Accessed Globalization Resources by Country ….........................90

11. Least Accessed Globalization Resources by Country ...........................90

12. Most Preferred Globalization Resources by Country ..............................91

13. Least Accessed Globalization Resources by Country ............................91

14. Mean Attitudes toward Globalization and Social Work Education ..........103 by Country

15. Percentage of Levels of Agreement by Country for "Global...................105 problems are only important for social work graduates in other countries." 
16. Frequencies and Percentages of Yes/No Responses by Country to ......106 "Is the social work program at your school responding to globalization?"

17. Frequencies and Percentages of Yes/No Responses by Country to ......107 "Are globalization topics included in courses at your school or in your classes?"

18. Mean Percentage of Required Social Work Courses with 108 Globalization Topics by Country

19. Mean Percentage of Elective Social Work Courses with 108 Globalization Topics by Country

20. Mean Percentage of Social Work Educators' Courses with. 109 Globalization Topics by Country

21. Mean Percentage of Student Interest in Globalization by Country 109

22. Frequencies and Percentages Yes/No by Country of "Are there challenges to teaching about globalization?"

23. Frequencies and Percentages Yes/No by Country of "Does globalization have an effect on your teaching methods?"

24. Frequencies and Percentages Yes/No by Country of "Will 114 globalization influence the future of social work education?" 


\section{CHAPTER I}

\section{PROBLEM STATEMENT}

"Globalization is not new, but the present era has distinctive features. Shrinking space, shrinking time and disappearing borders are linking people's lives more deeply, more intensely, more immediately than ever before," states the 1999 Human Development Report of the United Nations Development Programme (UNDP, p. 1). From expanded economic markets and social rules to new political actors and cultural tools, the dimensions of globalization and its processes towards increasing global interdependence are shaping people's realities in the world today.

In the last half of the past century, globalization has evolved into a phenomenon of unprecedented change across the planet. The top 100 economies are now split between transnational corporations and countries. Supranational and multinational organizations have emerged including the United Nations, the World Bank, and the European Union. The creation of the internet has also revolutionized communications and accelerated networking worldwide (Steger, 2003).

Globalization is often viewed as having a negative impact on individuals and communities as they deal with the pressures of an increasingly interdependent world. Haug (2005) states, "Loss of culture, polarization of 
wealth, destruction of the environment, marginalization of Indigenous peoples, increasing corporatization, militarization, US hegemony, and reactionary extremism and terrorism are rooted in trans-national structures and relationships" (p. 133).

Reported consequences of globalization include an increase in all of the following: malnutrition and food insecurity, infectious disease and migration, urbanization and overpopulation, border protection and immigration, terrorism and regional conflicts, modern lifestyle diseases of obesity and smoking, and exposure to the environmental health risks of pollution and toxins due to exploitive technologies (Keigher, 1998).

Social workers must understand how global forces are affecting peoples' environments in order to effectively address social needs at local, national, and international levels (Hare, 2004).The social work profession, with its mandate to promote the welfare of humanity through its knowledge and skills for working with diverse populations, can make a significant contribution to the areas of need resulting from the dynamics of globalization. Globalization, in its many forms, is an issue that challenges dichotomizing practices of micro versus macro or domestic versus international as awareness of the reciprocal influence and integrated experience of the global and local becomes everyday reality.

The development of an awareness of global interdependence and the need to implement the maxim 'think global, act local' are not new for the social work profession. In 1930, Jane Addams, one of the founders of American social work, subtitled her autobiography Growing World Consciousness. She 
encouraged a global awareness in local practice as the profession began to develop across the globe (Healy, 2001). Hartman (1990) described the social work profession as existing in a "global village" where an increasingly interdependent world produces both a clash and collaboration between its local and global realities. To remain relevant in this dialectic, Dominelli (2005) suggests taking an approach to social work that "localizes the global and globalizes the local" (p. 505).

Asamoah, Healy, and Mayadas (1997) encourage social workers worldwide to look beyond domestic borders as changes around the globe have created new global-local contexts for social work practice:

(a) international issues and events, especially movement of populations, have changed ... domestic practice and demand new knowledge and competencies; (b) social problems are commonly shared by developed and developing countries to an unprecedented degree; (c) the political, economic, and social actions of one country directly and indirectly affect other countries' social and economic well-being; and (d) new opportunities for international sharing and exchange are made possible by extraordinary technological developments. (p. 390)

After examining the positive and negative consequences of globalization, Midgley (2005) expressed concern about its impact on the social work profession itself. The author observed a lack of understanding of implications for social work practice and education around the world. 
The majority of the social work literature on globalization describes general consequences of the phenomenon for society and social work practice (Dominelli, 1999; Hare, 2004, Hartman, 1990; Hokenstad, Khinduka, \& Midgley, 1992; Hokenstad \& Midgley, 2004; Jones \& Chandler, 2001; Keigher, 1998; Midgley, 1997; Mohan, 2005; Polack, 2004; Prigoff, 2000; Reisch, 2000; Reisch \& Jarman-Rohde, 2000; Rossell, 1996; van Wormer, 2005) and/or offers new practice models to address the impacts of globalization (Ahmadi, 2003; Cox \& Pawar, 2006; Finn \& Jacobson, 2003; Gray \& Fook, 2004; Healy, 2001; Midgley, 2005; Morley, 2004; Ramanathan \& Link, 1999; Reichert, 2003; Shera \& Bogo, 2001; Yip, 2005).

As the changes in society have created new contexts for social work, the social work profession has the opportunity to re-evaluate its concepts for education and practice. With an orientation towards international social work and the awareness of an increasingly global-local reality, research and theorizing on the globalization of social work is limited but growing. The few studies that have been conducted on this topic found a growing interest and recognition of the effects of globalization among social workers. These studies also identified a need for more information and education about globalization to develop professional responses on a local and global scale (Findlay \& McCormack, 2005; Kondrat \& Ramanathan, 1996; Rowe, Hanley, Moreno, \& Mould, 2000).

Are students being prepared to practice in a globalizing world? Related research looks mostly at classroom content on international issues and finds it is increasing in curricula of schools of social work (Ulrich, 2006). However, this 
international profession has yet to adopt a global approach to practice in these schools of social work (Healy, 2001). In light of this discrepancy, there is a resounding call within the literature for more education on the impact of globalization on social work and for schools to respond to this need (Ahmadi, 2003; Asamoah, Healy \& Mayadas, 1997; Caragata \& Sanchez, 2002; Cox \& Pawar, 2006; Garber, 1997; Hare, 2004; Hartman, 1990; Healy, 2001; Hokenstad \& Midgley, 2004; Mohan, 2005; Morley, 2004; Nagy and Falk, 2000; Polack, 2004; Ramanathan \& Link, 1999; Reisch, 2000; Reisch \& Jarman-Rohde, 2000; van Wormer, 2005).

Nagy and Falk (2000) identified barriers to the profession's ability to embrace and address the issue of globalization as (a) difficulties in operationalizing the concept, (b) differences in the degree of experience of resulting social problems, (c) a lack of awareness of social work's potential roles and interventions in evolving global issues that have local impact, and (d) a lack of willingness on the profession's part to critically assess its participation in the negative aspects of globalization.

A perceived lack of relevance of global topics for classroom content by social work educators and a lack of faculty knowledge on global topics were also suggested as obstacles to incorporating a global perspective in the curricula of schools of social work (Nagy \& Falk, 2000). As the individuals responsible for the dissemination of information on critical issues for social work practice to students, social work educators' knowledge and interest in globalization is paramount. 
Globalization is seen as impacting schools of social work within institutions of higher education (Irving \& Payne, 2005; Watkins \& Pierce, 2005). As universities respond to the processes of globalization, there is an increased interest in the internationalization of programs to prepare students for a globally interdependent reality. To remain viable in universities and valued by students, schools of social work need to evaluate their international efforts and develop a response to a globalized academic agenda. Not just a topic for curriculum content, globalization also affects the academic environment and influences teaching methods (Irving \& Payne, 2005). Social work educators need to be aware of these initiatives and their effect on the future of social work education.

\section{Purpose of the Study}

The timeliness and significance of examining the status of globalization and social work education cannot be more critical. The processes of globalization, as described by Nagy and Falk (2000, p. 49), are having "a dramatic impact on the social work profession and on the educational needs of students preparing for that profession." The purpose of this dissertation is to add to the body of knowledge on globalization's influence on social work education around the world. This study seeks to investigate both the knowledge and attitudes of social work educators towards globalization as (a) a topic for curricula and as (b) a phenomenon affecting the processes of social work education.

Though there are a few studies with practitioners in the field, the status of the response of social work educators to globalization has not been previously analyzed, either within or across countries. This study explores different 
perspectives on globalization through responses from social work educators in China, Germany, Russia and the USA. From earlier writings and previous experiences of the author of this dissertation, reflections on these countries and global issues shed light on personal inspirations leading to the development of this multinational study and add weight to the relevance of examining the impact of globalization on social work education.

\section{Personal Reflections}

As an example of the growth of interest in the differences between countries in their approach to social work and global issues, the following is an excerpt from a journal entry in July of 2003:

On my second academic exchange trip to Germany, I was once again intrigued by the development of the social work profession in this country as compared to my own. Beginning at a similar time in history, social work education in the two countries appears to have followed a common path as they both tend to emphasize a client-centered approach to practice. However, the needs of the person versus the people were described by our German hosts as being met in different ways in the two countries. The German perspective, as compared to the American approach, focuses more on behaviors that are communal than individualistic or group-oriented than one-on-one. How did this come about? Are we trained differently? Are there other circumstances that affect these outcomes? I am curious to know how history, economics, and geopolitical realities may be factors in this difference between our 
countries. I also wonder how much we have influenced each other in our mutual endeavors with professional social work practice and education.

The contrast between our countries was not only experienced in the classroom or on agency visits during this journey. While standing in the middle of the Marienplatz in Munich, I was witness to an anti-war rally against America's war with Iraq. This was the beginning of the conflict and I was struck by the strong social activism on this issue although Germany is not directly involved in the military activities. Even though the protest was against my own country, I admired the collective action of the German citizens who wanted peace in the world and for others to learn from the mistakes of their former government leaders. From a country with an individualistic agenda in many areas other than just social work, I wonder if America is even interested in listening to their message. As a social worker and an American, I am glad to have had the opportunity to hear it and I look forward to more educational experiences with my German friends. I imagine we have a lot to learn from each other as we continue to share this planet together.

From another travel experience, the feeling of finding ground with another culture in response to shared global social concerns was expressed in a report on a group trip to Russia in 2005:

From the 24th of August to the 6th of September of 2005, seven doctoral students had the privilege and pleasure of participating in the first Kent School student exchange to Russia... one of the many exciting 
opportunities provided by the Kent School to enable its students to expand their global consciousness and critically examine the nuances of the social work profession around the world.

As a cultural immersion, students were exposed from day one to the foreign values and penchants of their host country. Tours of historical cities, sacred cathedrals, rolling countryside, and even forest glens shared and shaped impressions of the renowned Russian landscape. Multiple course meals with ritual toasts of endearment warmed hearts and abundantly satisfied all appetites.

Coinciding visits to old age homes and orphanages of youth created visual contrasts as students were exposed to the needs of vulnerable citizens and the community response to diverse client populations. Lectures on social work topics challenged assumptions about the profession in the two countries and engendered dialogue about mutual concerns for the past, present, and future.

In regards to a comparison of the American and Russian cultures, the commonalities began to stand out as the differences subsided. The students, in the end, were impacted by this educational experience which made them feel at home on foreign land and inspired by the initiatives of their new-found friends (Wright, 2005, p.1).

As experiences with other cultures grew, the interest in exploring responses to global events was further enhanced and began to take shape as a topic for research in a reflection on a visit to China in August of 2006: 
Traveling to China with a keen interest in the impacts of globalization, I was not disappointed upon my arrival to Zhongguo [China]. With its many juxtapositions between the ancient and the new, China provided multiple examples of how a country can participate in the current state of world affairs without losing its strong cultural identity. From the metropolis of Chongqing and the cultural artifacts of Beijing to the compassionate efforts of our Wuhan colleagues, all of these elements made the two-week trip to China an unforgettable journey and a truly enjoyable learning experience.

As an American laoshi [teacher], I explored my interests in globalization and social work with the eager Chinese xuesheng [students]. I discussed how globalization, from its impacts on local communities to its effects on national economies, has the potential to not only influence society but to also shape the professional activities of social workers as they interact with changing social systems. Throughout the course of the lecture on this topic, I was impressed with the students' knowledge on this complex subject, their responses to the presented information, and their willingness to consider the topic in terms of the discipline of social work.

This recent experience with the Chinese students and universities has further increased my interest in examining how globalizing trends affect social work education. What are students learning about globalization as it relates to social work locally or globally? How are professors responding to the challenge of teaching about this topic? How 
are social work programs in different countries, including China, preparing their students for a professional career in an age of globalization? These are the basic questions that will guide my dissertation as I focus on how the phenomenon of globalization impacts the content and/or process of social work education.

This trip to China reaffirmed for me the importance of this type of research and the need to gather information about the global social work response to a changing world. With my new colleagues in China agreeing to help facilitate this study in their country, I am grateful once again for this recent trip to China that has brought new experiences, new friends, and now new opportunities for the future.

As shown in these examples, personal experience can influence interests and stimulate curiosity. These excerpts of the author's travel writing trace the development of the awareness of how a global reality is locally shared across countries and between cultures.

Exploring perspectives on globalization from these countries, this study can contribute to the development of an understanding of how common responses to global social issues may be reached from seemingly divergent backgrounds. Along with gaining experience in implementing studies at an international level, previous research with multiple countries enlightened this author to the value and need for comparative analysis between nations in order to learn from each other and work together on mutual concerns. 
Experience with teaching social work courses educated this author about the multiple factors affecting how and what is taught within a curriculum. Opportunities to teach at a local university and abroad provided insight into the challenges of integrating new material, working with advanced technologies, and fulfilling the many roles of a social work educator regardless of location in the world. With its potential to place more demands on the present and future realities of social work educators, information on globalization's impact on teaching and learning is critical but lacking in the literature.

This investigation of social work education and globalization seeks to fill that gap in knowledge from a multinational perspective. Examining their similarities and differences, the evaluation of responses to globalization can provide information about the range of experiences with the phenomenon from social work educators at schools of social work in different parts of the world. This study also presents an opportunity to explore an important social issue with countries that have different histories in their development of social work education but may have a common future as a result of globalization.

The next section of this chapter provides an introduction to the status of social work education in age of globalization. The development of the concept of globalization and international interpretations of the phenomenon will then be reviewed. Created for this study, an initial definition with the core concepts and dimensions found in the literature is presented. The chapter will also examine a framework for exploring perspectives on globalization and conclude with the research questions for this study. 


\section{The Status of Social Work Education}

Social work education has evolved in different ways and at various times over the past century. Many factors have come to play in this development of social work education across the globe that includes cultural, economic, and political elements of societies. The survival and growth of social work education is dependent on the national systems in which it exists and is subject to the trends of the global environment in which it functions. To set the stage for exploring its future in a globalized world, this section highlights the background and current standing of social work education in China, Germany, Russia, and the United States of America.

\section{China}

Social work education in China originally began in the 1920 s but was discontinued with the takeover of a communist government in 1949. At that time, social work was considered a product of capitalism and not needed in a communist country (Saunders, 2006). However, many decades later, an increasingly capitalist Chinese state reinitiated social work programs in the late1980s. By 1994, the China Association for Social Work Education (CASWE) was founded and has reported considerable growth in the development of social work programs. As of 2005, 173 Chinese universities were offering a bachelor's degree in social work although a comparable number of graduate programs have yet to be established throughout the country.

\section{Germany}


Germany's social work education began with courses being offered on social assistance work in the 1890s. A two year program on social work was established in 1908 and became a model for training in the discipline that quickly spread across the country (Otte, 1997). Since that time, social work education in Germany has experienced many transitions including the influence of Nazi control in 1933, the change in status from professional schools to university level colleges in 1971, and the recent adaptation to standards for comparable education between European Union member countries in 1999.

Currently, there are close to 100 social work education programs throughout Germany. Although several schools may continue to provide a traditional Diploma in either social work or social pedagogy, the majority of these programs have adopted an international model of bachelor's and master's degrees for professional training in social work (Society for International Cooperation in Social Work, n.d).

\section{Russia}

In contrast to the other countries, social work education in Russia has only been established since 1991 when the country transitioned from a communist to democratic state (larskaia-Smirnov \& Romanov, 2002). Programs for social work training have since been developed in over 120 universities throughout Russia. Graduates from these programs typically hold either a specialist or bachelor's degree in social work. However, master's and post-graduate level degree programs are now beginning to be offered within the country.

\section{USA}


Similar to the pattern in Germany, social work education training programs began in the United States in the late 1890s and schools were being established by the early 1900 s (Leighninger \& Midgley, 1997). The Council on Social Work Education (CSWE) was formed in 1952 and sets standards for the country's 670 undergraduate and graduate degree programs (CSWE, 2006). These social work schools in the United States may offer bachelor's, master's, or doctoral levels of education in the discipline.

Overall, the expansion of social work education across the globe is still a relatively recent phenomenon and is ultimately a "product of the $20^{\text {th }}$ century" (Garber, 2007, p. 159). Much of the development of the training for social work has evolved out of international collaborations or the transplanting of educational models from one country to another. With the current pressure to adapt to global and regional standards for social work education, schools of social work across the globe are working to develop their training programs to meet the needs of the nation's populations and to reflect their country's cultural traditions. Globalization contributes to the challenge of meeting these international professional standards while maintaining local systems of knowledge and service delivery.

\section{The Concept of Globalization}

To investigate the impact of globalization on social work education in these different countries, it is important to recognize the difficulties in creating an operational definition of the phenomenon. Defining globalization is in itself a challenge as it is an evolving concept subject to a range of interpretations. As the "significant force of the late $20^{\text {th }}$ and early $21^{\text {st }}$ centuries," globalization is 
becoming a generally accepted concept within social work (Asamoah, 2003, p.1). Popping up in the literature, conference agendas, and classroom content, globalization is a term frequently used although there is little consensus about its meaning within the profession. Globalization is found to be an ambiguous and elusive concept within the social work discourse. This lack of clarity on globalization in social work is related to (a) the ubiquity of the term and (b) the complexity of the concept.

\section{Ubiquity of the Term}

As a buzzword, globalization is a term used loosely, inconsistently, and somewhat carelessly to describe a set of processes impacting people around the world (Lyons, Manion, \& Carlsen, 2000). Doel and Shardlow (2002) observed globalization is "a fashionable term intended to capture a central element of life in the late twentieth and early twenty-first centuries" (p. 12).

Pugh and Gould (2000) propose that the ubiquity of the term makes it familiar even though there is a lack of clarity about its nature:

The omnipresence of the term contributes much to the 'taken-for-granted' acceptance of the idea, but establishing exactly what globalization is, is problematic because there is no single unified theory. Unfortunately, globalization is a term which is sometimes used and accepted without a sufficiently rigorous examination of its various theses, nor of the evidence which purportedly supports them. (p.124) 
With many definitions citing its omnipotence and historical uniqueness, globalization is often presented as "a mysterious all-enveloping process that underpins every change in society" (Pugh \& Gould, 2000, p. 126).

Globalization is also frequently used interchangeably with words that may have different connotations in context. For example, international and global can be misinterpreted as having the same meaning. While international implies relations between two or more countries, globalization suggests all countries around the world are involved and impacted to some degree when nations interact (Midgley, 1997).

\section{Complexity of the Concept}

As an evolving and complicated subject, globalization is difficult to operationalize due to the prevalence of vague definitions. Indistinct descriptions of globalization as a process towards a state of global interdependence and interconnectedness between countries are replete throughout the literature (Elliot \& Mayadas, 1999; Healy, 2001; Hokenstad \& Midgley, 2004; Link \& Healy, 2005; Lyons et al., 2006; Tripodi \& Potocky-Tripodi, 2007; van Wormer, 2005).

In their review of the social work literature, Pugh and Gould (2005) found definitions of globalization tend to imply "a direct causal link between globalization, its processes, and particular consequences" (p. 126). The authors expressed concern for these depictions of globalization as they lacked substance in their application and implied a reality that is still in dispute. There is also contention about the existence of globalization and that social work's role in it may be limited if it does (Webb, 2002). 
Another common example of a definition of globalization from the International Federation of Social Workers (IFSW) suggests a merging or convergence between countries. IFSW proposed that it is "the process by which all peoples and communities come to experience an increasingly common economic, social and cultural environment ... [and] the process affects everybody throughout the world" (n.d., ๆ 1).

In contrast, descriptions of globalization also described it as creating division and exacerbating the differences between rich and poor, East and West, North and South, developed-developing-undeveloped-underdeveloped, and firstsecond-third worlds (Lyons et al, 2006; Sowers \& Rowe, 2007). However, Cox and Pawar (2006) suggest that its effects are more dialectical than polarizing in what the authors see as a tension between globalization-localization or a globalization from above and a globalization from below.

Definitions of globalization highlighted positive or negative aspects of the phenomenon. The Social Work Dictionary examined the debate between supporters and opponents of globalization in its definition:

The movement to make economic and cultural activity world-wide in scope and application. Proponents argue that this fosters economic development for all through enhanced trade, lower costs, efficiencies, and competitiveness. Critics argue that the internationalization of corporations may enable them to circumvent a nation's worker protection and environmental laws and that it lowers wages and working conditions by a 
threat of moving employment opportunities to other countries. (Barker, 2003, pp. 180-181)

Illustrating the conflicts and opportunities within globalization, this description highlights that there are winners and losers in its outcomes. One feature of this definition that presents confusion about the meaning of globalization is that it references culture but does not elaborate on this characteristic in its discussion.

Many definitions of globalization identify its various outcomes or dimensions of its processes. The most frequently observed examples of aspects of globalization included its cultural, economic, environmental, political, social, and technological impacts. As indicators of these dimensions, Midgley (1997) described the main characteristics of globalization as advancements in communications and transportation technologies, the expansion of global markets and global politics, and the increase of cultural diversity within countries.

Other descriptions of these dimensions focused on globalization as an impact on social systems from individuals and communities to countries and supranational entities. Globalization was seen as having a disparate effect on economies around the world and threatening both national sovereignty and local traditions (Pugh \& Gould, 2005). With the changing status of nation-states in a new world order, Haug (2005) credited globalization with strengthening cultural hegemonies and exacerbating ethnic discord. Lyons et al. (2000) also proposed that the forces of globalization have created new conditions for natural and forced migration, pandemics, and environmental pollution. 
Several definitions featured one of the dimensions as the main force of globalization, especially economic globalization. As an example of economics as a driver and outcome, Dominelli (2004) stated globalization was "the global spread of capitalist social relations and their integration into every aspect of life the social, political, cultural, economic and personal, and the consequent reordering of social relations in all these spheres" (p. 7). The author asserts that the marginalizing aspects of globalization have produced new forms of social exclusion and impoverishment through the decentralization of the state and privatization of public services. Consequently, the social work profession must address the restructuring of the welfare state, the adaptation of its services to market demands, and prepare for new social dilemmas.

Frequently referred to in the social work literature, Midgley's definition indicates that globalization is an accelerating and multidimensional process that intensifies reality with a global-local state of consciousness. Globalization is a "process of global integration in which diverse people, economics, cultures, and political processes are increasingly subjected to international influences ... [and] also refers to a greater awareness of the role of these influences in every day experiences" (1997, p. xi).

In review of these examples, globalization is difficult to define as a result of its ambiguity, variety of dimensions, and global-local dialectic. With multiple definitions and experiences with globalization, there are many challenges to establishing its meaning and implications for social work education. These different interpretations of its processes and outcomes contribute to the difficultly 
in operationalizing globalization and a univocal definition is found to be lacking in the social work literature.

\section{International Definitions of Globalization}

Interpretations and definitions of social phenomenon, like globalization, can be influenced by cultural background or personal attitudes. Watts states that it is difficult to develop social work concepts with a common understanding between cultures and across languages (1997). Elliot and Mayadas (1999) note that these elements are part of the challenge in creating an operational definition of globalization for social work include the difference The difficulties in defining globalization, as suggested by the authors, are (a) the different degrees of experience with problems resulting from globalization, (b) the cultural values and social customs shaping the interpretation of these experiences, and (c) the regional perspectives and media positions towards globalization that also influence these interpretations.

Attempting to develop a definition of globalization based on the social work literature is potentially impacted by cultural influences. Haug (2005) has found indication of pervasive imperialist and paternalistic perspectives in the international social work discourse. As a Western cultural hegemony, the social work literature is seen as privileging a unitary system of knowledge at the expense of the multitude of social work paradigms and cultural voices within the profession. "Western" commonly denotes nations that are within the EuropeanNorth Atlantic region of the world and the former European colonies of Australia and New Zealand (Geyer \& Bright, 2000). 
Due to language and time constraints, this review is based on documents available in English and predominantly written by individuals from Westernized countries. A range of interpretations from different countries and cultures were not found in the literature. However, one study was found in the literature that included definitions of globalization from social workers from different countries. Shedding light on international interpretations of the phenomenon, the responses of these social workers are important for this review.

In their international study of responses to globalization, Rowe, Hanley, Repetur-Moreno, and Mould (2000) found that most of the social workers they sampled described globalization as a critical issue for social work practice. The authors also found that there was a wide array of definitions on globalization from these social workers who were members of IFSW. Highlighting the definitions here, further description of the study is found in Chapter II.

Similar to the previous discussion on definitions, Rowe et al. (2000) observed examples of definitions of globalization that addressed its processes as convergent or divergent influences. A social worker from Cuba described "the intensification of social relations, the forces of production and the superstructure that is being imposed around the world ... merges distinct and distant places, giving them its own [the superstructure's] character, however the process is heterogeneous, as are its consequences" (p. 70). Another definition by a social worker in the Philippines described these effects as a loss of indigenous identities when cultures blend together in a borderless society. 
Interpreted as ambivalence towards the phenomenon, definitions were portrayed mixed views on globalization as a positive or negative experience (Rowe et al., 2000). An example comes from a social worker in Jamaica: In one context [globalization] can be described as a view of the world as one large village which provides remarkable opportunities to learn about the varying inhabitants and their social, economic and political issues and organizations. In another context it can be viewed as an imposition of values, ideologies and beliefs of larger stronger industrial nations on smaller weaker and developing and underdeveloped nations. (p. 71) A Palestinian social worker stated, "Globalization for me has two conflicting sides: easy communication and exchange of experiences and research findings in all professional fields on one side; and lack of balance when being exposed to the influences and interests of the super powers" (Rowe, et al., 2000, p. 71).

Several of the definitions collected by Rowe et al. (2000) identified consequences of globalization for people around the world. These dimensions of globalization reported by social workers included previously mentioned cultural, economic, environmental, political, social and technological features. As an example of economic dimensions, a social worker in Sri Lanka described globalization as "a process of converting producers in third world countries into consumers through a capitalist economic process" (p. 70). Suggesting other dimensions, a Canadian social worker defined globalization as propelled in both past and present times by 'religion, economy, technology and empire" (p. 70). 
Globalization was also recognized as an age-old process that was recently increasing in scope and pace in intensification of reality (Rowe et al., 2000). A Spanish social worker hinted at changes in spatial-temporal awareness with globalization as "... something that happens in one specific place [and] can have consequences many kilometers away regardless of their distinct languages, customs and ideologies" (p. 71).

Rowe et al. noted that definitions that only mentioned positive impacts of globalization were from social workers living in Westernized nations (2000). From this observation, the authors proposed that attitudes towards globalization could be related to country or culture. Characteristics of this nature need to be explored further to determine if there are cultural norms in perspectives of globalization.

In review of this discussion, these definitions of globalization provide further illustration of the variety of ways to describe the phenomenon. The examples suggest that globalization can be experienced at different levels and that interpretations of this experience may reflect cultural attitudes. Overall, this range of perspectives continues to demonstrate that there are problems with operationalizing the concept with so many competing and contradictory perceptions of its outcomes.

\section{An Initial Definition of Globalization}

The different definitions and descriptions in this review depict globalization as an evolving concept within the profession that appears to almost defy definition. It may not even be desirable for the profession of social work to have 
one definition as a set of definitions may more appropriately represent the many interpretations or cultural perspectives of globalization.

As a complex and multidimensional phenomenon, globalization is impacting people in a myriad of ways from a local to global scale. Facilitated by improvements and developments in modern technologies, the processes of increasing global interdependence have enabled people, products, and knowledge to come in contact, connect, and enmesh at unprecedented levels.

For the purposes of this study, a simplified definition of globalization was derived from the social work literature to explore its meaning with social work educators (Figure 1). The definition provided on the survey was "Globalization is the growing interdependence of systems around the world." As it is experienced in many different ways across the planet, dimensions of globalization included on the survey were cultural, economic, environmental, political, social, and technological aspects of this phenomenon. Though it is subject to the definitional challenges of examples from the social work literature, this initial definition of globalization was selected to represent the core concept of the process and the common areas of impact of these processes.

\section{A Framework for Perspectives on Globalization}

Globalization has thus far been presented as an evolving concept with a range of interpretations of its processes and consequences. Since the inception of the concept of globalization, theories of globalization have been proposed and debated. However, the scholarship on globalization continues to expand and reflects multiple stages in this development of the concept. These stages of 


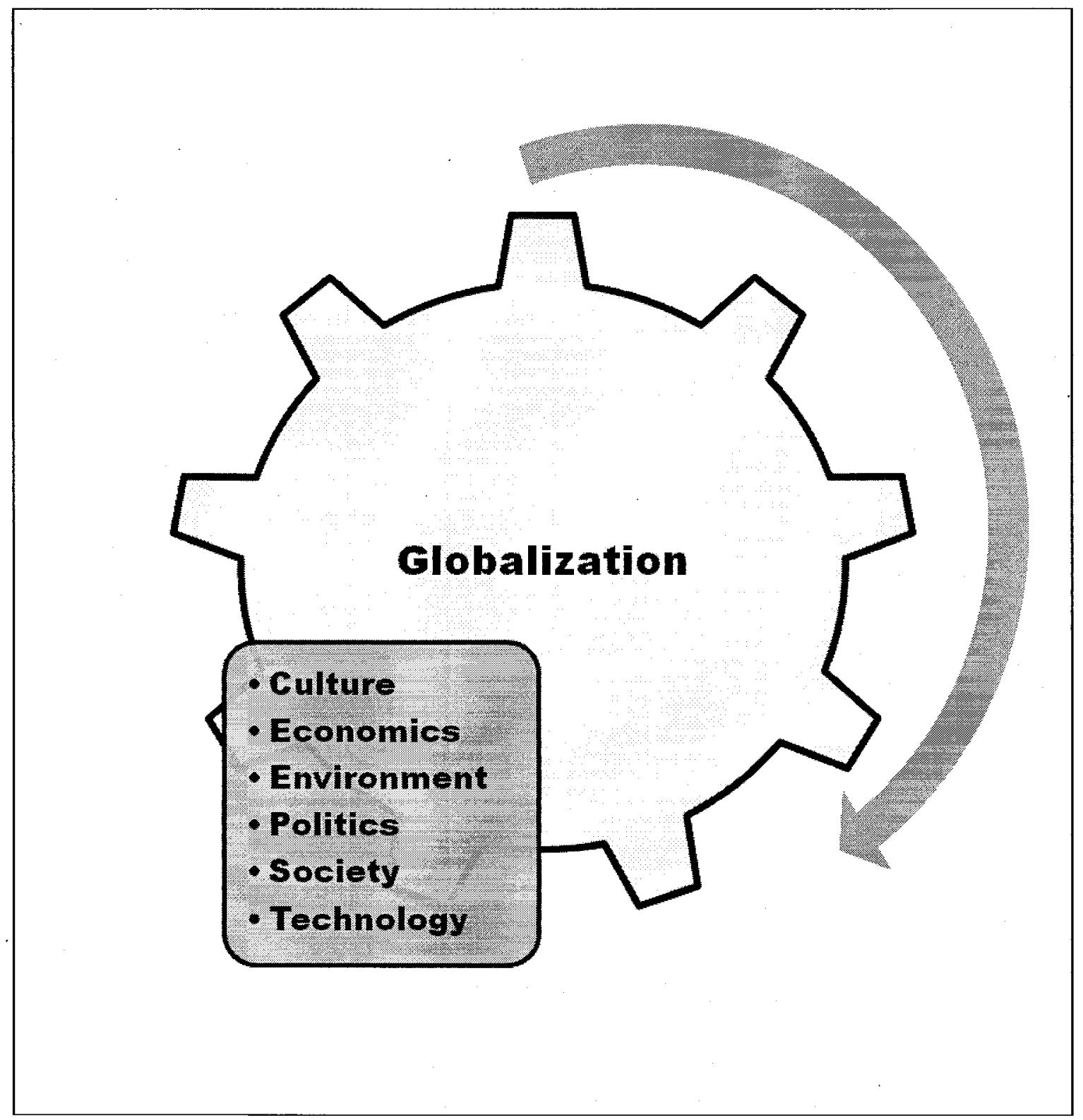

Figure 1. Components of an Initial Definition of Globalization

interpretations of globalization are not mutually exclusive or linear in progression but they do suggest a framework for evaluating the different perspectives that are found in definitions of the phenomenon (Genschel, 2004; Held \& McGrew, 2007; Tikly, 2001).

This proposed schema is organized around stages in the discourse on globalization which include (a) theoretical, (b) historical, (c) institutional, and (d) 
deconstructive conceptualizations of globalization. These categories of interpretations also reflect globalist, global skeptic, transformationalist, and revisionist perspectives on globalization (Genschel, 2004; Held \& McGrew, 2007; Tikly, 2001).

\section{Theoretical}

As one of the early descriptions of its impacts and global consequences, the theoretical approach views globalization as a systematic process of worldwide social change (Held \& McGrew, 2007). Depending on the level of global integration, globalists or hyperglobalists are represented in this category with their perspective of globalization's processes as irreversible and inevitable. The perceived outcomes of globalization include the growth of global capitalism and free markets, the development of new transnational forms of global governance and a global citizenry, and an overall demise of "borders" between countries (Tikly, 2001).

\section{Historical}

Citing little evidence of change as a result of globalization's processes, the historical interpretation of globalization examines whether or not there is uniqueness in the current trends of global social relations (Held \& McGrew, 2007). This perspective challenges the concept of globalization as a new phenomenon and also questions the reality of its purported effects. As viewed by these global skeptics, increased global interdependence has not diminished the relevance of nation states or created a global culture that supersedes national identities (Genschel, 2004). 


\section{Institutional}

Another stage of development of the concept of globalization, the institutional interpretation explores its impact as a dialectical process of convergence and divergence in political structures and cultural traditions (Held \& McGrew, 2007). In the sharing of ideas and practices through increased global interactions, countries have the potential to become more similar or homogenized in their policies and cultural habits. At the same time, reactions to dominant cultures produce a heterogenization and strengthening of local or regional cultural identities. Transformationalists claim the development of new and fluid ethnicities is a result of cultural hybridization (Tikly, 2001). However, anti-globalists point to the inequities in the process as producing or exacerbating social stratification and fragmentation between groups across countries.

\section{Deconstructivist}

As the latest stage to develop, a deconstructivist or post-structural analysis of globalization recognizes that there are many competing and often contradictory interpretations of its processes which are intrinsic to understanding the meaning of the phenomenon (Held \& McGrew, 2007). Global revisionists agree with previous arguments that the level of recent global interconnectedness is found to be greater now than at other times in history but is not necessarily a new process. They also recognize the imbalance in the effects of globalization around the world. A revisionist perspective of globalization refutes hegemony in the interpretation of globalization. It also takes into consideration that globalization may be more of a consequence of social change rather than a 
cause of it. Globalization may be the solution for social problems around the world (Genschel, 2004).

Though it is a loose categorization of the perspectives on globalization, this heuristic of perspectives as identified by Genschel (2004), Held and McGrew (2007), and Tikly (2001) on the evolving concept is as an example of a framework for exploring developing stages of perspectives on the phenomenon and implications of its impact. However, it has not been tested as a framework for analysis and may not be representative of all interpretations or cultural variations of perspectives on globalization.

\section{Conclusion}

In this chapter, globalization is shown to be a phenomenon impacting society as a concept or process. The variety of interpretations of the concept makes it difficult to operationalize and produce a universal definition of globalization without oversimplification. The processes of globalization are seen to be changing social consciousness as events from abroad can influence activities at home. In this respect, globalization poses a dialectic for social work between the local and global in practice and education. As Ife (2000) states, "No longer can we think globally and act locally, but rather it has become necessary to think and act at both local and global levels, and to link the two" (p. 62).

Social work educators are in positions to contribute to the emerging knowledge on these global-local issues and would be remiss to ignore them. Research has not previously been conducted to evaluate how social work educators view this critical issue and their awareness of the multiple dimensions 
of globalization. This dissertation seeks to fill that gap in knowledge and offer insight into how globalization is experienced and perceived by social work educators in different parts of the world. As an exploratory study, this dissertation is an initial international inquiry into the perspectives of social work educators on globalization and its impact on social work education. To investigate the globalization of social work education from an international perspective, the responses of social work educators from China, Germany, Russia, and United States will be analyzed to explore similarities and differences between countries in (a) definitions (b) attitudes, and (c) responses to the phenomenon.

\section{Research Questions}

With an emphasis on the international comparative analysis of globalization and social work education between and within the countries of China, Germany, Russia, and the United States of America, the following research questions for this study were posed:

1. How is globalization defined by social work educators in China, Germany, Russia, and the USA?

2. What are the attitudes of these social work educators towards globalization?

3. How are social work educators in these countries responding to globalization?

4. What are the impacts of globalization on social work education in these different countries?

5. What are the implications of globalization for social work education? 
The following chapter will review literature relevant to the study to examine the influence of globalization on higher education and implications for schools of social work around the world. 


\section{CHAPTER II}

\section{LITERATURE REVIEW}

This chapter is an overview of the opportunities and challenges posed by globalization to social work education. The review explores the status of social work education as it resides within institutions of higher education and as it exists within a globalized world. The significance of globalization for the profession is examined through reports from the higher education field, discourse on the subject in the social work literature, and related documents developed by regional and international organizations. As this is a developing topic within social work, this review seeks to highlight globalizing trends within social work education and the profession's current responses. The first part of this chapter will describe (a) the globalizing environment of higher education and (b) the implications for social work education. The second section will review the discussion on (c) the globalization of social work education and (d) related research within the profession.

This is an international study and takes the position that social work is a profession practiced within both local and global contexts around the world. As a topic with global implications for the profession, the literature reviewed in this study is by scholars in the field from many different countries. However, the material was primarily available in English and the majority of the authors are 
from Westernized countries. It is important to note this limitation in the diversity of perspectives in the material and acknowledge the potential for cultural bias.

\section{The Globalization of Higher Education}

The United Nations Educational, Scientific, and Cultural Organization (UNESCO) is a department within the United Nations that focuses on the learning capacities and needs of its 192 member countries. Identifying globalization as a critical issue for education in these countries, UNESCO (2004) stated that the phenomenon has the following effects on their systems of higher education: (a) promotion of a knowledge society/economy, (b) new trade agreements in education services, and (c) innovations in information and communication technologies. UNESCO also noted that the impact of globalization will have ramifications, in varying degrees per country, on the availability, type, and financing of education around the world.

How universities react to these effects of globalization can depend on national policies and economic conditions. The level of priority placed on education as a public good can also determine who is responsible for providing higher education. The interests and missions of the providers of education are another influence on how universities administer their programs and what strategies they pursue within the context of globalization (UNESCO, 2004). In respect to the choice schools can make to respond to the phenomenon, this section reviews various perspectives on the impact of globalization on higher education for (a) universities as institutions or industries and (b) educational policies as producing convergent or divergent technological realities. 


\section{Institutions vs. Industries}

A review of higher education policy responses to globalization may evoke competing images of schools as (a) industries for knowledge production and the expansion of the workforce, or as (b) learning institutions for the generation of ideas and human development. While this portrayal of universities is not unique to the present day, they are painted on a new canvas as the globalization of higher education has intensified the international dimension of the academic agenda and challenged its traditional modes of operation.

Universities have to respond to pressures from both external and internal sources as they attempt to sustain or establish their position within their own countries and in an increasingly interdependent world. Comparing the push for schools to becoming more globally-integrated as similar to the development of transnational corporations, Allen and Ogilvie (2004) contended that the "consequent implications for universities of this change in conceptualization of nation and culture are increasing pressures for greater privatization, transformation into market institutions, and loss of cultural norms" (p. 76).

Allen and Ogilvie (2004) analyzed these impacts on higher education through (a) neo-liberal, (b) liberal, and (c) social transformation perspectives of globalization to better understand potential outcomes for universities. As the framework on perspectives of globalization was introduced in Chapter I, Allen and Ogilvie's portrayal of perspectives on globalization is presented here to provide insight into possible scenarios and dilemmas for higher education.

\section{Neo-Liberal}


The neo-liberal ideology of globalization espouses an industrial capitalist ethic. By promoting a shift in funding from public to private initiatives, universities can pursue strategies for economic development without federal or state restrictions on investments and allocations (Allen \& Ogilvie, 2004). Underutilized subsidies are reduced as wages, tuition, and fees are allowed to be determined by the market. There is a focus on profits and products as students become consumers and academic sponsors are mostly corporations. With reductions in funding from government resources, schools may need to increase marketability on both local and global scales for sustainability. Within the university network, programs with the most lucrative research and potentially profitable relationships are rewarded and recognized. The globalization of university programs also involves the expansion of international partnerships for the creation of new resources for research and development.

\section{Liberal}

Downplaying the economic priority in operations, a more liberal point of view on education administration in an age of globalization is on improving the viability and success of the university as both an industry and an institution. To operate in an interdependent society, a goal of increasing multicultural relations will support the expansion of international programs (Allen \& Ogilvie, 2004). Programs are to provide learning experiences and raise consciousness as they facilitate interactions and collaboration between groups from different ethnicities, customs, and traditions. To remain relevant and competitive in an age of globalization, students entering the workforce need to be trained in skills for 
working in diverse environments and with people from a vast array of backgrounds. With a liberal agenda, universities actively take advantage of global contacts through web-based networks to recruit students from other countries, to provide opportunities for students and faculty to participate in crosscultural exchanges, and to develop relationships for international job training or employment for graduates.

\section{Social Transformation}

In contrast to the neoliberal and liberal perspectives, a social transformation outlook on the globalization of higher education attempts to maintain the climate of the learning institution (Allen \& Ogilvie, 2004). According to these authors, a social transformation model values developing a critical awareness of the interconnected networks of the university within local, national, and international contexts. Steps are taken to reduce structural inequities and increase opportunities for disadvantaged groups. To prevent negative and exploitive consequences of globalization, the development and expansion of social networks for university initiatives are assessed for their impacts on individuals and communities at home and abroad.

The social transformation view of the globalization of university programs is focused on creating international partnerships centered on reciprocity and global social justice (Allen \& Ogilvie, 2004). As both the preservers and purveyors of knowledge, universities implementing a one-way export of their programs to other countries are considered as engaging in contemporary forms of colonialism and cultural imperialism. The social transformation model, on the 
other hand, advocates for an export-import model of education that encourages mutuality between institutions and respects cultural norms and learning traditions for all involved.

Taking an ideological approach to analyzing policy agendas within universities, Allen and Ogilvie (2004) provide insight into the potential responses of institutions of higher education to globalization forces. Their analysis produces a set of perspectives for understanding university actions in a context of globalization. These reactions of universities may trickle down to social work or even stem from initiatives within social work programs.

\section{Convergence vs. Divergence}

National, regional, and international policies also exert influence on the actions and reactions of schools dealing with changes in higher education. The concept of globalization as creating a 'borderless' society is applicable to the current state of higher education. UNESCO (2004) posited that "borderless education refers to the blurring of conceptual, disciplinary and geographic borders traditionally inherent to higher education" (p. 7). While this may be a new reality for systems of education, the UNESCO authors assert that borders do not actually lose their importance as regulatory domains since responsibilities for higher education still resides within nation-states.

Borderless education involves access to education regardless of location as technological advancements revolutionize higher education. For example, distance education and virtual universities (i.e. on-line degree programs) allow students to receive an education from sites convenient to them (UNESCO, 
2004). Transnational educational agreements, like the Bologna Process in the European Union, are another aspect of borderless education that enables students to obtain a commensurate degree at the school of their choice within the participating countries (Martinez-Brawley, 2005).

This spread of borderless education is not without consequences. As another perspective of globalization, the convergence-divergence analysis developed by Vaira (2004) sheds light on its impact on the content and processes of higher education.

Claiming globalization as the "main structural feature of the contemporary world," Vaira (2004) looked at its influence on organizational changes in higher education. The author explained convergence as "the progressive and sometime ineluctable trend toward homogenization...founded on a linear, top-down and sometimes deterministic causal explanation" (p. 484). In contrast, divergence is focused more on diversification or heterogeneity of globalization's impacts that emphasize "bottom-up processes of manipulation, localization, interpretation, mediation, resistance and so on. . . is non-linear, non-deterministic, conflictual and, sometimes voluntaristic" ( Vaira, 2004, p. 484). A merging of these convergent-divergent tendencies of globalization results in the concept of the glocal as the dialectic between the complex and sometimes contradictory processes of globalization.

Universities are subject to the whims of the global market and are also under pressure to update to new models for learning. Vaira (2004) found the increased use of and value placed on information and communication 
technologies (ICT) to be reflective of the development of the knowledge society within global higher education. The knowledge society manifesting through the expanded use of ICTs is linked to competitive knowledge production processes and the shift towards academic training for highly technical occupations rather than manually skilled labor. As universities converge in a global academic environment, their marketability can depend on their incorporation of current technologies for student access and technical training options.

In response to the trends of the knowledge society, universities are requiring the integration of ICT processes across departments and organizational systems. Vaira (2004) contended that the rush to incorporate ICTs at all levels could lead to a commodification and homogenization of knowledge transmission and production. The coming together or convergence within global higher education has a universalizing effect on the delivery of education within institutions and educators will have to adapt accordingly.

The divergence argument asserts that educational culture around academic freedom has not yet been deinstitutionalized (Vaira, 2004). Even while they participate in borderless education movements, national governments are still responsible for the regulation of their countries' systems of higher education. Local cultures and needs will also continue to shape and influence the missions of their learning institutions. As the traditional modes of operation within schools are not superseded in the use of ICTs, the knowledge society is thus considered a myth. Acceptance of the convergence theory in the globalization discourse is 
criticized as a prioritization of technology and markets which focuses more on quantity than quality in education around the world.

The convergence-divergence debate on ICTs in higher education is helpful for exploring how recent trends can be seen as having positive or negative outcomes depending on one's perspective of the influence of globalization. The dialectic of convergence-divergence is useful to consider in assessing other effects of globalization on schools of higher education.

In review of both of these perspectives on changes in universities, caution is recommended to prevent a tendency to attribute all changes in the current landscape of higher education to the influence of globalization (Irving \& Payne, 2005). As an evolving concept, the globalization thesis may not always be applicable or accurate depending on country and culture. However, the higher education literature reveals there are new developments in the field across the globe and globalization is increasingly given the title of agent of change.

\section{Social Work and Globalized Higher Education}

Social work education does not exist in isolation of higher education. Schools of social work reside within institutions of higher learning and are subject to changes within the academic system. The influence of global movements in higher education on university units is an external pressure affecting internal operations. These changes in higher education are seen as creating new challenges for the academic environment of social work programs.

The globalization of higher education creates both tensions and opportunities for social work education. Young and Burgess (2005) have noted 
that recent developments in higher education are affecting the daily activities of social work educators. With new outcomes for accountability, a movement to professionalize teaching for quality assurance has increased paperwork and administrative burdens. Educators are also experiencing a higher load of students with the increase in access to higher education. These authors reported that the increase in student participation has not translated into an expansion of resources. In a tight economic climate, funding for university units has declined while the ratio of students to staff continues to climb.

"The world in which we live and work is one where geographic boundaries are permeable and where access to information is both rapid and almost universal, "stated Watkins and Pierce (2005, p. 21). Challenging "traditional power relations" of educators as gatekeepers of knowledge, students have access to the same information as educators through on-line networks (Young \& Burgess, 2005, p. 5).The vast quantity of material available through electronic sources creates a struggle for educators as they balance the needs to remain current in the field and to prepare classroom content. There is also demand for educators to be proficient in new technologies for teaching (i.e. Blackboard and PowerPoint) that are more familiar to a younger generation of students and meet the needs of those participating in distance education courses.

Social work administrators and faculty with an awareness of recent trends in higher education can take steps to ensure the success of their programs. Social work schools may put pressure on faculty to focus on developing and conducting research to supplement program budgets and raise the profile of the 
department. By taking on leadership positions within their academic community, social work educators also have an opportunity to enact structural changes that benefit rather than burden the school (Watkins \& Pierce, 2005). Requiring advanced skills and competencies, these activities broaden the role of the social work educator as more than a lecturer.

The internationalization of university programs is another response to globalization by institutions of higher education that will affect social work education (Irving \& Payne, 2005). The process of internationalization will impact both departmental operations and curriculum content within the university setting. Internationalization may be manifest in a) schools being encouraged to expand their global networks for new partnerships and development projects, and b) programs incorporating course material oriented towards training students for a globalized job market. This increased need for the internationalization of social work education is both an external pressure from universities and an internal movement within the profession.

\section{Social Work Education and Globalization}

The discussion thus far has focused on globalization as a phenomenon influencing higher education. Schools of social work reside within the institutions of higher education and are subject to the impacts of globalization on the academic environment. However, globalization is also seen as leaving its mark on the practice of social work across the globe. As a result, social work education is engaged with both university systems and the profession of social work in responding to globalization. 


\section{Responses to Globalization}

In an age of globalization, Rotabi, Gammonley, Gamble, and Weil (2007) contend that social work education needs to address its outcomes for internationalization with "an increased understanding of the complexities and human costs and benefits of a globalized and interdependent world with rapidly changing social, technological, and economic systems" (p. 1). This discussion on internationalization of social work education in the social work literature primarily revolves around the impact of globalization in (a) curriculum content or (b) educational policy initiatives. This section is followed by a discussion on the homogenizing influence of globalization on the internationalization of social work education.

\section{Curriculum Content}

"Is social work education relevant in the $21^{\text {st }}$ century?" ask Watkins and Pierce (2005). The authors question the academy's efforts to meet the current needs of society in a globalized world. The call for social work schools to adapt their training towards addressing social problems as globally interdependent issues has many supporters within the profession (Ahmadi, 2003; Asamoah, Healy \& Mayadas, 1997; Caragata \& Sanchez, 2002; Cox \& Pawar, 2006; Garber, 1997; Hare, 2004; Hartman, 1990; Healy, 2001; Hokenstad \& Midgley, 2004; Link \& Healy, 2005; Midgley, 1997; Mohan, 2005; Morley, 2004; Nagy and Falk, 2000; Polack, 2004; Ramanathan \& Link, 1999; Reisch, 2000; Reisch \& Jarman-Rohde, 2000; van Wormer, 2005; Yip, 2005). 
Either as a specialization or an infusion, Healy (2001) argued for the inclusion of international content in social work curricula as a necessary requirement for social worker students to learn how to practice effectively and competently in a globalized world. The author asked the following:

In designing curriculum for the future, the question should not be whether to include international perspectives in social work education; rather, one should ask how educators could conceive of teaching only a nationspecific curriculum. Why has the concept of borders prevented social work educators from adopting a holistic and global approach to the profession? (p. 256)

For practice in a globalized world, Rotabi et al. (2007) suggested that social work curricula should include content on the various causes and consequences of globalization, the related ethical dilemmas and responses, and cultural competence for global social justice and human rights awareness. The authors encourage engaging students in a world-systems perspective to develop their understanding of how events on a global scale can impact living at a local level.

Areas of the curriculum for the infusion of content on globalization include human behavior in the social environment, comparative social policy, community development, and sustainable development courses (Rotabi et al., 2007). To make globalization relevant in all aspects of social work education, the authors recommended defining the phenomenon by its positive and negative consequences or as an interdependence of economic, social, and cultural systems around the world. 
The internationalization of curriculum content as a primary method for preparing students with a global approach to practice is not a new initiative in social work education. As quoted by Stein in 1965, "We neglect our responsibility in social work education when we do not provide a world view to our students and we neglect our responsibility to our profession and our government when we do not contribute to international service" (Healy, 1986, p. 135).

Recent research demonstrates growth in the discipline's efforts towards incorporating material on global subject matter into the curriculum. As an example from the USA, Healy (1995) found that only one third (30\%) of the 214 social work graduate schools had content on global issues in their classes and less than half $(42 \%)$ offered specialized courses on international topics. A more recent study of 91 U.S. graduate schools indicated the majority (82\%) were taking steps to integrate international content into the curriculum (Ulrich, 2006).

Even with increased content in curricula, the link between local and global issues in practice has yet to materialize. Kondrat and Ramanathan (1996) found that social work practitioners serving as field instructors in the United States had limited perspectives on the significance of global issues in practice. The 130 surveyed field instructors reported difficulty in perceiving a connection between local and global issues in practice or policy. Findlay and McCormack (2005) found similar results with 66 Australian social workers and suggested that educational training was a factor in the social workers' lack of ability to understand the impact of global issues in local practice. As these studies are the only examples of efforts to assess the awareness of the global-local dialectic, the 
research and theorizing on the relationship between education on global content and the ability to apply its concepts in practice are only in their initial stages.

\section{Policy Initiatives}

Educational policies for social work education can be found at all levels from local to global. While some of the policies propose standards for performance, others outline requirements for the learning objectives within programs. These policies are described in the social work literature as shaping content towards global issues or influencing content in the global arena. The following examples illustrate the differences in these policies at national, regional, and international levels.

As an example on the national level, the accrediting body for schools of social work in the United States has made efforts to integrate a global perspective into American social work education and help create an expectation for the inclusion of global topics in the classroom (Healy, 2001; Link \& Healy, 2005). The Council on Social Work Education (CSWE) in the United States has adopted Educational Policy and Accreditation Standards which maintain that models of effective social work education must prepare students "to recognize the global context of social work practice" and "the global interconnections of oppression" (2001, p. 5). Suggested classroom content from CSWE included the analysis of social policy and social service delivery in an international context.

The European Union's Bologna Declaration is an example of a regional policy for the standardization of educational programs of participating member states. The policy was established to allow for student mobility in learning within 
and between countries within the European Union (EU). Martinez-Brawley (2005) described this education model as an example of the convergence of higher education policies that occurs in globalization and social integration. In contrast to harmonization as a general policy applied in different countries for their own individual outcomes, this case of convergence is the process of each country applying common rules for the same or similar results.

In terms of social work education in the European Union, this policy of convergence could lead to a standardization of education and homogenization of curriculum content irrespective of the unique practice needs in the different EU nations. Martinez-Brawley (2005) posited that this broad effort to set standards may have "decreased the relationship between learning and local contexts" ( $p$. 21). The author suggested that the EU policy is only one example of a growing lack of differentiation in social work education due to the push for universal standardization from external pressures.

Another educational policy coming under criticism in the wake of globalization is the Global Standards document created by the International Federation of Social Workers and the International Association of Schools of Social Work. The Global Standards have nine components from mission statement and ethics to the administration and curriculum of schools of social work around the globe (Sewpaul \& Jones, 2005). Developed with "an assumption there is a common core to social work on a global level", the standards were created to take into account the impact of globalization on social work education and attempts were made to reject market and managerial language (p. 217). 
Though the standards may be based on educational ideals and policies collected from countries around the world, Askeland and Payne (2006) found the emphasis on universal definitions and applications in the Global Standards as reflecting the homogenizing trends in globalization. Yip (2004) viewed the standard as lacking a conceptualization of social work that reflects the multidimensionality of the cultures in which it is practiced. Implemented as written, the standards require countries to adapt or indigenize implicit western cultural expectations that may be difficult to achieve or in conflict with local traditions. Yip attested that the individualist perspective in the standards document does not adequately translate into effective learning outcomes for Chinese culture as it focuses more on responsibility than rights.

\section{Homogenization and Internationalization}

Challenging the intent of internationalization practices, Dominelli (2005) cited Abye Tasse as stating "that internationalization is a predominantly western preoccupation, because developing countries are already 'westernized' and its migrating elites are familiar with the languages and cultures of the west prior to migration" (p. 505). The implication of a Western standard for the internationalization of social work that may not be relevant or applicable in a globalized world has also been raised in the social work literature as an issue needing critical analysis (Asamoah, Healy, \& Mayadas, 1997; Finn \& Jacobson, 2003; Fulcher, 2003; Gray \& Fook, 2004; Hartman, 1990; Haug, 2005;

Hokenstad, Khinduka, \& Midgley, 1992; Mohan, 2005; Morley, 2004; Yip, 2005). 
Askeland and Payne (2006) stated that the influence of globalization has not decreased cultural homogenization or hegemony in social work education as a global-local awareness has increased. In their analysis of the internationalization of social work education, the authors found that dominant cultures and languages were still defining the values which dictate the knowledge of the profession:

Social work education becomes part of the global market in that those who have the resources to produce and market social work literature are able to disseminate their theoretical views and skills in social work throughout the world as the way of handling social issues in a professional way, ignoring the different local context in which it is produced and in which it should be read. (p. 734)

The extensive use and requirement for material in the English language was seen as a main form of this cultural hegemony in social work education.

To reduce the homogenizing influences of globalization on social work education, Askeland and Payne (2006) advocated for social work educators to promote cultural diversity in their use of educational materials and resources. Recommended strategies towards this aim included (a) increasing the presence of cultural minorities in the professional literature through translations and copublications, (b) creating measurable learning outcomes for education on globally diverse cultures in curriculum, (c) developing training for the understanding of cultural differences and domination in local and global contexts, (d) identifying the cultural context in which ideas are created to assist in the interpretation and 
adaptation of materials for other settings, (e) maintaining openness to different cultural approaches to teaching and learning, and (f) making the effort toward openness and inclusion regardless of the difficulties in cultural translation.

\section{Social Work Research on Globalization}

In the previous section, the increase of a global-local consciousness in social work education was not seen as correlating with a trend toward an improved cultural diversity in social work education. The awareness of differences did not result in efforts to develop methods or materials with respect to these differences. Research with social work educators on their perspectives of this seemingly incongruent dynamic has yet to be conducted. However, the global-local dialectic in social work has been a focal point of three studies with social workers in the field. As exploratory research, these studies are the initial efforts to develop an understanding of the significance of globalization for the profession. As a review of social work research on globalization, these three studies by Kondrat and Ramanathan (1996), Rowe, Hanley, Repetur-Moreno, and Mould (2000), and Findlay and McCormack (2005) are presented here in their order of publication and with the details provided by their authors.

\section{Kondrat and Ramanathan}

In their review of the arguments for the internationalization of the profession, Kondrat and Ramanathan (1996) found that globalization was frequently raised as "a phenomenon that increasingly affects domestic practice" (p. 2). However, the authors reported that they found a lack of research 
supporting this assertion from the perspectives of those in the field dealing with the day-to-day consequences of globalization.

To fill this gap in knowledge, Kondrat and Ramanathan (1996) conducted a study with practitioners serving as field supervisors in the USA about their need for training on international issues. The researchers examined practitioners' knowledge of the impact of global issues on practice, their attitudes toward the internationalization of social work education, and their interest in learning more about international topics for practice. Following previous research on how crosscultural experiences can increase global awareness, Kondrat and Ramanathan included variables on exposure to other cultures through education, travel, or work.

Via a mailed questionnaire to a convenience sample, Kondrat and Ramanathan surveyed field instructors at social work schools in the Midwestern United States (1996). Out of a total population of 175, they had 130 participants, for a response rate of $74 \%$. Demographically, their sample was predominantly Caucasian females around 40 years of age. The practicum instructors practiced mostly in urban settings and spent $50 \%$ or more of their time in direct practice.

Primarily employed in mental health/developmental disability, child welfare, health, or substance abuse settings, the field instructors were split fairly equally into low, moderate and high levels of exposure to diverse cultures in the workplace and in educational training (Kondrat \& Ramanathan, 1996). Fifteen percent had lived abroad for four months or more, half of the sample had some international travel experience, and one-third had never left the country. Kondrat 
and Ramanathan hypothesized that the amount of cross-cultural experience in this group would influence attitudes towards education on international topics and levels of awareness about the impacts of global issues on daily social work practice.

From analysis of statements on five-point Likert scales from $1=$ Strongly Disagree to $5=$ Strongly Agree, Kondrat and Ramanathan (1996) found that the majority of the field instructors reported a relatively low level of ability to perceive a linkage between the local and global for practice $($ mean $=2.26, S D=1.07)$ or policy $($ mean $=2.25, \mathrm{SD}=1.03)$. With the majority of the participants $(71 \%)$ reporting interest in receiving more training on global issues, the practitioners expressed moderate to high levels of support for international material in the classroom (mean $=3.95, \mathrm{SD}=.99)$ and field content for students $($ mean $=3.60$, $S D=1.13)$. Viewing global issues as a distant concern, the perception of several of the field instructors was that an emphasis on the internationalization of the profession was a misdirected focus as cultural issues within the country should come first in practice and educational priorities.

With the assumption that "perceived heterogeneity of client population would predispose practitioners to generalize from local to international diversity" (p. 9), Kondrat and Ramanathan (1996) found a moderate correlation between multicultural exposure at work and level of global awareness for their sample of practicum instructors $(r=.29, p<.001)$. For example, globalization was a more relevant issue and "an easily identifiable reality" for respondents working with immigrant and refugee populations. There were somewhat stronger findings 
between these cultural experiences in the practice setting and support for global content in curriculum $(r=.38, p<.001)$ and practicum $(r=.41, p<.001)$.

However, there were no significant relationships between travel or educational training with perceptions and attitudes of international issues and social work practice and education.

In 1996, Kondrat and Ramanathan published the first study on social work practitioners and globalization. Having focused on the interaction of cross-cultural exposure with awareness and attitudes on global issues, the authors suggested that future research include other personal variables such as "language facility, immigration history, and work abroad experiences" (p. 13). Although the field instructors appeared to have narrow or limited perspectives on the significance of global issues for practice, the authors found general support for the inclusion of global content in social work education and for more training on the subject.

Not generalizable outside of their region of the country, the results of the study do indicate a need for further exploration of professional perceptions of globalization. As there are many studies on the quantity of international content in curricula, the suggested lack of relationship between exposure to international content and awareness of global issues also poses questions about the quality of the material provided to social work students.

\section{Rowe, Hanley, Repetur-Moreno, and Mould}

To better understand the various practice responses to the phenomenon of globalization, Rowe et al. (2000) conducted a qualitative study with practitioners who were members of the International Federation of Social 
Workers and could represent a range of personal and professional backgrounds. Though a response rate is not reported and country of residence is not recorded, 25 social work professionals completed surveys that had been translated into English, French, and Spanish. A review of the individual comments in the published report shows that study participants were from at least 18 different countries and represented most regions of the world. The authors collected qualitative feedback on survey questions that addressed the definition of globalization and its impacts on social work, society, and international social work practice.

As described in Chapter I, Rowe et al. (2000) found that globalization was typically described as "an economic, social, cultural, political and environmental issue of central importance to their practice of social work" (p. 69). Several respondents commented on how the processes of globalization had been occurring for hundreds of years. However, its effects were magnified in recent times. Elaborated upon earlier in this literature review, the respondents' definitions of globalization tended to focus on the growth of inequalities and economic ideologies, the experience of shared social problems in a borderless society, and the increased opportunities for personal and professional networking.

While the definitions from the respondents were often a recount of the destructive effects of globalization on society, Rowe et al. (2000) observed that many social workers appeared undecided about globalization in their description 
of both its benefits and its consequences. The authors interpreted these results as follows:

These statements reflect the feeling that while there are serious threats involved in the current manifestation of globalization as dominated by multinational corporations and international investors, the ideas of increased communication and cooperation between people and communities offers possibilities for social workers resisting the negative effects of globalization. (p. 71)

Concerns expressed by the social workers included the loss of cultural identity in the development of a universal perspective and approach to social problems (Rowe et al., 2000). Globalization was cited for causing changes in client populations due to migration and immigration and cuts in funding as a result of the restructuring of the global economy. The authors also reported that respondents who described globalization as a positive experience without any mention of negative consequences were identified as social workers from Westernized countries. However, they did not elaborate further and did not specify what countries fell into this category.

Constructed around themes gleaned from their research, Rowe et al.'s (2000) article on the impressions of social work practitioners on the significance of globalization for the profession is purely descriptive in nature. The authors do not provide much background on their study protocol or surveyed population. Their efforts indicate the need for further assessment of these experiences to lend validity to the realities of globalization for social work professionals. Though 
they did not rigorously analyze how the different backgrounds of the population influence the responses, they did observe cultural differences in their results. As their research demonstrates, the problems of a globalized world are not experienced in isolation and social work professionals can only begin to address the related issues by understanding that there are ramifications for all.

\section{Findlay and McCormack}

Following the path of previous research, Findlay and McCormack (2005) queried Australian social work practitioners to learn their perspectives on globalization and its relevance for social work practice. Similar to Kondrat and Ramanathan's (1996) research, this study also explored personal characteristics that could influence individuals' awareness of globalization and support for the internationalization of the social work profession.

The exploratory study by Findlay and McCormack used a convenience sample of social work practitioners from both local and national sources (2005). After a pilot test of the questionnaire, it was distributed to social workers employed by local community organizations and to practitioners attending a national social work conference. With a response rate of $32 \%, 66$ of the 205 distributed questionnaires were able to be used for this study.

Findlay and McCormack's (2005) sample was mostly composed of Australian born women with a mean age of 43 years. With the majority working in urban settings, this group had been in practice from 1 to 40 years with an average of 15 years of experience in a range of fields. One-fifth of the population was working with a culturally diverse client groups and just over half of all 
respondents were in direct practice. Most of these social workers had travelled abroad and half of them lived in other countries for six months or more. Observing a high number of respondents with international experiences, the authors noted that the sampled population could be overrepresented in this area of interest. As a result, Findlay and McCormack hypothesized that these social workers would be supportive of a professional response to the impact of globalization due to the extent of their cross-cultural experiences.

The questionnaire created for this study was modeled after Kondrat and Ramanathan's 1996 version utilizing a five-point Likert scale instrument to assess social work practitioner agreement with statements about globalization. Findlay and McCormack (2005) reported that " $100 \%$ of respondents believe the social work profession has a role to play in dealing with global issues" (p. 239). They found that the significance of globalization for social work practice was generally supported, though there was a portion of the surveyed social workers $(13.6 \%)$ who disagreed at some level or were unsure of its relevance.

As opposed to earlier research, the Australian social work practitioners were reported as demonstrating a high level of awareness of globalization (Findlay \& McCormack, 2005). Approximately $86 \%$ of the sample partly or totally agreed that they could readily observe the link between global issues and local practice and $95 \%$ indicated that globalization was affecting their clients or communities. Globalization was credited with increasing opportunities for professional networking at an international level and for impacting the lives of people as a result of changes in Australia's immigration and trade policies. 
Findlay and McCormack (2005) also explored the use of international policies in social work practice and found the group split between those who used such policies some of the time (43.9\%) and those who applied them on a regular basis (46.9\%). The Universal Declaration of Human Rights was one of the examples of global policies for social work practice that was provided on the survey. The authors suggested that the lack of application of these types of policies in practice could challenge the validity of the group's demonstrated high levels of awareness of global issues.

A few statements on Findlay and McCormack's (2005) scale addressed personal rather than professional attitudes towards globalization. The authors found that the majority of the social work practitioners had personal interests in global issues ( $87.7 \%)$ and considered themselves global citizens $(82.8 \%)$. However, further exploration of the data yielded results on a group that the authors' described as "less global" than the rest of the sample. As compared to the other respondents, these nine individuals were less likely to observe the global-local link of issues for practice and indicated that globalization was a less relevant topic for the profession. The group was demographically different from the norm in that they had a tendency to be male, under 35 or over 53 years of age, and had not lived out of the country even if they had traveled overseas.

Nearly ten years after Kondrat and Ramanathan's 1996 study, Findlay and McCormack (2005) have found their sample of Australian social workers to be more aware of global issues and the related impact on daily practice than the group of American practicum instructors. Though they do not speculate on 
cultural or regional differences between the two groups, the authors suggested that the heightened awareness of globalization for their sample may be a result of the topic's rise in popularity over time. This study had a different approach from Rowe et al. (2000), although it also identified an interest and need for more education and research on globalization's impacts on the social work profession.

\section{Conclusion}

The research on the impact of globalization on social work is only in its beginning stages and has primarily focused on practice issues. Similar research on how social work educators respond to globalization has not previously been initiated. What are the perspectives of social work educators on globalization? With much attention in the literature on the need for more knowledge on the topic for both social work practitioners and students, how do the individuals responsible for the dissemination of the material feel about globalization? Are they interested in globalization as a topic for curricula and are they aware of it as a process impacting the delivery of social work education?

These questions are part of the inquiry engendering this exploratory study as the first of its kind on the impact of globalization on social work education. Conducted with social work educators, it is an analysis of their perspectives on how it influences the profession. Information on their general knowledge of globalization is also collected to gain a sense of its meaning for these social work educators. This study was implemented in China, Germany, Russia, and the United States to investigate what other factors may affect how social work educators respond and relate to globalization. The next chapter describes the 
methodology of this study on globalization and the variables that will be examined. 


\section{CHAPTER III \\ METHODOLOGY}

With the purpose of investigating the status of globalization in social work education, this study examines the influence of globalization on social work education's content and processes from a multinational perspective. The study of the interaction between globalization and social work education is an effort to (a) explore this emerging reality as it is experienced in multiple settings, and (b) to conduct an international comparative analysis of its impacts. To accomplish this task, research was conducted with social work educators in four different countries on their responses to globalization: China, Germany, Russia, and the United States. This chapter is organized to present the many aspects of the research methodology from (a) research design, (b) participating populations, (c) operationalization of the variables, (d) the research instrument and data collection, to (e) data analysis procedures.

\section{Research Design}

For an exploratory study with the requirements of international cooperation for its implementation, a survey was chosen to facilitate the data collection from social work educators from the four participating countries. For an initial crosscultural examination of globalization and social work education, a preexperimental multi-group post-test only design was selected: 


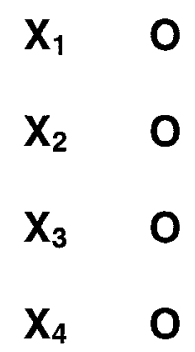

in which $\mathbf{X}_{\mathbf{1}}=$ Social Work Educators in China

$\mathbf{X}_{\mathbf{2}}=$ Social Work Educators in Germany

$\mathbf{X}_{3}=$ Social Work Educators in Russia

$\mathbf{X}_{4}=$ Social Work Educators in the United States

The $\mathbf{X s}$ represent the primary independent variable, country, and the Os represent the main dependent variables at posttest only, social work educators' knowledge about and experiences with globalization.

With a threat to internal validity due to history or other events affecting the impressions of the participants, this design allowed for the creation of a baseline of information about the perspectives of social work educators and their experiences with globalization. This post-test only design was selected to gather rich accounts of these experiences and to generate hypothesis for further research. Since the results of this research will not be generalizable outside of the schools surveyed, their outcomes and implications will be utilized as a starting point of inquiry on this subject to inform future studies.

\section{Participants}

Employing a blended purposive/convenience sampling strategy, this research purposefully sought the participation of social work educators in a convenience sample of countries in which collegial relationships had already 
been established: China, Germany, Russia, and the United States. The schools participating in this study included the following: the China Civil Affairs College in Beijing, China; the Chongqing City Management College in Chongqing, China; and the Wuhan Civil Affairs Vocational College in Wuhan, China; the Katholischestiftungfachhochschule (KSFH) in Munich, Germany; the Belgorod State University in Belgorod, Russia; the Kent School of Social Work in Louisville, Kentucky USA.

The participants are members of the selected schools' faculty who were currently teaching courses in the social work degree programs and available at the time of the implementation of the study. This focus on social work educators as the unit of analysis was to investigate globalization as perceived by the individuals responsible for the dissemination of the discipline's knowledge and for training of social workers for professional practice. The awareness and interest of educators in addressing the topic of globalization in the classroom could influence how prepared students are to assist clients directly impacted by related issues.

\section{Key Variables}

In relation to the questions of this research project, the dependent variables for this exploratory study include the definition and dimensions of globalization, and the related responses and attitudes of social work educators. The main independent variable is the country of residence for each of the participating social work educators. Other characteristics analyzed as predictive factors for social work educator responses and attitudes toward globalization 
include professional and personal backgrounds, resources, and international experience. These variables are operationalized in Table 1.

\section{Definition and Dimensions}

One of the primary goals of this research was to provide more clarity about the definition and impact of globalization. To gain a better understanding of its meaning, a conceptual definition of globalization was provided for the social work educators on the survey that they could then expand upon, refute, or revise in their own terms (Appendix A). Descriptions of the dimensions of globalization were also collected to provide examples of the perceptions of social work educators from each country.

\section{Responses}

Responses to issues of globalization were collected as the specific individual or collective efforts within the academic arena to address the topic of globalization in social work programs and/or in the classroom. A response example could refer to the infusion of globalization topics as required content across school curriculum or the inclusion of a specific course on the subject.

\section{Attitudes}

The variable of attitudes towards globalization was measured on an ordinal level as the opinions or beliefs about the importance of this topic for social work. Areas addressed included concerns about globalization for social workers, social work students, social work educators, and social work education. 
Table 1

Variable Names, Data Levels, and Operational Definitions

\begin{tabular}{|c|c|c|}
\hline Variable & $\begin{array}{l}\text { Data } \\
\text { Level }\end{array}$ & Operational Definitions \\
\hline $\begin{array}{l}\text { Definition of } \\
\text { Globalization }\end{array}$ & Nominal & $\begin{array}{l}\text { Definition of globalization as provided by } \\
\text { educator }\end{array}$ \\
\hline $\begin{array}{l}\text { Impacts of } \\
\text { Globalization }\end{array}$ & Nominal & $\begin{array}{l}\text { Descriptions and examples of cultural, } \\
\text { economic, environmental, political, social, } \\
\text { technological or other impacts of globalization } \\
\text { as provided by educator }\end{array}$ \\
\hline $\begin{array}{l}\text { School Response to } \\
\text { Globalization }\end{array}$ & Nominal & $\begin{array}{l}\text { Yes or No response to school's social work } \\
\text { program responding to globalization; If yes, } \\
\text { examples as provided by educator }\end{array}$ \\
\hline $\begin{array}{l}\text { Globalization Topics } \\
\text { at School and in } \\
\text { Classes }\end{array}$ & Nominal & $\begin{array}{l}\text { Yes or No response to globalization topics } \\
\text { being included at school or in classes; If yes, } \\
\text { examples as provided by educator }\end{array}$ \\
\hline $\begin{array}{l}\text { Required Courses } \\
\text { with Globalization } \\
\text { Topics }\end{array}$ & Ratio & $\begin{array}{l}\text { Percentage of required social work courses } \\
\text { with globalization topics }\end{array}$ \\
\hline $\begin{array}{l}\text { Elective Courses with } \\
\text { Globalization Topics }\end{array}$ & Ratio & $\begin{array}{l}\text { Percentage of elective social work courses } \\
\text { with globalization topics }\end{array}$ \\
\hline $\begin{array}{l}\text { Educator Courses } \\
\text { with Globalization } \\
\text { Topics }\end{array}$ & Ratio & $\begin{array}{l}\text { Percentage of educator's social work courses } \\
\text { with globalization topics }\end{array}$ \\
\hline $\begin{array}{l}\text { Social Work Students } \\
\text { Interested in } \\
\text { Globalization }\end{array}$ & Ratio & $\begin{array}{l}\text { Percentage of social work students interested } \\
\text { in globalization }\end{array}$ \\
\hline $\begin{array}{l}\text { Challenges to } \\
\text { Teaching about } \\
\text { Globalization }\end{array}$ & Nominal & $\begin{array}{l}\text { Yes or No response to challenges to teaching } \\
\text { about globalization and social work education; } \\
\text { If yes, examples as provided by educator }\end{array}$ \\
\hline
\end{tabular}


Table 1 (continued)

Variable Names, Data Levels, and Operational Definitions

\begin{tabular}{lll}
\hline Variable & $\begin{array}{l}\text { Data } \\
\text { Level }\end{array}$ & \multicolumn{1}{c}{ Operational Definitions } \\
\hline $\begin{array}{l}\text { Effects of } \\
\text { Globalization on } \\
\text { Teaching Methods }\end{array}$ & Nominal & $\begin{array}{l}\text { Yes or No response to globalization having an } \\
\text { effect on teaching methods; If yes, examples } \\
\text { as provided by educator }\end{array}$ \\
\hline $\begin{array}{l}\text { Influence of } \\
\text { Globalization on } \\
\begin{array}{l}\text { Future of Social } \\
\text { Work Education }\end{array}\end{array}$ & Nominal & $\begin{array}{l}\text { Yes or No response to globalization having an } \\
\text { influence on future of social work education; If } \\
\text { yes, examples as provided by educator }\end{array}$ \\
\hline
\end{tabular}

Attitudes Towards

Globalization and

Social Work

Education
Scores on attitudes to statements about

Ordinal globalization and social work education

1 to 5 rating of Disagree to Agree

\begin{tabular}{lll}
$\begin{array}{l}\text { Areas of } \\
\text { Qualifications }\end{array}$ & Nominal & Degrees, diplomas, or titles held by educator \\
\hline Years of Teaching & Ratio & Number of years teaching in social work \\
\hline $\begin{array}{l}\text { Courses Teaching } \\
\text { Currently }\end{array}$ & Ratio & Number of courses currently being taught \\
\hline $\begin{array}{l}\text { Course Areas } \\
\text { Teaching Currently }\end{array}$ & Nominal & $\begin{array}{l}\text { Social work course areas currently teaching: } \\
\text { field practicum, human behavior, policy, } \\
\text { practice, research, theory, other; If other, } \\
\text { examples provided by educator }\end{array}$ \\
\hline $\begin{array}{l}\text { Course Areas Taught } \\
\text { in the Past }\end{array}$ & Nominal & $\begin{array}{l}\text { Social work course areas taught in the past: } \\
\text { field practicum, human behavior, policy, } \\
\text { practice, research, theory, other; lf other, } \\
\text { examples provided by educator }\end{array}$
\end{tabular}


Table 1 (continued)

Variable Names, Data Levels, and Operational Definitions

\begin{tabular}{|c|c|c|}
\hline Variable & $\begin{array}{l}\text { Data } \\
\text { Level }\end{array}$ & Operational Definitions \\
\hline $\begin{array}{l}\text { Level of } \\
\text { Teaching }\end{array}$ & Nominal & $\begin{array}{l}\text { Levels of teaching in social work: bachelor's, } \\
\text { master's, doctorate, specialist, other; If other, } \\
\text { examples provided by educator }\end{array}$ \\
\hline $\begin{array}{l}\text { Time Spent on } \\
\text { Professional } \\
\text { Activities }\end{array}$ & Ratio & $\begin{array}{l}\text { Percentage of time spent on professional activities: } \\
\text { teaching, practice, research, administration, other; If } \\
\text { other, examples provided by educator }\end{array}$ \\
\hline $\begin{array}{l}\text { Areas of } \\
\text { Interest }\end{array}$ & Nominal & $\begin{array}{l}\text { Main social work areas of interest as provided by } \\
\text { educator }\end{array}$ \\
\hline $\begin{array}{l}\text { Approach to } \\
\text { Social Work }\end{array}$ & Nominal & Preferred approach to social work as macro or micro \\
\hline $\begin{array}{l}\text { Years of } \\
\text { Practice }\end{array}$ & Ratio & $\begin{array}{l}\text { Number of years of practice in the field of social } \\
\text { work }\end{array}$ \\
\hline $\begin{array}{l}\text { Work with } \\
\text { Different } \\
\text { Cultural } \\
\text { Groups }\end{array}$ & Nominal & $\begin{array}{l}\text { Yes or No response to work with people from } \\
\text { cultural or language backgrounds that are different } \\
\text { from educator; If yes, examples provided by } \\
\text { educator }\end{array}$ \\
\hline $\begin{array}{l}\text { Professional } \\
\text { International } \\
\text { Activities }\end{array}$ & Nominal & $\begin{array}{l}\text { Yes or No response to involvement in professional } \\
\text { international activities; If yes, examples provided by } \\
\text { educator }\end{array}$ \\
\hline $\begin{array}{l}\text { Current } \\
\text { Globalization } \\
\text { Resources }\end{array}$ & Nominal & $\begin{array}{l}\text { Resources currently used to learn about } \\
\text { globalization: radio, television, internet, videos, } \\
\text { books, newspapers, magazines, scholarly journals, } \\
\text { conferences, workshops, academic exchanges, } \\
\text { community meetings, travel, other, and none; If } \\
\text { other, examples provided by educator }\end{array}$ \\
\hline
\end{tabular}


Table 1 (continued)

Variable Names, Data Levels, and Operational Definitions

\begin{tabular}{|c|c|c|}
\hline Variable & $\begin{array}{l}\text { Data } \\
\text { Level }\end{array}$ & Operational Definitions \\
\hline $\begin{array}{l}\text { Preferred } \\
\text { Globalization } \\
\text { Resources }\end{array}$ & Nominal & $\begin{array}{l}\text { Preferred resources for learning about } \\
\text { globalization: radio, television, internet, videos, } \\
\text { books, newspapers, magazines, scholarly journals, } \\
\text { conferences, workshops, academic exchanges, } \\
\text { community meetings, travel, other, and none; If } \\
\text { other, examples provided by educator }\end{array}$ \\
\hline $\begin{array}{l}\text { Country of } \\
\text { Residence }\end{array}$ & Nominal & $\begin{array}{l}\text { Country where educator currently resides: China, } \\
\text { Germany, Russia, USA }\end{array}$ \\
\hline Country of Birth & Nominal & $\begin{array}{l}\text { Yes or No response to currently residing in same } \\
\text { country as country of birth; If no, example provided } \\
\text { by educator }\end{array}$ \\
\hline $\begin{array}{l}\text { Travel Outside } \\
\text { of Country }\end{array}$ & Nominal & $\begin{array}{l}\text { Yes or No response to traveling outside of country } \\
\text { of current residence; If yes, examples of countries } \\
\text { and dates of travel provided by educator }\end{array}$ \\
\hline $\begin{array}{l}\text { Time Traveled } \\
\text { Abroad }\end{array}$ & Ratio & $\begin{array}{l}\text { Longest approximate length of time traveled } \\
\text { abroad }\end{array}$ \\
\hline $\begin{array}{l}\text { Spoken } \\
\text { Languages }\end{array}$ & Nominal & Languages spoken by educator \\
\hline $\begin{array}{l}\text { Family } \\
\text { Background }\end{array}$ & Nominal & $\begin{array}{l}\text { Family ethnic, cultural, and religious backgrounds } \\
\text { as provided by educator }\end{array}$ \\
\hline $\begin{array}{l}\text { Socioeconomic } \\
\text { Status }\end{array}$ & Ordinal & Level of socioeconomic status: low, middle, high \\
\hline Gender & Nominal & Gender: female, male \\
\hline Age & Ratio & Calculated from date of birth \\
\hline
\end{tabular}




\section{Data Collection}

As an international study, the collection of data for this research involved much cooperation and collaboration between the researcher and the participating schools of social work. Following a discussion on the instrument created to collect the data on social work education and globalization from the different countries, the data collection procedures from translation to distribution of the survey are reviewed.

\section{The Instrument}

As there are no known measurement tools on the topic of globalization and social work education, a new questionnaire was developed to measure the responses and impressions of social work educators towards globalization.

Beginning with a request for feedback or innovative ideas on a general definition of globalization, this survey sought information on the observed impact of globalization and on respondents' experiences with globalization as classroom educators. Ten statements about globalization were developed and incorporated into the questionnaire to give a more in-depth measure of social work educators' attitudes and their levels of agreement on its relevance for social work education. For each of the ten statements, participants rated the items on five-point scale from $1=$ Strongly Disagree to $5=$ Strongly Agree. Responses to specific items on the measurement tool were used for comparison of results between countries.

Basic demographics and information on social work experiences were included in the questionnaire to gain knowledge about the background of respondents. Previous research results have suggested that an individual's 
exposure to other cultures via personal experience abroad or in local settings may influence a person's openness to global issues (Kondrat \& Ramanathan, 1996). As a result, questions about travel to other countries and employment interactions with people of different cultures were integrated into the survey. In addition, the literature on globalization has highlighted how media and technology resources can affect personal opinions and awareness of events around the world (Findlay \& McCormack, 2005; Stromquist, 2002). The social work educators completing the survey were asked to provide information about their use of and access to such resources including the Internet and international publications.

\section{Translations}

Prior to data collection, the preamble and survey questionnaire was piloted for accuracy of meaning and veracity of intent with visiting international social work educators. To not require all respondents to be fluent in English, the study materials were translated into the respective languages of each participating country. These materials were then back-translated into English to verify content. Fluent in English and one of the other languages, authorized individuals or official translators at each institution conducted these translations and confirmed the back-translations (Appendix B).

\section{Procedures}

For international and national research standards, permission to conduct the study was obtained from the participating schools. On January $8^{\text {th }}$ of 2007 , the University of Louisville Institutional Review Board approved this study as exempt 
from further review as it does not present any unforeseeable risks to the social work educators as human subjects (Appendix C). Participants were not required to provide identifying information on the survey. However, they were given an opportunity to provide their contact information if they would like to receive the results of the analysis. The identity and privacy of these individuals were protected as this information was not released to anyone outside of the research team and the results of the data are only reported in aggregate form.

After translation of the study materials, the collection of data for this research was conducted between April and September, 2007. At the Kent School of Social Work, the surveys were distributed and collected on-site from faculty of the school. For the international participants, the translated survey questionnaires were sent electronically to the schools in China, Germany and Russia for distribution to teaching faculty. Key individuals at each school agreed to be responsible for providing a copy of the survey to social work faculty members and collecting the forms for the researcher. The completed surveys were returned to the researcher via email or in person by visiting faculty from the participating institutions. The collected information from the schools was then translated into English for data analysis by the researcher.

\section{Data Analysis}

Following the collection of the completed questionnaires from the different countries, the data from the surveys was entered into a Statistical Package for the Social Sciences (SPSS) database file for data management and analysis. Descriptive statistics were used to create summaries of the data on key variables 
and provide general descriptions of the social work educators' responses about the impact of globalization. Qualitative data was coded and compared for themes. The results from these analyses are presented in the following chapter. 


\section{CHAPTER IV}

\section{RESULTS}

This chapter begins with a description of the personal demographics and professional characteristics of the social work educators based on country of residence. The definitions and dimensions of globalization provided by the social work educators are reviewed to highlight the similarities and differences that exist within and between groups. The analysis that follows examines how these social work educators, as a whole and by country, perceive and respond to globalization and its impact on social work education.

\section{The Total Sample}

As described in previous chapters, social work educators from schools in four different countries were invited to participate in this study. From a total population of 94 faculty members from these schools, 46 social work educators completed the survey for a response rate of $49 \%$. The breakdown of participation and rate of response per country is as follows: China $(n=17,68 \%$ of 25$)$, Germany ( $n=6,22 \%$ of 27$)$, Russia $(n=6,38 \%$ of 16$)$, and USA $(n=17,65 \%$ of 26). As an exploratory study that is not generalizable outside of the schools surveyed, the data allows for a preliminary inquiry into the perspectives of social work educators in different countries about globalization and can suggest areas for further research. 


\section{Personal Demographics}

To understand the background of the social work educators as individuals, the demographics of the sample include age, gender, socioeconomic status (SES), family background, language ability, and travel experience. The SES levels reported by the social work educators reflect the unique social and economic conditions within each of their countries. Table 2 shows the mean ages of the social work educators by country and Table 3 illustrates additional demographic variables by country for ease in comparing similarities and differences.

Table 2

Mean Age of Social Work Educators by Country

\begin{tabular}{lrrrrr}
\hline Country & $\boldsymbol{n}$ & Mean & \multicolumn{1}{c}{ SD } & Minimum & Maximum \\
\hline China & 17 & 34.18 & 8.68 & 24 & 60 \\
Germany & 6 & 54.17 & 10.57 & 43 & 68 \\
Russia & 6 & 38.00 & 8.10 & 27 & 50 \\
USA & 16 & 49.81 & 11.07 & 36 & 71 \\
Total & 45 & 42.91 & 12.52 & 24 & 71 \\
\hline
\end{tabular}

\section{China}

As one of the two larger populations $(n=17)$ in the study, the Chinese social work educators were both similar and different from the other countries and total sample. Seventy-one percent of the Chinese participants were male. 
Table 3

Frequencies and Percentages of Demographic Variables by Country

\begin{tabular}{|c|c|c|c|c|c|c|c|c|c|c|}
\hline \multirow{2}{*}{ Demographics } & \multicolumn{2}{|c|}{$\begin{array}{l}\text { China } \\
(n=17)\end{array}$} & \multicolumn{2}{|c|}{$\begin{array}{c}\text { Germany } \\
(n=6)\end{array}$} & \multicolumn{2}{|c|}{$\begin{array}{l}\text { Russia } \\
(n=6)\end{array}$} & \multicolumn{2}{|c|}{$\begin{array}{c}\text { USA } \\
(n=17)\end{array}$} & \multicolumn{2}{|c|}{$\begin{array}{c}\text { Total } \\
(N=46)\end{array}$} \\
\hline & $n^{\mathrm{a}}$ & $\%$ & $n^{\mathrm{a}}$ & $\%^{b}$ & $n^{\mathrm{a}}$ & $\%^{b}$ & $n^{a}$ & $\%^{b}$ & $n^{\mathrm{a}}$ & $\%^{b}$ \\
\hline \multicolumn{11}{|l|}{ Gender } \\
\hline Female & 5 & 29 & 2 & 33 & 5 & 83 & 9 & 53 & 21 & 46 \\
\hline Male & 12 & 71 & 4 & 67 & 1 & 17 & 8 & 47 & 25 & 54 \\
\hline \multicolumn{11}{|l|}{ SES } \\
\hline Low & 5 & 29 & 0 & 0 & 3 & 50 & 0 & 0 & 8 & 17 \\
\hline Middle & 12 & 71 & 6 & 100 & 3 & 50 & 13 & 76 & 34 & 74 \\
\hline High & 0 & 0 & 0 & 0 & 0 & 0 & 4 & 24 & 4 & 9 \\
\hline \multicolumn{11}{|l|}{$\begin{array}{l}\text { Lives in } \\
\text { Country of } \\
\text { Birth }\end{array}$} \\
\hline Yes & 17 & 100 & 6 & 100 & 5 & 83 & 13 & 77 & 41 & 89 \\
\hline No & 0 & 0 & 0 & 0 & 1 & 17 & 4 & 24 & 5 & 11 \\
\hline \multicolumn{11}{|l|}{$\begin{array}{l}\text { Speaks More } \\
\text { Than One } \\
\text { Language }\end{array}$} \\
\hline Yes & 13 & 77 & 5 & 83 & 6 & 100 & 7 & 41 & 31 & 67 \\
\hline No & 4 & 24 & 1 & 17 & 0 & 0 & 10 & 59 & 15 & 33 \\
\hline \multicolumn{11}{|l|}{$\begin{array}{l}\text { Traveled Out of } \\
\text { Country }\end{array}$} \\
\hline Yes & 5 & 29 & 6 & 100 & 2 & 33 & 15 & 88 & 28 & 61 \\
\hline No & 12 & 71 & 0 & 0 & 4 & 67 & 2 & 12 & 18 & 39 \\
\hline
\end{tabular}

Note. ${ }^{a}$ Numbers may not equal sample total due to missing data. ${ }^{b}$ Percentages may not equal $100 \%$ due to rounding.

With a range of 24 to 60 years, the mean age of the Chinese is $34(S D=8.68)$. Almost three-fourths $(71 \%)$ of the Chinese reported a mid-level SES with close to one-third at a low level (29\%). All of the social work educators in this group described their cultural or ethnic backgrounds as Han Chinese; two individuals 
were Buddhists. All of the Chinese were born in China and $77 \%$ speak more than one language, even though only $29 \%$ have traveled to other countries. English was the most popular second language and North America was the most frequently visited continent.

\section{Germany}

The surveyed group of German social work educators is very small $(n=6)$ and also differs in various ways from the rest of the educators in the study. Similar to the Chinese, over twice as many men (67\%) as women (33\%) participated in this study. The Germans' ages ranged from 43 to 68 , with an average of $54(S D=10.57)$. They all indicated they had a middle SES level. All six of these social work educators identified with a Bavarian heritage and were born in Germany. Most of the Germans (83\%) reported an ability to speak at least two languages with English and French as the most popular second and/or third languages. All of the Germans had traveled abroad, especially throughout Europe and North America.

\section{Russia}

In contrast to the Chinese and Germans, 5 of the 6 participating Russian social work educators were women (83\%) and the average age was $38(S D=$ 8.10). Their ages ranged from 27 to 50 years. The Russians were split evenly between low and middle levels of SES. Though one individual was born in Uzbekistan, all of these individuals reported Russian as their ethnic or cultural heritage. One person also listed atheism while others indicated a Russian Orthodox background. All of the Russians speak more than one language, with 
English as the most frequent second language. Only 2 of the 6 Russian social work educators had traveled out of the country and visited the Ukraine. One of these individuals had also traveled to the United States.

USA

The social work educators from the United States $(n=17)$ were more representative of the total sample for gender with a close balance between male (47\%) and female (53\%) participants. With an age range from 36 to 71 , the average age of this group was 50 years $(S D=11.07)$. Over three-fourths $(76 \%)$ of the American social work educators reported a mid SES level. The rest of the group $(24 \%)$ was the only portion of the total sample reporting a high level of socioeconomic status. The cultural, ethnic, and religious responses of the Americans predominantly reflected a Caucasian background with a Christian faith (e.g. Catholic or Protestant). Almost one-fourth of the Americans were born outside of the United States.

In contrast to the other countries, less than half $(41 \%)$ of the American group speaks an additional language. French and Spanish were most often listed as second languages. The majority of the American social work educators ( $88 \%)$ had traveled out of the country, with Canada, Europe, and Mexico as the most frequently visited locations.

\section{Total Sample}

Beyond the inherent differences based on country of residence and national culture, the sample of social work educators in this study is a collective of diverse individuals. As a total sample without regard to country, the social work 
educators are almost evenly split between men (54\%) and women (46\%). The total sample had an average age of 43 years $(S D=12.52)$ and a median age of 40. Three-fourths of the social work educators (74\%) reported a mid level of SES. The majority of the social work educators (89\%) lived in the countries of their births. Over half of the total sample $(61 \%)$ have traveled outside of their countries and over two-thirds (67\%) speak two or more languages. Table 4 lists reported languages spoken by the sample.

Yet, these trends are not wholly reflective of the groups from the different countries as demonstrated in the previous discussion. For example, the Chinese and the Russian social work educators were a decade or two younger, on the average, than the German and American social work educators. The Germans and Americans also tended to have higher socioeconomic levels and more travel experiences than the Chinese and Russian social work educators.

\section{Professional Characteristics}

As a multinational group of social work educators, the sample is composed of individuals with an assortment of professional qualifications and a range of teaching experiences. The countries represented in this study have different educational systems that present a challenge in comparing the degrees obtained by the social work educators and the levels of courses they are teaching. Their programs were also established at different points in time. Social work education in China and Russia has only developed within the past 15-20 years while Germany and the USA have had programs for over a century. It is critical to keep these factors in mind in the analysis and interpretation of the data. 
Table 4

Languages Spoken by Country

\begin{tabular}{|c|c|c|c|c|c|c|c|c|c|c|}
\hline \multirow{2}{*}{ Languages } & \multicolumn{2}{|c|}{$\begin{array}{c}\text { China } \\
(n=17)\end{array}$} & \multicolumn{2}{|c|}{$\begin{array}{l}\text { Germany } \\
\qquad(n=6)\end{array}$} & \multicolumn{2}{|c|}{$\begin{array}{l}\text { Russia } \\
(n=6)\end{array}$} & \multicolumn{2}{|c|}{$\begin{array}{c}\text { USA } \\
(n=17)\end{array}$} & \multicolumn{2}{|c|}{$\begin{array}{c}\text { Total } \\
(N=46)\end{array}$} \\
\hline & $n^{\mathrm{a}}$ & $\%^{b}$ & $n^{\mathrm{a}}$ & $\%^{b}$ & $n^{a}$ & $\%^{b}$ & $n^{a}$ & $\%^{b}$ & $n^{a}$ & $\%$ \\
\hline Afrikaans & 0 & 0 & 0 & 0 & 0 & 0 & 2 & 12 & 2 & 4 \\
\hline Chinese & 17 & 100 & 0 & 0 & 0 & 0 & 0 & 0 & 17 & 37 \\
\hline Dutch & 0 & 0 & 0 & 0 & 0 & 0 & 2 & 12 & 2 & 4 \\
\hline English & 12 & 71 & 5 & 83 & 4 & 67 & 17 & 100 & 38 & 82 \\
\hline French & 0 & 0 & 3 & 50 & 1 & 17 & 2 & 12 & 6 & 13 \\
\hline German & 0 & 0 & 6 & 100 & 1 & 17 & 0 & 0 & 7 & 15 \\
\hline Italian & 0 & 0 & 2 & 33 & 0 & 0 & 0 & 0 & 2 & 4 \\
\hline Romanian & 0 & 0 & 0 & 0 & 0 & 0 & 1 & 6 & 1 & 2 \\
\hline Russian & 1 & 6 & 0 & 0 & 6 & 100 & 0 & 0 & 7 & 15 \\
\hline Spanish & 0 & 0 & 0 & 0 & 0 & 0 & 2 & 12 & 2 & 4 \\
\hline Ukrainian & 0 & 0 & 0 & 0 & 2 & 33 & 0 & 0 & 2 & 4 \\
\hline
\end{tabular}

Note. ${ }^{a}$ Numbers may not equal sample total due to missing data. ${ }^{b}$ Percentages may not equal $100 \%$ due to rounding.

Similar to the previous section on demographics, the professional characteristics of the social work educators from each country will be described and then followed by a discussion of the results from the total sample. These professional characteristics include years of teaching (Table 5), number of classes taught (Table 6), and percentage of professional time devoted to 
teaching (Table 7). Table 8 illustrates levels of degree obtained and taught, degrees in social work, course subjects taught, approaches to social work, and professional experiences related to different cultures at home or abroad. This section concludes with a review of the resources utilized by social work educators to gather information about globalization and to learn about its influence on the social work profession.

Table 5

Mean Years of Teaching in Social Work by Country

\begin{tabular}{lrrrrr}
\hline Country & $\boldsymbol{n}$ & Mean & \multicolumn{1}{c}{ SD } & Minimum & Maximum \\
\hline China & 16 & 5.59 & 3.48 & 1.5 & 15 \\
Germany & 6 & 19.67 & 13.41 & 5.0 & 36 \\
Russia & 6 & 6.25 & 3.37 & 2.0 & 10 \\
USA & 17 & 15.09 & 9.97 & 4.0 & 30 \\
Total & 45 & 11.14 & 9.61 & 1.5 & 36 \\
\hline
\end{tabular}

Table 6

Mean Number of Social Work Courses Taught by Country

\begin{tabular}{lrrrrr}
\hline Country & $\boldsymbol{n}$ & Mean & SD & Minimum & Maximum \\
\hline China & 15 & 2.13 & 1.19 & 0 & 4 \\
Germany & 6 & 5.25 & 2.79 & 1 & 10 \\
Russia & 6 & 6.17 & 1.84 & 3 & 8 \\
USA & 17 & 2.53 & 1.91 & 0 & 6 \\
Total & 44 & 3.26 & 2.34 & 0 & 10 \\
\hline
\end{tabular}


Table 7

Mean Percentage of Professional Time Spent Teaching by Country

\begin{tabular}{lrrrrr}
\hline Country & $\boldsymbol{n}$ & Mean & \multicolumn{1}{c}{ SD } & Minimum & Maximum \\
\hline China & 16 & 58.13 & 18.96 & 30 & 90 \\
Germany & 6 & 54.17 & 18.55 & 20 & 70 \\
Russia & 5 & 56.00 & 5.48 & 50 & 60 \\
USA & 17 & 27.24 & 19.17 & 0 & 60 \\
Total & 44 & 45.41 & 22.79 & 0 & 90 \\
\hline
\end{tabular}

\section{China}

Fifty-nine percent of the surveyed Chinese social work educators held either bachelors or masters degrees. With a brief recent history of social work in their country, only $24 \%$ of the Chinese listed social work as their major and the average number of years the Chinese social work educators had been teaching in social work was $6(S D=3.48)$. The average current course load of this group was 2 classes $(S D=1.19)$ and they spent an average of $58 \%$ of their professional time teaching $(S D=18.96)$.

With $24 \%$ of these social work educators teaching at the bachelor's level, the rest of the Chinese (76\%) indicated they had other experiences including teaching courses in high school, three year degree programs, and technical colleges. Though there was not a particular course that a majority of the group were teaching, the Chinese social work educators were responsible for a variety of subjects including field practicum, human behavior, policy, practice, research, theory and other course topics. 
Table 8

Frequencies and Percentages of Professional Characteristics by Country

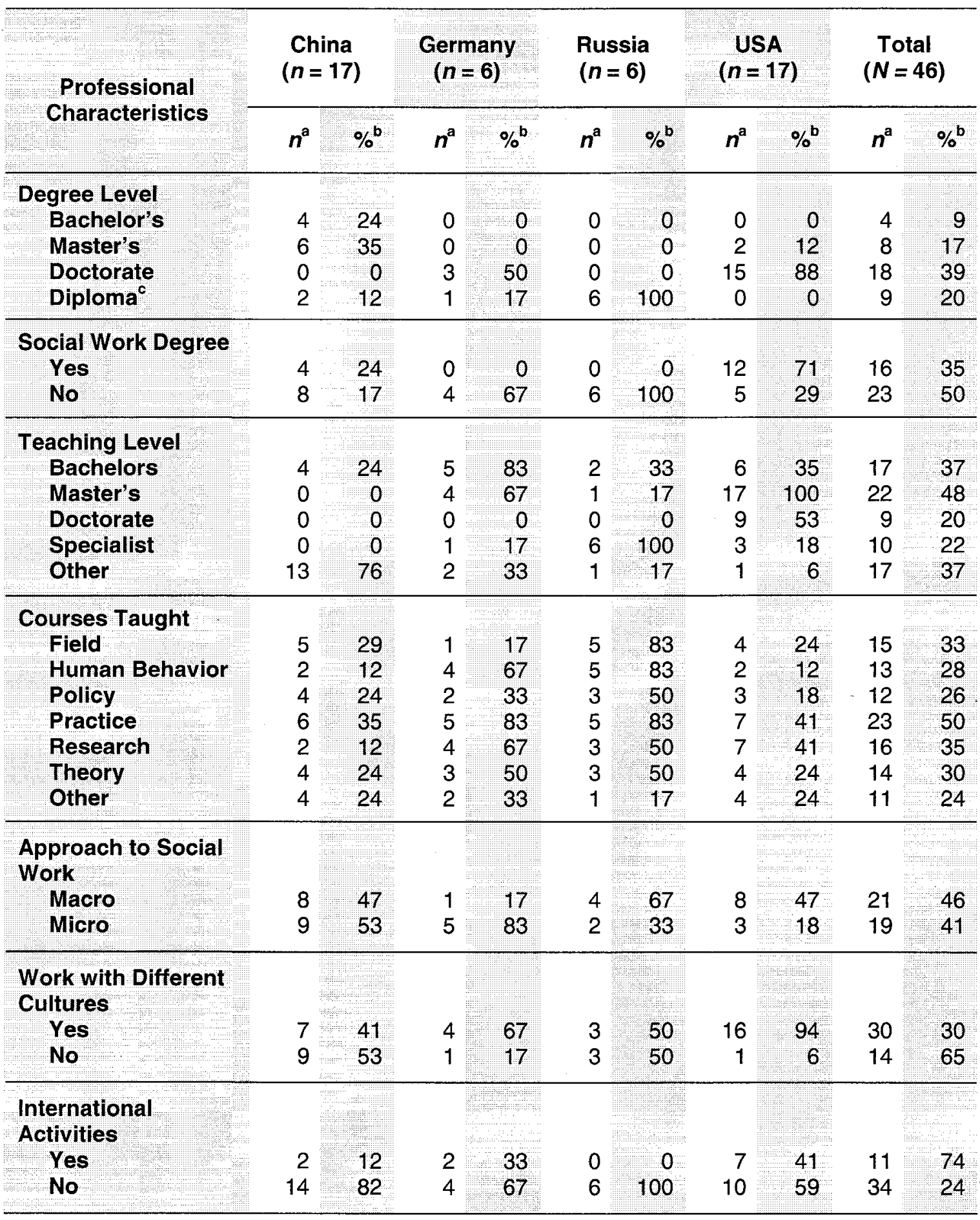

Note. ${ }^{a}$ Numbers may not equal sample total due to missing data. ${ }^{b}$ Percentages may not equal $100 \%$ due to rounding. 'Unspecified level of degree. 
The Chinese were split between macro (47\%) and micro (53\%) approaches to social work. Their areas of interests predominantly focused on children and youth but also on the aging/elderly and drug or alcohol issues. Forty-one percent of the group had worked with people from backgrounds different than their own and only $12 \%$ of these social work educators indicated they were involved in professional international activities.

\section{Germany}

The results from the German social work educators demonstrated that half of the group had doctorates although none of them indicated their degrees were in social work. However, it is important to note that there are no social work doctoral degree programs in Germany.

With a long history in social work that covers the past century, the German sample had a wider range of 5 to 36 years of social work teaching experience with an average of 20 years $(S D=13.41)$. Including an individual from this group reporting a responsibility for 10 social work courses at the university, the average number of current classes taught was $5.25(S D=2.79)$. The Germans spent an average of $54 \%(S D=18.55)$ of their professional time teaching. Most of this sample was currently teaching practice (83\%), human behavior $(67 \%)$, or research $(67 \%)$ courses. The majority of the German social work educators had taught at either the bachelor's (83\%) or master's levels (67\%).

Only $17 \%$ of the Germans had a preference for the macro versus the micro approach to social work. Their areas of interest tended to focus on children and families, adults and alcohol, and the developmentally disabled. Over half of 
the group $(67 \%)$ reported experience with individuals from different cultural or language backgrounds and $33 \%$ of the German social work educators were participating in professional international activities.

\section{Russia}

Though not in the field of social work, the degree levels of the entire Russian group were unspecified in translation. Similar to the Chinese experience, social work education is a recent discipline and the Russian social work educators had only been teaching in social work for an average of 6 years $(S D=$ 3.38). With an average current course load of 6 classes $(S D=1.84)$, the Russians spent an average of $56 \%(S D=5.477)$ of their professional time teaching. The majority ( $83 \%)$ of this group was teaching field practicum, human behavior, and practice courses. All of the social work educators from Russia had taught at the specialist level and $33 \%$ had taught bachelor's level courses.

The Russian sample tended to prefer a macro (67\%) as opposed to a micro (33\%) approach to social work. Their professional areas of interest included children, elderly, drugs and alcohol, and HIV/AIDS. Half of the Russian group had worked with diverse cultural populations but none of them were involved in professional international activities.

\section{USA}

The American social work educators either have doctorates $(88 \%)$ or masters degrees (12\%). Differing from the social work educators in other countries, almost three-fourths of the group $(71 \%)$ has a degree in the social work discipline. With a long history of social work education programs in the 
United States, the Americans have taught social work from 4 to 30 years with an average of 15 years of teaching in social work $(S D=9.97)$.

Reporting an average current course load of 2.5 classes $(S D=1.91)$, the American social work educators contrasted from the other groups as they spent an average of $27 \%(S D=19.17)$ of their professional time on teaching. A closer inspection of the data revealed that more of the Americans' time is spent conducting research rather than teaching courses. The Americans were most likely to be teaching practice $(41 \%)$ or research $(41 \%)$ subjects. As the only group with experience teaching doctoral courses, all of the Americans had taught at the master's level and $33 \%$ at the bachelor's level.

Close to half of the American sample indicated a preference for a macro approach to social work (47\%) although this is the only group that created its own combined category of micro and macro perspectives in their responses (24\%). Topics of interest for the American social work educators included children and youth, aging, families, social policy, and research. Almost the entire group (94\%) had experience with individuals from cultural backgrounds different than their own but less than half $(41 \%)$ of the American social work educators have participated in professional international activities.

\section{Total Sample}

While half of the social work educators held a doctorate (39\%) as their highest degree, other degrees held included bachelor's $(9 \%)$, master's $(17 \%)$, or an unspecified diploma (20\%). Just over one-third (35\%) of the social work educators indicated their degree referred to the social work discipline. 
The social work educators had spent from 1.5 to 36 years teaching in social work with an average of 11 years $(S D=9.62)$. Alhough responsibility for two classes was most frequently reported, the social work educators indicated that they were teaching anywhere from 1 to 10 courses. Ranging from 0 to $90 \%$, they spent an average of $45 \%(S D=22.73)$ of their time teaching rather than on practice, research, or administrative duties.

Half of the group was currently teaching practice classes with close to one-third teaching field practicum, human behavior, policy, research, or theory courses. Other subjects included administration in social work, chemical dependency, civil affairs, community theory, ethnic customs, grant writing, health social work, human sexuality, mental health, nonprofit management, program evaluation, social gerontology, social work with people with disabilities, and technology. With social work education established at different times in the past century for each country, this sample has taught at many levels including bachelor's (37\%), master's (48\%), doctorate $(20 \%)$, specialist $(22 \%)$, and other levels (37\%).

Overall, the social work educators presented a close balance between their macro (46\%) and micro (41\%) preferences for approaches to social work. Work with children or youth was the most frequent area of interest, although aging/elderly, alcohol/drugs, families, community organizing, social policy, research, or a combination of any of these were also popular subjects.

While only $24 \%$ of the social work educators were involved in professional international activities, the majority of the group (65\%) had experience working 
with people from different cultural or language backgrounds. Professional international activities included exchange programs and academic partnerships with schools in other countries, participation in international conferences or development projects, and membership in international social work organizations.

Both local and global settings were in the examples of their work experiences with diverse populations. Clients, students, and colleagues were among the groups described as coming from these different cultural or ethnic backgrounds. Professional or volunteer work with refugees was the most frequently mentioned example of experiences with different populations. However, practice with individuals with hearing or visual impairments or developmental disabilities were also listed by a few of the social work educators.

Keeping in mind the challenges of comparing education systems across countries, many differences were found between countries in their teaching experiences. For example, social work educators from countries where the discipline has only been established for the past $15-20$ years (i.e. China and Russia) had an average of less than half the number of years of experience as those from countries with a long history in social work education.

In a different pairing of countries, the Chinese and American social work educators were teaching less than half as many classes as the Germans and Russians. In this respect, years of experience teaching in social work did not correlate with current course load for the social work educators. 
Along with inquiry into their professional background and experiences, the social work educators were asked about the resources they accessed to find information about globalization and which ones they would prefer to use to learn about globalization and social work (Table 9). Suggested globalization resources included academic exchanges, books, community meetings, conferences, the internet, newspapers, magazines, radio, scholarly journals, television, travel, videos, and workshops.

To learn about globalization, the internet (87\%), newspapers $(76 \%)$, television (76\%), and books (74\%) were the most frequently accessed by the social work educators (Table 10$)$. Videos (22\%), community meetings (24\%), and workshops (39\%) were the least accessed resources (Table 11). As shown in Table 12, the top preferred globalization resources were the internet $(70 \%)$ and journals $(65 \%)$. Table 13 shows the least preferred resources were videos $(22 \%)$, community meetings (24\%), and workshops (35\%).

The Chinese social work educators tended to use the internet $(88 \%)$ as their resource for information on globalization, although newspapers (77\%), books $(71 \%)$, and television ( $71 \%)$ were also frequently accessed. This group preferred to learn about globalization as it relates to the social work profession through the internet (82\%), journals (82\%), and television (77\%).

The top three currently used globalization resources of the German social work educators were the radio $(83 \%)$, internet $(83 \%)$, or books $(83 \%)$. The Germans selected academic exchange (67\%) or travel $(67 \%)$ as their preferred resources. 
Table 9

Frequencies and Percentages of Globalization Resources by Country

\begin{tabular}{|c|c|c|c|c|c|c|c|c|c|c|}
\hline \multirow{2}{*}{ Globalization Resources } & \multicolumn{2}{|c|}{$\begin{array}{c}\text { China } \\
(n=17)\end{array}$} & \multicolumn{2}{|c|}{$\begin{array}{c}\text { Germany } \\
(n=6)\end{array}$} & \multicolumn{2}{|c|}{$\begin{array}{c}\text { Russia } \\
(n=6)\end{array}$} & \multicolumn{2}{|c|}{$\begin{array}{c}\text { USA } \\
(n=17)\end{array}$} & \multicolumn{2}{|c|}{$\begin{array}{c}\text { Total } \\
(N=46)\end{array}$} \\
\hline & $n^{\mathrm{a}}$ & $\%^{b}$ & $n^{\mathbf{a}}$ & $\%^{b}$ & $n^{a}$ & $\%^{b}$ & $n^{\mathrm{a}}$ & $\%^{b}$ & $n^{\mathrm{a}}$ & $\%^{b}$ \\
\hline \multicolumn{11}{|l|}{ Accessed Resources } \\
\hline Academic Exchanges & 11 & 65 & 3 & 50 & 1 & 17 & 9 & 24 & 24 & 52 \\
\hline Books & 12 & 71 & 5 & 83 & 4 & 67 & 13 & 76 & 34 & 74 \\
\hline Community Meetings & 6 & 35 & 0 & 0 & 0 & 0 & 5 & 29 & 11 & 24 \\
\hline Conferences & 7 & 41 & 4 & 67 & 5 & 83 & 11 & 65 & 27 & 59 \\
\hline Internet & 15 & 88 & 5 & 83 & 6 & 100 & 14 & 82 & 40 & 87 \\
\hline Journals & 11 & 65 & 3 & 50 & 5 & 83 & 12 & 71 & 31 & 67 \\
\hline Magazines & 11 & 65 & 2 & 33 & 3 & 50 & 11 & 65 & 27 & 59 \\
\hline Newspapers & 13 & 76 & 4 & 67 & 4 & 67 & 14 & 82 & 35 & 76 \\
\hline Radio & 8 & 47 & 5 & 83 & 3 & 50 & 12 & 71 & 28 & 61 \\
\hline Television & 12 & 71 & 4 & 67 & 5 & 83 & 14 & 82 & 35 & 76 \\
\hline Travel & 4 & 24 & 4 & 67 & 2 & 33 & 11 & 65 & 21 & 46 \\
\hline Video & 2 & 12 & 0 & 0 & 1 & 17 & 7 & 41 & 10 & 22 \\
\hline Workshops & 5 & 29 & 3 & 50 & 3 & 50 & 7 & 41 & 18 & 39 \\
\hline \multicolumn{11}{|l|}{ Preferred Resources } \\
\hline Academic Exchanges & 10 & 10 & 4 & 67 & 1 & 17 & 10 & 59 & 25 & 54 \\
\hline Books & 11 & 65 & 1 & 17 & 1 & 17 & 11 & 65 & 24 & 52 \\
\hline Community Meetings & 5 & 29 & 1 & 17 & 2 & 33 & 3 & 18 & 11 & 24 \\
\hline Conferences & 6 & 35 & 3 & 50 & 5 & 83 & 9 & 53 & 23 & 50 \\
\hline Internet & 14 & 82 & 2 & 33 & 6 & 100 & 10 & 59 & 32 & 70 \\
\hline Journals & 14 & 82 & 2 & 33 & 6 & 100 & 8 & 47 & 30 & 65 \\
\hline Magazines & 11 & 65 & 2 & 33 & 4 & 67 & 5 & 29 & 22 & 48 \\
\hline Newspapers & 11 & 65 & 3 & 50 & 3 & 50 & 7 & 41 & 24 & 52 \\
\hline Radio & 8 & 47 & 1 & 17 & 2 & 33 & 7 & 41 & 18 & 39 \\
\hline Television & 13 & 76 & 1 & 17 & 4 & 67 & 7 & 41 & 25 & 54 \\
\hline Travel & 5 & 29 & 4 & 67 & 2 & 50 & 14 & 82 & 25 & 54 \\
\hline Video & 4 & 24 & 0 & 0 & 1 & 17 & 5 & 29 & 10 & 22 \\
\hline Workshops & 5 & 29 & 2 & 33 & 4 & 67 & 5 & 29 & 16 & 35 \\
\hline
\end{tabular}

Note. ${ }^{a}$ Numbers may not equal sample total due to missing data. ${ }^{b}$ Percentages may not equal $100 \%$ due to rounding. 
Table 10

Most Accessed Globalization Resources by Country

\begin{tabular}{|c|c|c|c|}
\hline \multirow{2}{*}{ Country } & \multicolumn{3}{|c|}{ Most Accessed Resources } \\
\hline & First & Second & Third \\
\hline China & Internet & Newspapers & Books/ Television ${ }^{a}$ \\
\hline Germany & Books/ Internet/ Radio ${ }^{a}$ & $\begin{array}{l}\text { Conferences/ } \\
\text { Newspapers/ Television/ } \\
\text { Travel }^{\mathrm{a}}\end{array}$ & $\begin{array}{l}\text { Academic Exchanges/ } \\
\text { Journals/ Workshops }\end{array}$ \\
\hline Russia & Internet & $\begin{array}{l}\text { Conferences/ Journals/ } \\
\text { Television }^{\text {a }}\end{array}$ & Books/ Newspapers ${ }^{a}$ \\
\hline USA & $\begin{array}{l}\text { Internet/ Newspapers/ } \\
\text { Television }^{\mathrm{a}}\end{array}$ & Books & Journals/ Radio ${ }^{a}$ \\
\hline Total & Internet & Newspapers/ Television ${ }^{a}$ & Books \\
\hline
\end{tabular}

Note. ${ }^{\mathrm{T}}$ Tied for position.

Table 11

Least Accessed Globalization Resources by Country

\begin{tabular}{|c|c|c|c|}
\hline \multirow{2}{*}{ Country } & \multicolumn{3}{|c|}{ Least Accessed Resources } \\
\hline & First & Second & Third \\
\hline China & Videos & Travel & Workshops \\
\hline Germany & $\begin{array}{l}\text { Community Meetings/ } \\
\text { Videos }^{a}\end{array}$ & Magazines & $\begin{array}{l}\text { Academic Exchanges/ } \\
\text { Journals/ Workshops }\end{array}$ \\
\hline Russia & Community Meetings & $\begin{array}{l}\text { Academic Exchanges/ } \\
\text { Videos }^{a}\end{array}$ & Travel \\
\hline USA & Community Meetings & Videos/Workshops ${ }^{\mathrm{a}}$ & Academic Exchanges \\
\hline Total & Videos & Community Meetings & Workshops \\
\hline
\end{tabular}

Note. ${ }^{\text {T}}$ Tied for position. 
Table 12

Most Preferred Globalization Resources by Country

\begin{tabular}{|c|c|c|c|}
\hline \multirow{2}{*}{ Country } & \multicolumn{3}{|c|}{ Most Preferred Resources } \\
\hline & First & Second & Third \\
\hline China & Internet/ Journals & Television & Books/ Magazines/ Newspapers ${ }^{a}$ \\
\hline Germany & $\begin{array}{l}\text { Academic Exchanges/ } \\
\text { Travel }^{a}\end{array}$ & $\begin{array}{l}\text { Conferences/ } \\
\text { Newspapers }^{a}\end{array}$ & $\begin{array}{l}\text { Internet/ Journals/ Magazines/ } \\
\text { Workshops }^{a}\end{array}$ \\
\hline Russia & Internet/ Journals ${ }^{a}$ & Conferences & $\begin{array}{l}\text { Magazines/Television/ } \\
\text { Workshops }^{\mathrm{a}}\end{array}$ \\
\hline USA & Travel & Books & Academic Exchanges/ Internet ${ }^{a}$ \\
\hline Total & Internet & Journals & $\begin{array}{l}\text { Academic Exchanges/ } \\
\text { Television/ Travel }\end{array}$ \\
\hline
\end{tabular}

Note. ${ }^{\mathrm{a}}$ Tied for position.

Table 13

Least Preferred Globalization Resources by Country

\begin{tabular}{|c|c|c|c|}
\hline \multirow{2}{*}{ Country } & \multicolumn{3}{|c|}{ Least Preferred Resources } \\
\hline & First & Second & Third \\
\hline China & Videos & $\begin{array}{l}\text { Community Meetings/ } \\
\text { Travel/ Workshops }{ }^{a}\end{array}$ & Conferences \\
\hline Germany & Videos & $\begin{array}{l}\text { Books/ Community } \\
\text { Meetings/ Radio/ } \\
\text { Television }^{\text {a }}\end{array}$ & $\begin{array}{l}\text { Internet/ Journals/ } \\
\text { Magazines/ Workshops }\end{array}$ \\
\hline Russia & $\begin{array}{l}\text { Academic Exchanges/ } \\
\text { Books/ Videos }^{\text {a }}\end{array}$ & $\begin{array}{l}\text { Community Meetings/ } \\
\text { Radio/ Travel }^{\mathrm{a}}\end{array}$ & Newspapers \\
\hline USA & Community Meetings & $\begin{array}{l}\text { Magazines/Videos/ } \\
\text { Workshops }^{\text {a }}\end{array}$ & $\begin{array}{l}\text { Newspapers/Radio/ } \\
\text { Television }^{\mathrm{a}}\end{array}$ \\
\hline Total & Videos & Community Meetings & Workshops \\
\hline
\end{tabular}

Note. ${ }^{\mathrm{a}}$ Tied for position. 
All of the Russian social work educators reported that they used the internet for information on globalization. The majority of the group (83\%) also used television, journals, and conferences. The internet and scholarly journals were the preferred resources for learning about globalization and social work by the entire group of Russians.

The Americans predominantly ( $82 \%$ ) learned about globalization through the internet, television, and newspapers. In contrast to the Russians, this group of social work educators indicated a preference for the resources of travel $(82 \%)$ and books (65\%) as opposed to the internet (59\%) and scholarly journals (48\%) for learning about globalization and social work.

Overall, the review of the resources used to learn about globalization sheds light on which resources are accessed by and available to the social work educators. These results could be useful in developing materials for mediums utilized and preferred by social work educators.

As with the demographics, the analysis of the professional characteristics and globalization resources provides a backdrop to the commonalities and differences between the social work educators from the participating schools in China, Germany, Russia and the USA. It is important to note that the results are not generalizable outside of these schools and are only indicators of possible trends. With consideration of the differences between the countries, the next section of this chapter explores the perspectives of the social work educators on globalization and investigates its impact on social work education. 


\section{Definitions and Dimensions of Globalization}

As discussed in Chapter I, globalization is a concept with myriad definitions to describe its processes and impact around the world. To gain an understanding of their perspectives on globalization, the social work educators were asked to provide their own definitions of the phenomenon. Descriptions of many of the dimensions of globalization commonly discussed in the literature were also requested. These aspects of globalization focused on culture, economics, the environment, politics, society, and technology. This section provides an overview of the general themes in the social work educators' definitions and descriptions of globalization. Qualitative responses and quotations, as translated from the different countries, are included in the discussion.

\section{Definitions of Globalization}

The definitions collected in this study primarily described globalization as a process with many dimensions or indicators. Illustrations of its intensification of social reality were provided by the social work educators along with references to its universalizing effects on world-wide social systems. Overall, the range of definitions provided by the social work educators revealed that there are many different perspectives on the phenomenon within and between countries.

Similar to the definition provided as an example on the survey, globalization was frequently defined by many of the social work educators as process toward mutual and reciprocal interdependence of world systems: "Globalization refers to the process in which all countries interact and influence 
each other in economy, politics and culture and so on" (China); "Globalization is the process, where the world - the countries, nations- grows together and get more and more dependent on each other" (Germany); and "Globalization is the increased interaction and interdependency of people around the world" (USA). The concept of globalization as a global village was often used to summarize this interactive process.

Convergent philosophies were found among the definitions of the social work educators and were primarily expressed by Russian or Chinese social work educators. As defined by Russian social work educators, globalization is "the process of transformation of the world into a single system" or the "diffusion of universal standards of life arrangements among different countries". This homogenization of social systems was addressed by a Chinese social work educator as "the way of doing is [the] same in all of [the] world because of the same humanity." The Chinese were the only individuals providing definitions that referred to global interdependency as both intensifying and compressing reality.

There were many dimensions of globalization highlighted in the social work educators' definitions. A German social work educator defined globalization as "divisions of labor between individuals and groups in [an] international perspective." An American perspective focused on the "economic and cultural flattening of barriers to commerce and cultural exchange." A Russian definition described globalization as the interdependence of social, political, and ecological systems across the globe. A Chinese social work educator elaborated, "Globalization is a diversified concept with economy as a core, including [the] 
interconnection of different people in different countries in political, cultural, technological and science, military, defense, ideological, lifestyle, and values."

Globalization was often defined in terms of the economic dimensions of its processes. "Globalization mainly means economic globalization," stated one Chinese social work educator. Another Chinese proposed that globalization is primarily economics as reflected by trade breaking through national boundaries and the flow of capital around the world. In this social work educator's perspective, countries and international organizations were seen as using technology to maximize profits and create conspiracies that have the potential to destroy multinational agreements.

The processes of globalization were not always viewed by the social work educators as having equal results. An American social work educator suggested that globalization is "a process on the rise in the world today characterized by increasing communication and interaction among peoples and nations worldwide which favors the powerful." Another American offered, "Globalization is the growing interdependence of economic and financial systems around the world and the consequential impact on other social and political systems."

Overall, the majority of the definitions provided by the social work educators were akin to the concept and components discussed in Chapter t. Globalization was frequently defined as a process toward increasing interdependence of world systems. Many of the social work educators elaborated on their definitions with specific dimensions or examples. However, most of the responses did not reflect a particular perspective on globalization other than to 
indicate that it was (a) a process in motion, (b) increasing in action, and (c) involving all people. The awareness of the global-local link was implied in the concept of global interdependence but was not explicitly stated. As a result, these definitions of the social work educators do not necessarily challenge or change the initial definition proposed in this dissertation.

\section{Dimensions of Globalization}

Similar to the diversity in definitions proposed by the social work educators, there was a range of descriptions of the different dimensions of globalization. These examples of the various aspects of globalization provide a richer account of the phenomenon and enhance understanding of the many interpretations of globalization.

\section{Cultural}

The cultural impacts of globalization were most frequently described by the social work educators as the transfer of habits; customs, and preferences from one country to another. The exchange between cultures could be mutual, borrowed, or forced and it was described as an influence on food, music, arts, education, entertainment, lifestyles, business, language, religion, and even breastfeeding practices. Though the German examples focused on globalizing trends in music and movies, cultural globalization in the American descriptions was experienced through exposure to other backgrounds and behaviors via media, travel, or contact with immigrants.

From the Russian comments on cultural globalization, the sharing of cultural assets and values was seen as creating a standardization of culture 
through the global promotion of consumerism and the international commercialization of culture products. As described by a Chinese social work educator, "On the one hand, it appears as a global McDonaldisation or globalization of American instant food culture; on the other hand, many other minor cultures [are] diffused into commercial tide, and provide some new elements to the new global culture."

\section{Economic}

The growing interdependence of global finances and international markets were the key features of economic globalization. As described by a Chinese social work educator, it is an "internationalization of capital investment; liberalization of trade and communication; the formation of world-system:" A German social work educator depicted economic globalization as "increasing entanglement of the world trade system; global networking of the financial capital." An American described this aspect as "the increased interdependence of all humankind based on the free flow of capital" and a Russian educator offered that it is the "growth in international corporations, companies, and variety in tax systems and collection."

The increase in cashless payment options, the growth in systems of production that involve multiple countries, the movement of jobs, and differentiation in forms of property were also provided by the social worker educators as examples of economic globalization occurring world-wide. However, the benefits of economic globalization were not seen as equal among all countries. An American described, "World cities are linked by the flow of 
capital; people/cities/countries not connected to these command and control centers are increasingly marginalized." A Chinese social work educator commented, "It is a mutually dependent process in economics but [a] developing country seems to be more exploited and in [a] disadvantaged position."

\section{Environmental}

Two themes found in the social work educators' descriptions of the environment and globalization were the borderless consequences of environmental problems and the need for transnational solutions. "Their smog is our smog" stated an American social work educator while one of the Germans exclaimed, "The nuclear cloud does not stop at state borders!" Several Russian participants described ecological security as a global phenomenon needing international cooperation. As suggested by a Chinese social work educator, "... avoiding a worse environment is the same mission for all countries in the world."

Ecological security, global warming, pollution and exploitation of natural resources were all common elements of the descriptions of the environmental aspects of globalization. Other examples from the social work educators of environmental causes and concerns included architecture and the development of the environment, the transfer of garbage from developed countries to developing countries, the destruction of the environment for capital profit, tsunamis and climate changes, "dirty" industrial revolutions versus "green" movements, Chernobyl, outer space, and oil consumption that leads to war.

\section{Political}


The interdependence of local, national, regional, and international political systems has led to the development of transnational policies and supra national organizations as described by the social work educators in the political characterization of globalization. "The administration of the small state is not only his own affair," stated a Chinese social work educator while another suggested "some countries become dependent ones." As explained by a German social work educator, "All politics [are] local (the life, wealth or poverty depend on local decisions) but at the same time all politics [are] dependent on global developments."

An increased focus on international human rights and global civil society were depicted by several Russian social work educators as the political changes resulting from globalization. An example provided by an American of the new ways in which people are organizing for social justice included Rwandan villages seeking reconciliation from genocide through court processes. A strengthening of the United Nations and the implementation of the Universal Declaration of Human Rights are parts of the "international cooperation increasingly necessary to promote/ensure world peace" suggested by other American social work educators.

Capitalistic ventures, foreign oil dependencies, immigration and conflicts between political and religious values can also impact governmental decisionmaking. "Decisions made by leaders of one country can affect life in another," stated an American as a Chinese social work educator offered, "The change in leaders and policies in one country will influence the economic and foreign 
policies of other countries to that country." Political stability and interdependence are described by one American as directly related to interdependence or "the ability of countries to form political alliances" with each other.

\section{Social}

The increasing interconnectedness of societies that occurs as people move around the world is a critical component of social globalization found in the descriptions by the social work educators. Lifestyle, language, and cuisine are all impacted by the interaction of cultures and diversification of communities. As described by American social work educators, an enhanced global awareness comes from working with people from other cultures, intermarriages, and travel. Russians expressed support for the growth of a world civil society as a result of globalization. However, a Chinese social work educator asserted, "Social interaction becomes international; local community is becoming destroyed; social networks become important substitutes for socialization; the whole solidarity of society declines."

The spread of disease as a result of migration and the movement of jobs from country to country as a cause of migration were also social concerns resulting from globalization. A German social work educator commented further: "World-wide migration streams remain for hardly any country without consequences. Social and economic problems in a country lead to drifts in other countries and to an immigration into the social systems which can then collapse."

Technological 
Exchanges in technology between countries were the most frequent descriptions of this aspect of globalization. Energy, computer, communications, and transportation technologies were all seen as driving multinational industry and advancing global interdependency. "Globalization is a kind of engine for technological development," stated a German social work educator. The internet was listed as the prime example of technology resulting from the forces of globalization and was also seen as accelerating its processes. One American social work educator provided an example of the ease of international contact through online software, "In terms of technology we are very global already. My children are having Facebook connections with all their cousins in South Africa."

The pace and breadth of the technological advances in an age of globalization presented concerns for some of the social work educators. As described by a Chinese social work educator, "Science and technology are globalizing, but in a word, they only belong to a few men and a few countries." Another view is provided by an American: "Developments in this domain are reshaping the world faster than we can keep up. Sophistication and advancements shrink the world and the way we do business."

\section{Other Dimensions}

To encourage the social work educators to share their ideas on other ways in which globalization is experienced around the world, there were opportunities on the survey to suggest and describe other aspects of the phenomenon that were not previously addressed in the aforementioned categories. Other aspects of globalization provided by the educators were 
agriculture, education, health, languages, quality of life, religion, tourism, and war. Globalization was also described in this section of the survey through analogies by Chinese social work educators as "a two-edged sword" or "like a coin has two sides" with both positive and negative consequences. One social work educator from Germany concluded, "In my opinion, globalization is unifying and equalizing the world, in some ways for the good, in some for the bad (Vive la difference!)."

This overview of the social work educators' definitions and descriptions of the dimensions of globalization highlights the differences in individual perspectives and the commonalities across countries in the interpretations of the phenomenon. As an initial inquiry into social work educators' interpretations of globalization, further research is needed to analyze cultural nuances in the responses and to develop a definition inclusive of cultural variations.

\section{Perspectives on Globalization}

As the first study on globalization and social work education, efforts were made to explore the topic through a variety of perspectives including definitions of globalization and attitudes toward its impact on the profession. This section investigates the attitudes of social work educators toward globalization and responses to its influence on teaching and the future of social work education.

\section{Attitudes toward Globalization}

Levels of agreement on ten statements concerned with globalization and social work education were among the data collected and analyzed to assess the attitudes of the social work educators toward globalization and the profession 
(Table 14). These statements provided to the study participants addressed

globalization as an issue of concern for social work students, educators,

practitioners, the profession, and social work schools in local and global contexts.

Table 14

Mean Attitudes toward Globalization and Social Work Education

\begin{tabular}{|c|c|c|c|c|c|}
\hline Attitude Statements & $N$ & Mean & $S D$ & Minimum & Maximum \\
\hline $\begin{array}{l}\text { Social work students need to } \\
\text { understand how global issues affect } \\
\text { local communities. }\end{array}$ & 46 & 4.20 & .75 & 2 & 5 \\
\hline $\begin{array}{l}\text { Social workers need to learn about } \\
\text { globalization to work with diverse } \\
\text { groups. }\end{array}$ & 45 & 4.20 & .79 & 2 & 5 \\
\hline $\begin{array}{l}\text { Future social workers need to have } \\
\text { a global perspective of their } \\
\text { profession. }\end{array}$ & 46 & 4.13 & .78 & 2 & 5 \\
\hline $\begin{array}{l}\text { Schools of social work should } \\
\text { include international content across } \\
\text { their curriculum. }\end{array}$ & 45 & 4.13 & .92 & 1 & 5 \\
\hline $\begin{array}{l}\text { Social workers should be concerned } \\
\text { about globalization around the } \\
\text { world. }\end{array}$ & 46 & 4.11 & 1.02 & 1 & 5 \\
\hline $\begin{array}{l}\text { Social work educators must be } \\
\text { informed about globalization to be } \\
\text { relevant to students. }\end{array}$ & 46 & 3.91 & 1.08 & 1 & 5 \\
\hline $\begin{array}{l}\text { Globalization is a critical concern } \\
\text { for social work education. }\end{array}$ & 46 & 3.83 & .92 & 1 & 5 \\
\hline $\begin{array}{l}\text { Today's social work students } \\
\text { should be fluent in more than one } \\
\text { language. }\end{array}$ & 46 & 3.61 & .88 & 2 & 5 \\
\hline $\begin{array}{l}\text { The subject of globalization should } \\
\text { be a required topic in all social work } \\
\text { classes. }\end{array}$ & 46 & 3.02 & 1.13 & 1 & 5 \\
\hline $\begin{array}{l}\text { Global problems are only important } \\
\text { for social work graduates in other } \\
\text { countries. }\end{array}$ & 46 & 1.87 & 1.13 & 1 & 5 \\
\hline
\end{tabular}


A reverse statement on global problems as only important to social workers in other countries was also provided to ensure a contrasting perspective was included.

Responses were collected on levels of agreement with the statements from 1 as Strongly Disagree to 5 as Strongly Agree with 3 as a neutral category. A review of the means of each of the statements shows that the total sample for this study were generally supportive of globalization as a topic of concern for social work education in their own countries and around the world. While each statement offered a range of agree to disagree responses from the total group, there was a tendency to be neutral or ambivalent about globalization as a required topic for discussion in all social work classes.

As the only statement showing a range of difference between the responses of the social work educators by country, the data reveals that all of the Germans and Americans disagreed with the reverse attitude statement "Global problems are only important for social work graduates in other countries". However, social work educators from China and Russia had a variety of responses including individuals agreeing with the statement (Table 15).

In an overall assessment of the attitude statements, the social work educators tended to agree that globalization is a topic of concern for social work students as they learn how to work in local communities impacted by global issues and for social work educators as they prepare these students with a global perspective of the profession. While there was some disagreement about the 


\section{Table 15}

Percentage of Levels of Agreement by Country for "Global problems are only important for social work graduates in other countries"

\begin{tabular}{lcccccccccc}
\hline $\begin{array}{l}\text { Levels of } \\
\text { Agreement }\end{array}$ & $\begin{array}{c}\text { China } \\
(n=17)\end{array}$ & $\begin{array}{c}\text { Germany } \\
(n=6)\end{array}$ & $\begin{array}{c}\text { Russia } \\
(n=6)\end{array}$ & $\begin{array}{c}\text { USA } \\
(n=17)\end{array}$ & $\begin{array}{c}\text { Total } \\
(N=46)\end{array}$ \\
\cline { 2 - 10 } & $n^{\mathrm{a}}$ & $\%^{\mathrm{b}}$ & $n^{\mathrm{a}}$ & $\%$ & $n^{\mathrm{a}}$ & $\%^{\mathrm{b}}$ & $n^{\mathrm{a}}$ & $\%^{\mathrm{b}}$ & $n^{\mathrm{a}}$ & $\%^{\mathrm{b}}$ \\
\hline $\begin{array}{l}\text { Strongly } \\
\text { Disagree }\end{array}$ & 5 & 29 & 6 & 100 & 0 & 0 & 13 & 76 & 24 & 52 \\
\hline Disagree & 5 & 29 & 0 & 0 & 1 & 17 & 4 & 24 & 10 & 22 \\
\hline Neither & 5 & 29 & 0 & 0 & 3 & 50 & 0 & 0 & 8 & 17 \\
\hline Agree & 1 & 6 & 0 & 0 & 1 & 17 & 0 & 0 & 2 & 4 \\
\hline $\begin{array}{l}\text { Strongly } \\
\text { Agree }\end{array}$ & 1 & 6 & 0 & 0 & 1 & 17 & 0 & 0 & 2 & 4 \\
\hline
\end{tabular}

Note. ${ }^{a}$ Numbers may not equal sample total due to missing data. ${ }^{b}$ Percentages may not equal $100 \%$ due to rounding.

importance of global problems for all nations, the general attitude was still supportive of the relevance of globalization for social work education.

\section{Responses to Globalization}

To develop an understanding of reactions to globalization in different countries, the social work educators were asked (a) if their schools had a response to this phenomenon and (b) if topics on globalization were included in their course curricula. The social work educators also provided examples to support their answers. Additional information was collected on the social work 
educators' perspectives of the percentage of classes that include content on globalization and the amount of student interest in the subject of globalization.

\section{Program Responses}

The majority $(76 \%)$ of the social work educators reported that the social work programs at their schools were responding to globalization (Table 16). However, only half of the Chinese social work educators, as opposed to all of the Germans and Russians, felt that their social work programs were reacting in some way to globalization. Eighty-two percent of the Americans also indicated that their school was responding to the phenomenon.

Table 16

Frequencies and Percentages of Yes/No Responses to "Is the social work program at your school responding to globalization?" by Country

\begin{tabular}{|c|c|c|c|c|c|c|c|c|c|c|}
\hline \multirow{2}{*}{$\begin{array}{l}\text { Globalization } \\
\text { Response }\end{array}$} & \multicolumn{2}{|c|}{$\begin{array}{c}\text { China } \\
(n=17)\end{array}$} & \multicolumn{2}{|c|}{$\begin{array}{c}\text { Germany } \\
(n=6)\end{array}$} & \multicolumn{2}{|c|}{$\begin{array}{c}\text { Russia } \\
(n=6)\end{array}$} & \multicolumn{2}{|c|}{$\begin{array}{c}\text { USA } \\
(n=17)\end{array}$} & \multicolumn{2}{|c|}{$\begin{array}{c}\text { Total } \\
(N=46)\end{array}$} \\
\hline & $n^{\mathrm{a}}$ & $\%^{b}$ & $n^{\mathbf{a}}$ & $\%^{b}$ & $n^{\mathrm{a}}$ & $\%^{b}$ & $n^{a}$ & $\%^{b}$ & $n^{\mathrm{a}}$ & $\%^{b}$ \\
\hline Yes & 9 & 53 & 6 & 100 & 6 & 100 & 14 & 82 & 35 & 76 \\
\hline No & 8 & 47 & 0 & 0 & 0 & 0 & 3 & 18 & 11 & 24 \\
\hline
\end{tabular}

Note. ${ }^{a}$ Numbers may not equal sample total due to missing data. ${ }^{\mathrm{b}}$ Percentages may not equal $100 \%$ due to rounding.

American examples of program responses included the facilitation of student and faculty exchanges, the development of international research partnerships, the recruitment of international students, the infusion of international content in curriculum, and involvement with local refugee and immigrant communities. The Chinese responses primarily focused on 
cooperation and exchange with foreign colleges. Russian social work educators described how their program provided specialized courses on globalization. Lectures on the internationalization of social work and study models in other countries were also listed by the Germans.

\section{Topics on Globalization}

Regarding material and discussion on globalization in the classroom, the majority $(78 \%)$ of the social work educators indicated that this topic was found in courses at their schools or in their classrooms (Table 17). Examples of international social work practice, policy, and global/local social issues as topics on globalization were provided by social work educators from each country.

\section{Table 17}

Frequencies and Percentages of Yes/No Responses to "Are globalization topics included in courses at your school or in your classes?" by Country

\begin{tabular}{|c|c|c|c|c|c|c|c|c|c|c|}
\hline \multirow{2}{*}{$\begin{array}{c}\text { Globalization } \\
\text { Topics }\end{array}$} & \multicolumn{2}{|c|}{$\begin{array}{c}\text { China } \\
(n=17)\end{array}$} & \multicolumn{2}{|c|}{$\begin{array}{c}\text { Germany } \\
(n=6)\end{array}$} & \multicolumn{2}{|c|}{$\begin{array}{c}\text { Russia } \\
(n=6)\end{array}$} & \multicolumn{2}{|c|}{$\begin{array}{c}\text { USA } \\
(n=17)\end{array}$} & \multicolumn{2}{|c|}{$\begin{array}{c}\text { Total } \\
(N=46)\end{array}$} \\
\hline & $n^{\mathrm{a}}$ & $\%^{b}$ & $n^{\mathrm{a}}$ & $\%^{b}$ & $n^{\mathrm{a}}$ & $\%^{b}$ & $n^{\mathrm{a}}$ & $\%^{b}$ & $n^{\mathrm{a}}$ & $\%^{b}$ \\
\hline Yes & 11 & 65 & 5 & 83 & 6 & 100 & 14 & 82 & 36 & 78 \\
\hline No & 5 & 29 & 1 & 17 & 0 & 0 & 3 & 18 & 9 & 20 \\
\hline
\end{tabular}

Note. ${ }^{a}$ Numbers may not equal sample total due to missing data. ${ }^{b}$ Percentages may not equal $100 \%$ due to rounding.

To gather further information about the amount of material on globalization in school curricula, social work educators provided estimates of the social work courses with related topics and student interest in the subject. While Table 18 shows the mean percentage of required courses with globalization content by 
country, Table 19 illustrates the elective courses, and Table 20 focuses on the social work educators' courses. Table 21 highlights the mean percentage of student interest in globalization.

Table 18

Mean Percentage of Required Social Work Courses with Globalization Topics by Country

\begin{tabular}{lrrrrr}
\hline \multicolumn{1}{c}{ Country } & \multicolumn{1}{c}{$\boldsymbol{n}$} & \multicolumn{1}{c}{ Mean } & \multicolumn{1}{c}{$\boldsymbol{S} \boldsymbol{D}$} & Minimum & Maximum \\
\hline China & 15 & 13.93 & 14.02 & 0 & 60 \\
Germany & 2 & 12.50 & 3.54 & 10 & 15 \\
Russia $^{\mathrm{a}}$ & - & - & - & - & - \\
USA & 12 & 10.58 & 13.77 & 0 & 50 \\
Total & 28 & 12.45 & 13.26 & 0 & 60 \\
\hline
\end{tabular}

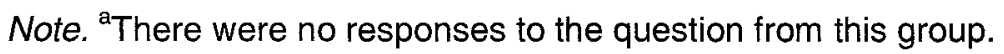

Table 19

Mean Percentage of Elective Social Work Courses with Globalization Topics by Country

\begin{tabular}{lrrrrr}
\hline Country & $\boldsymbol{n}$ & Mean & SD & Minimum & Maximum \\
\hline China & 13 & 12.23 & 12.98 & 0 & 50 \\
Germany & 2 & 17.50 & 10.61 & 10 & 25 \\
Russia $^{\mathrm{a}}$ & - & - & - & - & - \\
USA & 14 & 9.14 & 7.65 & 1 & 25 \\
Total & 29 & 11.10 & 10.43 & 0 & 50 \\
\hline
\end{tabular}

Note ${ }^{\text {a }}$ There were no responses to the question from this group. 
Table 20

Mean Percentage of Social Work Educators' Courses with Globalization

Topics by Country

\begin{tabular}{lrrrrr}
\hline Country & $\boldsymbol{n}$ & Mean & SD & Minimum & Maximum \\
\hline China & 16 & 11.13 & 7.54 & 0 & 30 \\
Germany & 5 & 16.00 & 12.94 & 0 & 30 \\
Russia & 3 & 50.00 & 0.00 & 50 & 50 \\
USA & 15 & 38.60 & 37.34 & 0 & 100 \\
Total & 39 & 25.31 & 27.71 & 0 & 100 \\
\hline
\end{tabular}

Table 21

Mean Percentage of Student Interest in Globalization by Country

\begin{tabular}{lrrrrr}
\hline Country & $\boldsymbol{n}$ & Mean & \multicolumn{1}{c}{$\boldsymbol{S D}$} & Minimum & Maximum \\
\hline China & 14 & 43.57 & 30.97 & 5 & 90 \\
Germany & 5 & 50.00 & 41.83 & 10 & 100 \\
Russia $^{\mathrm{a}}$ & - & - & - & - & - \\
USA & 15 & 22.20 & 23.58 & 1 & 80 \\
Total & 34 & 35.09 & 31.07 & 0 & 100 \\
\hline
\end{tabular}

Note ${ }^{\text {a }}$ There were no responses to the question from this group.

The mean percentage of required courses with globalization topics was $13 \%(S D=13.26)$ and elective courses was $11 \%(S D=10.43)$. In contrast, the average percent of the social work educators' classes including content on globalization was $25 \%(S D=27.71)$. For these results, the Russian social work 
educators only provided estimates on their own courses and stated they could not estimate the percentage of required or elective courses with content on globalization.

Regarding the social work educators' courses with globalization topics, there was a noticeable difference between groups in the mean percentages of the courses they teach. On the average, the Chinese (11\%) and the German social work educators (16\%) reported half as many of their courses included globalization topics as opposed to the Russians (50\%) and Americans (39\%). With a range of responses between the countries, the results also tended to demonstrate a lack of agreement on the perceived amount of required or elective courses including the topic of globalization within countries.

On the average, the social work educators indicated that $35 \%(S D=$ $31.07)$ of their students were interested in globalization. However, the Chinese (44\%) and Germans (50\%) reported twice as many of their students were keen on the subject as opposed to the American social work educators (22\%). None of the Russians responded to the query.

In this study, there was a noticeable difference between a country's average estimated amounts of student interest in globalization and courses with globalization topics. For example, the Chinese and Germans reported a higher level of student interest in globalization but indicated they included related material in fewer of their courses. The Americans felt there was less interest among their students although they included content on globalization in more of 
their courses. These results need further investigation to fully assess the implications of the findings.

\section{Impact of Globalization}

Along with their perspectives on the responses of programs and students to topic of globalization, the social work educators were asked about the impact of the processes of globalization as (a) a challenge to teaching about the subject, (b) an effect on teaching methods, and (c) an influence on the future of social work education. This section is a review of feedback on their experiences with globalization and its perceived relevance for the profession.

\section{Challenges to Teaching about Globalization}

Three-fourths of the social work educators reported there were challenges to teaching about globalization and social work (Table 22). In their responses to the question, social work educators from each country described difficulties in knowing what information about globalization is most pertinent and most accurate. An American social work educator warned of the risks of oversimplifying discussions on globalization and leaving out critical content.

The ambiguous nature of globalization and a lack of definitional parameters were obstacles to providing instruction on the subject. A Chinese social work educator stated that globalization was theoretical and therefore difficult to explain to students. A German suggested that its negative connotations and contradictions overshadow the positive learning opportunities that result from globalization. Social work educators from each country reported a 
Table 22

Frequencies and Percentages of Yes/No Responses to "Are there challenges to teaching about globalization?" by Country

\begin{tabular}{lcccccccccc}
\hline $\begin{array}{c}\text { Globalization } \\
\text { Challenges }\end{array}$ & $\begin{array}{c}\text { China } \\
(n=17)\end{array}$ & \multicolumn{2}{c}{$\begin{array}{c}\text { Germany } \\
(n=6)\end{array}$} & $\begin{array}{l}\text { Russia } \\
(n=6)\end{array}$ & \multicolumn{2}{c}{$\begin{array}{c}\text { USA } \\
(n=17)\end{array}$} & \multicolumn{2}{c}{$\begin{array}{c}\text { Total } \\
(\boldsymbol{N}=46)\end{array}$} \\
\cline { 2 - 10 } & $n^{\mathrm{a}}$ & $\%^{\mathrm{b}}$ & $\boldsymbol{n}^{\mathrm{a}}$ & $\%^{\mathrm{b}}$ & $\boldsymbol{n}^{\mathrm{a}}$ & $\%^{\mathrm{b}}$ & $\boldsymbol{n}^{\mathrm{a}}$ & $\%^{\mathrm{b}}$ & $\boldsymbol{n}^{\mathrm{a}}$ & $\%^{\mathrm{b}}$ \\
\hline Yes & 12 & 71 & 5 & 83 & 3 & 50 & 15 & 88 & 35 & 76 \\
No & 5 & 29 & 1 & 17 & 1 & 17 & 1 & 6 & 8 & 17 \\
\hline
\end{tabular}

Note. ${ }^{a}$ Numbers may not equal sample total due to missing data. ${ }^{b}$ Percentages may not equal $100 \%$ due to rounding.

need for more knowledge and training on the topic of globalization to be able to effectively educate students about its impact on social work practice.

The emphasis on national content, along with limited interest of students and faculty in the connection between global and local issues, was proposed as challenges to teaching about globalization by both American and Chinese social work educators. Regarding teaching about international social work as an element of instructing students about globalization, social work educators from the different groups suggested the models of other countries were unfamiliar and difficult to understand without direct experience. A lack of unified structure for the transfer of models was part of the problem, as identified by a Russian social work educator. The appropriateness of international material was a complication for social work educators in China as they questioned whether overseas knowledge would present cultural conflicts and fit within their programs.

\section{Effects on Teaching Methods}


The responses to whether globalization has an effect on teaching methods were split fairly evenly for the total sample of social work educators (Table 23). Observation of the data showed the Chinese and Russians were similarly divided in their responses. While slightly more of the Americans (59\%) tended to feel that their teaching methods were impacted by globalization, the majority of the German social work educators (67\%) contrasted with the other groups as they reported that they did not experience its effects on their teaching.

Table 23

Frequencies and Percentages of Yes/No Responses to "Does globalization have an effect on your teaching methods?" by Country

\begin{tabular}{|c|c|c|c|c|c|c|c|c|c|c|}
\hline \multirow{2}{*}{$\begin{array}{c}\text { Globalization } \\
\text { Effect }\end{array}$} & \multicolumn{2}{|c|}{$\begin{array}{c}\text { China } \\
(n=17)\end{array}$} & \multicolumn{2}{|c|}{$\begin{array}{c}\text { Germany } \\
(n=6)\end{array}$} & \multicolumn{2}{|c|}{$\begin{array}{l}\text { Russia } \\
(n=6)\end{array}$} & \multicolumn{2}{|c|}{$\begin{array}{c}\text { USA } \\
(n=17)\end{array}$} & \multicolumn{2}{|c|}{$\begin{array}{c}\text { Total } \\
(N=46)\end{array}$} \\
\hline & $n^{\mathrm{a}}$ & $\%^{b}$ & $n^{\mathrm{a}}$ & $\%^{b}$ & $n^{\mathbf{a}}$ & $\%^{b}$ & $n^{\mathbf{a}}$ & $\%^{\mathrm{b}}$ & $n^{\mathrm{a}}$ & $\%^{b}$ \\
\hline Yes & 9 & 53 & 1 & 17 & 3 & 50 & 10 & 59 & 23 & 50 \\
\hline No & 7 & 41 & 4 & 67 & 3 & 50 & 7 & 41 & 21 & 46 \\
\hline
\end{tabular}

Note. ${ }^{\mathrm{a}}$ Numbers may not equal sample total due to missing data. ${ }^{\mathrm{b}}$ Percentages may not equal $100 \%$ due to rounding.

One of the influences of globalization on teaching methods reported in all countries was the integration of international material into class discussions. A Russian social work educator cited the introduction of distance learning technologies. Americans acknowledged that globalization enhanced their worldview in teaching and expanded their teaching responsibilities to include a broader range of learners coming from increasingly diverse backgrounds. $A$ 
Chinese social work educator also felt globalization created the need to reframe the educator's role into teacher as partner with students in the learning process

\section{Influence on Future of Social Work Education}

The inquiry into the influence of globalization on social work education produced a majority response (85\%) of the total sample and in each country (China, 77\%; Germany, 83\%; Russia, 67\%, USA, 100\%) that it will impact the future of the discipline (Table 24). For all countries, the potential effects of globalization on social work education included the need for more international and intercultural knowledge. A German social work educator stated that there will be an increase in foreign language competencies. A Russian suggested that more practical training abroad opportunities for students will be created. An American saw future technological advances as improving access to other cultures and providing enhanced learning experiences for students.

Table 24

Frequencies and Percentages of Yes/No Responses to "Will globalization influence the future of social work education?" by Country

\begin{tabular}{lcccccccccc}
\hline $\begin{array}{l}\text { Globalization } \\
\text { Influence }\end{array}$ & $\begin{array}{c}\text { China } \\
(n=17)\end{array}$ & $\begin{array}{c}\text { Germany } \\
(n=6)\end{array}$ & $\begin{array}{c}\text { Russia } \\
(n=6)\end{array}$ & $\begin{array}{c}\text { USA } \\
(n=17)\end{array}$ & \multicolumn{2}{c}{$\begin{array}{c}\text { Total } \\
(N=46)\end{array}$} \\
\cline { 2 - 10 } & $n^{\mathrm{a}}$ & $\%^{\mathrm{b}}$ & $n^{\mathrm{a}}$ & $\%^{\mathrm{b}}$ & $n^{\mathrm{a}}$ & $\%^{\mathrm{b}}$ & $n^{\mathrm{a}}$ & $\%^{\mathrm{b}}$ & $n^{\mathrm{a}}$ & $\%^{\mathrm{b}}$ \\
\hline Yes & 13 & 77 & 5 & 83 & 4 & 67 & 17 & 100 & 39 & 85 \\
No & 3 & 18 & 1 & 17 & 2 & 33 & 0 & 0 & 6 & 16 \\
\hline
\end{tabular}

Note. ${ }^{a}$ Numbers may not equal sample total due to missing data. ${ }^{b}$ Percentages may not equal $100 \%$ due to rounding. 
The impact of globalization was described as forcing social work to adapt to changing social conditions on local and global levels to remain relevant. International collaborations or common standards for social work education were proposed by Chinese social work educators as methods for delivering and developing social work theories and skills models to address problems resulting from globalization. Immigration, migration, environmental disasters, international economics and global poverty were all listed as primary topics to be addressed by social work education in the future.

\section{Conclusions}

In this chapter, the analysis of the social work educators from the different countries was conducted with a small $N$ and the comparisons provide suggestions of areas to pursue in future research on the impacts of globalization. The overall results demonstrated that the many differences in the backgrounds of the social work educators did not necessarily produce divergent responses in their perspectives on the effects of globalization on social work education. A summary of the research findings and discussion of their implications are presented in the next chapter. 


\section{CHAPTER V \\ DISCUSSION}

This final chapter is a summary and discussion of the findings related to definitions, attitudes, program responses, and perspectives on the impact of globalization on social work education. The chapter includes implications of the results, limitations of the study, and suggestions for future research.

\section{Overview of the Study}

This dissertation is the first international investigation of the impacts of globalization on social work education. As exploratory research, the study examined globalization through the experiences of social work educators in China, Germany, Russia, and the United States of America. A total of 46 social work educators from seven schools in these countries participated in this study: China $(n=17)$, Germany $(n=6)$, Russia $(n=6)$, and USA $(n=17)$. The social work educators responded to translated surveys that collected data on their perspectives of globalization. Given a small $N$, frequencies, means, and standard deviations of social work educators' responses by country were calculated for descriptive purposes.

A lack of understanding of the concept of globalization for the profession was discussed in the first chapter as an obstacle to social work educators addressing the topic in the classroom (Nagy \& Falk, 2000). Though there are 
challenges to creating a universal definition of globalization, a simplified definition of its core characteristics was proposed: the growing interdependence of systems around the world. Dimensions of globalization included in this definition are cultural, economic, environmental, political, social, and technological aspects of the phenomenon. The definition and dimensions were presented to the social work educators on the survey to stimulate responses from them on how they define and describe globalization.

Another barrier to including content on globalization in curricula was the perceived lack of relevance of the phenomenon for the profession (Nagy \& Falk, 2000). The social work educators in this study were asked for their levels of agreement with statements that reflected attitudes toward the significance of globalization for social work education and practice.

The responses of schools of social work to a globalized higher education system included an increase in global topics in curricula, a transition toward using digital technologies for teaching, and a trend toward the internationalization of programs (Rotabi et al., 2007). To explore and expand upon these identified responses, social work educators in the study were queried about the challenges in teaching about globalization, its impact on their teaching methods, and its influence on the future of social work education. The social work educators were also asked to estimate the amount of classes with material on globalization and student interest in the topic.

Previous research studies suggested examining personal and professional characteristics when exploring perspectives on globalization (Findlay \& 
McCormack, 2005; Kondrat \& Ramanathan, 1996). Following the

recommendations of these studies, information on cross-cultural exposure, international experiences, and globalization resources was collected along with general demographics from the social work educators.

Overall, the study sought to explore the meaning of globalization for these social work educators and to investigate their similarities and differences, by country, in attitudes and responses to globalization. Data were collected from these social work educators to explore their perspectives on globalization and generate potential areas of interest for future research on the subject. Additional research is necessary to be able to generalize outcomes within and between these social work educators in China, Germany, Russia, and the United States, and to adequately assess the cultural implications of the findings.

\section{Background of the Social Work Educators}

An analysis of personal background and professional characteristics revealed that the social work educators in this study did not differ solely based on geography. Including the differences due to country of residence and national culture, these social work educators represent a diverse group of individuals. These differences between the countries are important to consider in the interpretation of collective responses to globalization and in respect to the potential influence of demographics on the personal and professional perspectives of the social work educators toward the impact of globalization.

\section{Personal Demographics}


The total sample of social work educators had a mean age of 43 years. However, a comparison of groups found the Chinese and Russians to be from 10 to 20 years younger on the average than the Americans and Germans. The American field supervisors studied by Kondrat and Ramanathan (1996) and the Australian social workers in Findlay and McCormack's (2005) globalization study also had similar ages with an average at or just above 40 years.

Regarding gender, the Chinese and German groups were mostly men while the Russian social work educators were predominantly women. The American group was almost evenly split between the number of women and men who responded to the survey. The majority of the total sample self-reported having a middle level of socioeconomic status. While the previous studies did not share findings on SES levels, their samples were mostly composed of women and contrasted with the gender results of this study (Kondrat \& Ramanathan, 1996; Findlay \& McCormack, 2005).

The majority of the total sample of social work educators in this study spoke at least two languages although the Americans differed from the other groups in their limited bilingual or multilingual abilities. English was the only language spoken by a majority of the social work educators.

In comparison to only one-third of the Chinese and Russian groups who had travelled abroad, most of the Americans and all of the Germans had travelled out of their countries. Almost all of the Australians in Findlay and McCormack's (2007) study had also traveled abroad and half of Kondrat and Ramanathan's (1996) American field supervisors had international travel 
experience. These comparisons suggest a possible link between more economically affluent populations and opportunities to travel.

\section{Professional Characteristics}

The professional characteristics of the social work educators were somewhat reflective of the history of social work education in each country. As a fairly recent profession in China and Russia, the social work educators from these countries had less than half the number of years of teaching experience of those from America and Germany, where social work education has been established for close to a century.

The educational systems between countries were not commensurate and posed a challenge in comparing the types of degrees held or taught by the educators. For the total sample, the majority of the social work educators had degrees equivalent to or higher than the master's level in the United States. The Americans were the only group reporting that a majority of their degrees were in social work. For levels of degrees taught, all of the groups had members who had taught one or more levels of social work education. However, there were differences between the countries at each level of degree. In summary, more of the Germans taught bachelor's courses while more of the Americans taught at the master's level. The Americans were the only group teaching at the doctoral level. More of the specialist level courses were taught by the Russians and more of other levels were taught by the Chinese.

Although most of the total sample reported they were teaching two classes, the Chinese and the American social work educators were teaching 
fewer classes, on the average, than the Germans and Russians. The majority of the social work educators spent more of their professional time teaching than on other duties except for the Americans who typically spent more time on research.

For all countries, work with children or youth was the most frequently reported area of interest and practice courses were taught more frequently than any other course. The social work educators were split between macro and micro approaches to social work, although the Germans more frequently indicated that they preferred a micro perspective.

Almost all of the Germans and Americans had experience working with individuals from different cultural backgrounds compared to half of the Russians and Chinese. Professional or volunteer work with refugees was the most frequently mentioned example of work with diverse populations. However, the majority of the social work educators in each country had not participated in professional international activities, including exchange programs, partnerships, conferences, research, or membership in international social work organizations.

Findlay and McCormack (2007) stated that only $20 \%$ of their sampled Australian social workers had worked with individuals from culturally or linguistically different backgrounds. In this study, the total sample of social work educators had more than twice as many individuals reporting experiences working with diverse populations than the Australian social workers. Not able to be determined from these results, this difference raises the question of whether there is more exposure to diverse groups in academic than professional work settings. 
Overall, a review of the demographics of the social work educators revealed that there were more differences than similarities between the social work educators by country and when compared with previous research. As a result, the total sample is seen as a group of individuals with a variety of personal backgrounds and professional experiences that could influence their perspectives on globalization. Due to a small $N$, the impact of these differences was unable to be fully addressed and should be considered in future studies with larger samples.

\section{Definitions of Globalization}

One of the goals of this study was to examine how social work educators in different countries define and describe globalization. Social work educators provided their own definitions and gave examples of impact of globalization on culture, economics, the environment, politics, society, and technology. These responses were developed into general themes that demonstrated variations in the perspectives of these social work educators toward globalization.

Similar to the example of a definition of globalization provided on the survey, globalization was frequently defined by the social work educators as a process towards the increasing interdependence of world systems. This process was described as influencing different dimensions of people's reality but very few of the definitions elaborated on what the impact was or how it was experienced. Some of the definitions implied that the processes of globalization were not experienced equally - either within or across countries. However, the majority appeared to follow the format of the definition provided on the survey. 
The definitions of the social work educators also appeared to be similar in structure although different in perspective from many of the examples collected by Rowe et al. (2000). For example, Rowe et al.'s group found their definitions tended to view globalization as a threat but the definitions of the social work educators did not reflect a particular viewpoint.

The definitions of the social work educators also did not necessarily provide support for Rowe et al.'s observation that individuals from Westernized countries would have more positive outlooks on globalization. Regardless of country, most of the social work educators' definitions presented neither positive nor negative perspectives of globalization. One of the American social work educators even hinted at negative effects of globalization in a description of the phenomenon as a force benefitting the "powerful." Out of the total sample, negative consequences of globalization were only cited by one Chinese social. work educator who described it as exploitive capitalism.

Differences between social work educators in the four countries in their definitions were observed in depictions of globalization as a universalizing force. While none of the Americans or Germans explicitly expressed this perspective, examples of convergence were found in the Russian and Chinese definitions. There were Russian social work educators who stated that increasing interdependency was creating a single world system. There were also Chinese social work educators who defined globalization as a "global village" or suggested that its processes fostered a global citizenry. Considering the political systems of the different countries, these responses raise the question of whether 
social work educators with Communist backgrounds may tend to provide definitions of globalization as a convergent force due to the influence of socialist ideologies in their countries' histories.

Expanded upon with descriptive examples in Chapter IV, the dimensions of globalization most frequently mentioned in the definitions were economics, culture, the environment, politics, and technology. As found in the social work literature, globalization was also specified as a primarily economic process in some of the definitions of the social work educators (Rowe et al., 2000).

Overall, these definitions of the social work educators provide more depth to the discussion on defining globalization but do not necessarily present any innovations in the concept. The range of these definitions also continues to present difficulties in operationalizing a concept of globalization that represents the variety of experiences or possible interpretations of the phenomenon.

\section{Attitudes toward Globalization}

To explore attitudes toward globalization, 10 statements on the survey addressed globalization as an issue of concern for social work students, faculty, practitioners, the profession, and social work schools in local and global contexts. These statements allowed a variety of subjects to be introduced on the survey. The social work educators indicated their levels of agreement with these statements and the means of their responses were used to compare results by country.

The responses of the social work educators demonstrated that globalization is a significant issue for the profession. Their responses to the 
attitude statements revealed agreement that globalization is a topic of concern for social work students as they learn how to work in local communities impacted by global issues and for social work educators as they prepare these students with a global perspective of the profession. However, there was a tendency among the social work educators to be ambivalent about globalization as a required topic in all social work classes and there was some disagreement about the importance of global problems for all nations.

The use of statements of agreement in this study is similar to methods used in previous studies on globalization (Findlay \& McCormack, 2005; Kondrat \& Ramanathan, 1996). While Kondrat and Ramanathan found low to moderate levels of awareness of globalization, Findlay and McCormack found an increase in the awareness of the phenomenon nine years later. The growth in the concept of globalization between the dates of the studies was considered a factor in the difference in their findings. Though Findlay and McCormack's study focused on social workers in the field, the results from this research with social work educators is comparable with their report of moderate to high levels of perceived relevance of globalization for the profession. As discussed in Chapter I, globalization is a frequent topic in the literature and this familiarity is also a possible influence on perceptions of globalization found in each of these studies (Pugh \& Gould, 2000).

Overall, the results of the attitude statements illustrate that globalization is a significant concern for social work educators in these different countries. The responses of the social work educators to the attitude statements contest Nagy 
and Falk's (2000) assertion that there is a perceived lack of relevance of globalization for social work education. Nonetheless, the results raise questions about which countries are perceived as being impacted the most by globalization. These differences and similarities in the results need further evaluation to be generalized outside of the sampled groups in this study.

\section{Responses to Globalization}

To explore how different countries are reacting to globalization, the social work educators were asked about their schools' responses to globalization and whether there were topics on globalization in their curricula. Estimates of the percentage of classes or students focused on the topic were also collected.

The results show that the majority of social work educators (76\%) feel their schools are responding to globalization. Their responses reflect trends toward the internationalization of programs identified in Chapter II (Irving \& Payne, 2005). American examples included international academic exchanges, research partnerships, and curriculum content. Other activities included the recruitment of international students and community work with refugees and immigrants. The Chinese indicated that international partnerships and academic exchanges were utilized in their schools. The Russian and German programs were providing specialized courses on global issues and/or international social work.

Similar to Ulrich's (2006) findings on American schools including international content in their curricula, the majority of the total sample of social work educators $(78 \%)$ reported that the topic of globalization was found in 
courses at their schools or in their classrooms. The estimated percentage of required or elective courses with related content was between $10-15 \%$. For their own courses, the Russian and the American social work educators included globalization topics in twice as many of classes as the Chinese and Germans. Responding to these questions appeared to be difficult for some of the social work educators because they wrote in comments that they could not estimate the amount of courses with globalization topics outside of their own classes. Yet, the social work literature shows that including global content in classes and curricula was the primary method for training students on the subject (Healy, 2001). The reluctance of social work educators in answering these questions suggests that there may be limited expectations for infusion of the topic or evaluation of related content throughout curricula of their schools. To determine whether material on globalization is being taught to students, future studies could examine other sources of data including syllabi, curricula, and education policy and accreditation standards. An investigation into student perspectives of content in the classroom is also a possible direction to take in future research.

When queried about student interest in globalization, the social work educators, on the average, felt that just over a third of their students were interested in the topic. The Americans differed as they reported half as much student interest in globalization as compared to social work educators in China and Germany. Overall, the relatively low level of student interest across the schools provokes questions about the future of social work education if a 
potentially critical topic is not of much concern to the next generation of practitioners.

\section{The Impact of Globalization}

To investigate perceptions of the impact of globalization, the social work educators were asked about challenges to teaching about the globalization, its effect on teaching methods, and its influence on the future of social work education. The results demonstrated that these social work educators feel that globalization has more of an impact on what they teach than how they teach.

The findings support the issue raised by Nagy and Falk (2000) about globalization's ambiguity making it a difficult subject for social workers. The majority of the social work educators $(76 \%)$ indicated that teaching about globalization was a challenge, especially in knowing what information is most pertinent and most accurate. Similar to concerns identified by Ramanathan and Kondrat (1996) and Askeland and Payne (2006), several social work educators also questioned whether the internationalization of curriculum was an appropriate response to globalization as content from other counties may conflict with cultural values or detract from focusing on national issues. The social work educators' need for more training on the topic of globalization to be able to educate students about its impact on a local and global scale also supports the results of previous studies (Findlay \& McCormack, 2005; Kondrat \& Ramanathan, 1996; Rowe et al., 2000).

In contrast to assertions by Young and Burgess (2005), the social work educators appeared to be ambivalent about globalization having an impact on 
teaching methods. They also did not appear to make a connection between their reports of technological advances (i.e. the internet) as factors of globalization and how these technologies may alter teaching methodologies. Only 2 of the 46 social work educators listed technological advances as an element of globalization's effect on teaching now or in the future.

Reflecting trends identified in social work literature, the need to increase global topics in social work curricula was reported by the social work educators as the main influence of globalization (Healy, 2001). Responses also suggested individuals' awareness of other influences of globalization including an increase in technology for teaching, enhanced global perspectives in the classroom, a more diverse student body, and the reframing of roles between students and teachers. With these examples, the social work educators' responses were similar to the reported effects of globalization on social work education identified in the social work literature (Young and Burgess, 2005).

Globalization was viewed as having an influence on the future of social work education by a majority of the social work educators ( $85 \%)$. This impact was seen as increasing the need for more international and intercultural knowledge, including foreign language competencies and training opportunities abroad. International collaborations or common standards for social work education were also expected to develop further. As described in Chapter II, globalization was perceived as enhancing access to knowledge through technological advances for students and social work educators (Watkins \& Pierce, 2005). The movement of people within and between countries, 
environmental issues, and global economic conditions were listed as topics needing more attention by social work education in the future.

Identified in previous research and confirmed in this study, there is a basic need for more education on globalization to understand its current and future impact on societies and the profession (Findlay \& McCormack, 2005; Kondrat \& Ramanathan, 1996; Rowe et al., 2000). The results from this study on resources for learning about globalization could address this need and can guide the development and distribution of materials on the topic to social work educators in different countries. For this small sample of social work educators, the internet was the resource of choice for learning about the topic although it may be preferred more because it is a conduit to other resources rather than as a source of new knowledge. Often available online, journals and newspapers were also resources used or preferred by the social work educators.

Regarding other resources, the social work educators from Germany and the USA more frequently indicated that they prefer direct experiences for learning about globalization, such as academic exchanges and travel. A possible factor in this difference in preferred globalization resources, these social work educators had more experience with travel abroad and higher socioeconomic levels than those from China and Russia. As a whole, the social work educators were least keen on the resources of videos, community meetings, and workshops. Alhough the results demonstrate that these resources are less popular among these social work educators, it could also mean that they are underutilized as tools for learning in general than just in regards to the topic of globalization. 
It is important to note that there is a potential for bias in these resources which could influence people's perceptions of globalization (Findlay \& McCormack, 2005; Haug, 2005; Stromquist, 2002). However, whether the internet, or another resource, was an influential factor in the social work educators' level of awareness or knowledge on globalization cannot be determined based on the results of this study.

\section{Implications for Social Work Education}

As the first study of the impact of globalization on social work education, the results of this research contribute to the professional literature by demonstrating that social work educators find globalization to be a relevant and significant social issue. The majority of the total sample of social work educators in this study presented a common perspective on globalization as both a concept for the classroom and a process impacting the profession. Although it was conducted with a small sample diverse in demographics and professional characteristics, the implication of these results is that globalization is a reality for social work educators regardless of location or individual background.

The results of this research further the profession's discourse on globalization in its examination of perspectives and definitions of the phenomenon. Although globalization is an abstract concept and subject to a variety of interpretations, the study illustrates that there are key elements in definitions of globalization which are consistent throughout the social work literature and within the responses of the social work educators. Generally accepted by the social work educators, the initial definition created for this study 
captures the core concept and dimensions of globalization and is useful for future investigation of its impact. Continued efforts to conceptualize globalization need to be undertaken to explore whether there is a difference in its meaning based on cultural contexts or political ideologies.

This study contributes to the discussion on creating concepts for social work that are globally applicable but also culturally specific. It is fallible to assume that voices not heard in the literature hold the same views as the dominant discourse. Differences in language do not dictate whether there is variance in the meaning of concepts for social work. Language may be a challenge in conducting cross-cultural or multinational research but should not be an obstacle to investigating and developing concepts that more accurately represent the range of perspectives of the members of the profession.

Outweighing the burdens of the effort, there are many benefits to conducting research that includes a multilingual and/or multinational perspective and enriches the knowledge base of the global profession. However, the time and energy required for this type of research need to be taken into consideration at the onset of a project as it may involve much collaboration for successful implementation. In response to the growing interest in international research, Tripodi and Potocky-Tripodi (2007) provide guidelines for improving outcomes of such studies conducted with culturally and linguistically diverse populations within, across, and between countries around the world.

With respect to the challenges in creating a univocal or universal meaning of the phenomenon, the difficulties in defining globalization should not keep the 
profession from moving forward in attempting to operationalize the concept for application in social work practice and education. For example, the definition and dimensions proposed in this study can be used to determine indicators of the consequences of globalization on a local and global scale. These indicators could be helpful in identifying resulting problems and recognizing potential benefits of the process of increasing global interdependence. Measured and ranked, the selected indicators could be compiled into an index or profiles of globalization for comparisons within and between communities and countries. The results of these comparisons could then inform classroom discussions, program responses, and policy initiatives of the social work profession.

Working with individuals and communities, social work is in a position to offer input on local experiences with the dimensions of globalization. With an appreciation for the micro effects of macro changes within systems, social work's expertise in local conditions can enrich the multidisciplinary debate on globalization and move the discussion from the theoretical to the practical. Social work's lack of engagement with the topic as a global-local issue hinders collaboration with other disciplines and suggests a limited awareness of how the profession can uniquely contribute to the globalization discourse.

Continuing to view globalization as only an international topic also poses a challenge in infusing the subject across curricula. While specialized courses on international topics may address the needs of a few individuals, the relevance of globalization as a local issue cannot be dismissed and related material needs to be included in more general courses. Lacking a formal framework for analyzing 
and understanding the global-local dialectic, it may be difficult for social work educators to be able to competently and confidently teach about globalization in a broader spectrum of courses.

Efforts are in motion to address the need for a global-local perspective in social work curricula. For example, Link and Healy (2005) have compiled syllabi for integrating global content in foundation, policy, practice, ethics, human behavior, and travel abroad courses. Rotabi et al. (2007) provide strategies for the incorporation of key globalization concepts relevant to social work across classes. As mentioned in Chapter II, national and international social work organizations are also developing standards to support and evaluate the internationalization initiative within schools of social work.

This study is an initial inquiry into the impact of globalization on social work education and explored many aspects of its sphere of influence. Although the results show that social work educators find globalization to be a relevant topic for the classroom, there was ambivalence about its effect on teaching methods and a general lack of awareness of its potential impact on many responsibilities of a social work educator. An implication of this research is that social work educators need to be better informed about how globalization affects the academic environment and what roles they can play in responding to its impact on higher education.

With most of the attention on classroom content, other influences of globalization on social work education is only beginning to be recognized. It behooves the profession to take more proactive steps toward understanding how 
globalization shapes both the content and process of social work education. Suggested responses to globalization and areas to be addressed within schools of social work can be developed from the experiences of the social work educators collected in this study.

Applicable to social work, higher education discourse provides much insight into the influence of globalization on the organizational structure of institutions, the objectives of their programs, and the activities of individuals within these academic settings (Allen \& Ogilvie, 2004; Vaira, 2004). With its holistic approach to the different levels of change within human social systems, social work can make an important contribution to a cross-disciplinary response to globalization and the internationalization of programs within universities and colleges around the world.

\section{Limitations of the Study}

There are limitations to this study relating to methodology as exploratory research and as an international inquiry. The small sample of social work educators was also a primary limitation to data analysis and interpretation of results. Overall, the design of the study lacks rigor as a pre-experimental multigroup post-test only research and is limited in the comparisons between groups. It was selected to generate ideas and to explore a topic with groups not typically represented in the social work literature. In many respects, this study can be considered a pilot undertaking of research on this subject.

A lack of generalizability is a critical limitation of this study. The sample was convenient to the researcher and represents comparable groups by 
occupation as social work educators. There were many differences between the groups of social work educators that further limit comparisons on both personal demographics and professional characteristics. Although the results are not generalizable outside of the schools sampled, the low response rates of some of the schools can also threaten the generalizability of the results to those schools. To discuss the results based on country may also be misleading as it can create and promote cultural stereotypes.

Initially piloted with visiting international faculty, the survey used for this study is a new instrument and lacks validation. Another concern with the survey was the inclusion of a definition of globalization. Although there was a range of responses from the social work educators, having a definition presented to them may have influenced the type and variation of the definitions they provided on the survey.

Cultural bias and face validity are limitations to the survey instrument used in this study. There may be different understandings of the concepts about globalization and social work education between the social work educators in the four countries. There may also be factors of survey construction that are culturally dependent. Due to time constraints and lack of resources on the subject, the researcher was limited in means to develop a culturally appropriate and conceptually accurate instrument. However, translation and back-translation processes were undertaken to reduce these threats. The responses of the social work educators were found to be consistent in concepts regardless of country and it is assumed the translations were adequate for the purpose of this study. 
The study relied upon self-reports from the social work educators which is another limitation of the research. Social desirability could have influenced their responses in reporting what they believe is the most preferred answer to items on the survey. To look current and up-to-date, social work educators may have indicated their schools were responding to globalization even if they were not.

Observations or perspectives of the social work educators are also not substitutes for concrete evidence. For example, an estimated percentage of courses with content on globalization may not be as accurate in measurement as the collection of course documents on the subject. However, the perceptions of the social work educators provide information into their awareness of globalization and their perspective as to its relevance for the profession. If the educators perceive that globalization influences social work education, they may also believe it can affect how or what they teach.

Another limitation of the study involved the distribution of the survey to the social work educators at the participating schools. Efforts were made to make the survey available to schools during their spring semesters but the distribution and collection of the surveys did not always occur during that timeframe. It was reported that it was difficult to contact some social work educators during the summer semester. There was limited control of the presentation of the study, the emphasis placed on the completion of the surveys and the collection of completed surveys as these processes of the research were handled by different individuals at each participating school. Although there are advantages to having an individual familiar to the social work educators coordinating these efforts on- 
site, the variability in the survey distribution and collection was a limitation to the study.

A factor in the delay of the distribution of the surveys was the amount of time it took for translation and back translation of the instrument. Even though most of the translators put a significant amount of time and energy into the translations, the efforts sometimes produced unsatisfactory results or created added expenses to the research. Coordinating the translations between individuals in different countries also proved to be an energy- and timeconsuming process.

Other aspects of the translation process were additional limitations to the study. Data were lost as a few of the surveys were completed in indecipherable script and unable to be translated. Translation of survey responses may have also resulted in data reduction or loss of specificity due to translator bias or limited knowledge of the concepts in the responses. To reduce bias and strengthen the accuracy of translation and back-translation, a panel of qualified persons could have been enlisted to review the materials and ensure a wider range of individuals were available to assist with these steps.

Including several surveys with incomplete responses, there was the possibility of loss of data through the interpretation of results. Condensing qualitative material into themes and codes can be a rigorous process, threatened by subjectivity, and can result in frequencies for summarization. It was also not a goal of this study to conduct a thorough content analysis for cultural implications or variations in the responses. As a result, it may not be appropriate to assume 
that the concepts in the social work educators' responses are commensurate and that they are able to be merged into a single perspective on globalization.

\section{Suggestions for Future Research}

A main objective of future research should be the reliability and validity of the measurement of globalization and its impact on social work education. Globalization may be difficult to operationalize but the definition and dimensions proposed in this study can provide a starting point for further inquiry on the subject. Overall, more effort needs to be taken to establish how to determine globalization's influence on the profession.

Regarding the differences between the responses of social work educators in China, Germany, Russia, and the USA, it may be beneficial to consider depth rather than breadth in future research. To conduct the study with multiple schools within a single country would greatly assist in being able to develop a country profile and test the cultural accuracy of the instrument. This step could be implemented with each country studied here. Then a comparison of country profiles could be conducted to test differences between countries on perspectives of the impact of globalization on social work education nationally. and internationally.

This research could have been greatly improved by triangulating data via interviews or program documents. Syllabi, curriculum, and course materials could be used to verify class content on globalization. One-on-one and focus group interviews would be helpful in creating a more accurate meaning of globalization

based on rich descriptions. These methods would allow for opportunities to clarify 
responses and request further information on topics relevant to the study. However, these methods can also be more time intensive and would require multiple language competencies or a translator.

The survey itself had two agendas that may be better served in separate studies for future research (i.e. the general concept of globalization versus its specific impact on social work education). General impressions of globalization could be collected through more qualitative formats to develop a richer description of perspectives on globalization. These perspectives could then be applied to the framework identified in Chapter I for analysis of interpretations of globalization. For further quantitative studies on the concept and dimensions of globalization, the accuracy of an individual's knowledge on its specific consequences could be tested in a survey.

Research on the impact of globalization on social work education could take more in-depth qualitative and quantitative routes. As previously mentioned, the use of interviews can provide further elaboration on personal experiences with globalization in the academic setting. Elements of the survey used in this study and responses from the social work educators could be adapted toward specific questions about individual and program reactions to globalization as a topic for classroom content and an influence on the activities of social work educators.

Another suggestion for future research is to consider other modes for collecting data. Although the surveys were made available in both paper and electronic formats, the data were collected from individually completed surveys 
rather than collectively through an online software program. As most of the social work educators indicated that they had access to the internet, an online program could increase the number of participants, expedite the data collection process, and more easily compile responses into a database. The difficulties in preparing a multilingual survey for an online program were deemed too extensive and expensive for this exploratory study. As technology continues to improve, these challenges in data collection may someday be resolved and significantly advance the opportunities for international research in the future.

All of these suggested measures could be done over time to determine if there is an increase in awareness of globalization and to evaluate if changing perspectives on globalization affect how and what is taught on the subject. Overall, a comparison over time and across groups could help assess the strengths and weaknesses of the methods utilized in social work education to address the impact of globalization.

\section{Conclusion}

As an exploratory study of the responses of social work educators to globalization, this initial inquiry is a small step toward understanding the significance of this phenomenon. As the first research on the impact of globalization on social work education, this study makes a great stride toward exploring a critical topic that has far-reaching implications for the profession around the world. Globalization may present challenges for the profession but ultimately creates opportunities for enlarging the sense of community from a local to a global scale. It is time for social work education to take a leap of faith and 
embrace the global-local dialectic as part of its mission in preparing future social workers for practice in an age of globalization. 


\section{REFERENCES}

Ahmadi, N. (2003). Globalisation of consciousness and new challenges for international social work. International Journal of Social Welfare, 12, 1423.

Allen, M., \& Ogilvie, L. (2004). Internationalization of higher education: Potentials and pitfalls for nursing education. International Nursing Review, 51, 73-80.

Asamoah, Y.A. (2003). International collaboration in social work education: An overview. In L. Healy, Y. Asamoah, M.C. Hokenstad (Eds.), Models of International Collaboration in Social Work Education. Alexandria, VA: CSWE.

Asamoah, Y. A., Healy, L. M., \& Mayadas, N. S. (1997). Ending the internationaldomestic dichotomy: New approaches to a global curriculum for the millennium. Journal of Social Work Education, 33 (2), 389-401.

Askeland, G., \& Payne, M. (2006). Social work education's cultural hegemony. International Social Work, 49 (6), 731-743.

Barker, R. L. (2003). The social work dictionary $\left(5^{\text {th }}\right.$ Ed.). Washington, D.C.: NASW Press.

Caragata, L., \& Sanchez, M. (2003). Globalization and global need: New imperatives for international social work education in North America. International Social Work, 45(2), 217-238. 
Council on Social Work Education (2006). Focusing on our future: Annual report 2005-2006. Retrieved November 16, 2007, from http://www.cswe.org/NR/rdonlyres/AF909CA2-F2CE-454B-95578D5048915BF0/0/cswe_AnnRpt0506.pdf

Council on Social Work Education (2001). Educational policy and accreditation standards. Alexandria, VA: Author.

Cox, D. \& Pawar, M. (2006). International social work: Issues, strategies, and programs. Thousand Oaks, California: Sage Publications.

Doel, M., \& Shardlow (2002). Introduction: international themes in educating social workers for practice. In S. Shardlow, \& M. Doel (Eds.), Learning to Practise Social Work: International Approaches (pp. 11-21). Philadelphia, PA: Jessica Kingsley Publishers.

Dominelli, L. (2005). News and views...from IASSW. International Social Work, $48(4), 504-507$.

Dominelli, L. (2004). International social work education at the crossroads. Social Work \& Society, 2 (1), 87-95.

Dominelli, L. (1999). Neo-liberalism, social exclusion and welfare clients in a global economy. International Journal of Social Welfare, 8, 14-22.

Elliot, D., \& Mayadas, N. (1999). Infusing global perspectives into social work practice. In C. Ramanathan, \& R. Link (Eds.), All Our Futures: Principles \& Resources for Social Work Practice in a Global Era (pp. 52-68). Belmont, CA: Wadsworth Publishing Company. 
Findlay, M., \& McCormack, J. (2005). Globalisation and social work: A snapshot of Australian practitioner's views. Australian Social Work, 58(3), 231-243.

Finn, J. L., \& Jacobson, M. (2003). Just practice: Steps toward a new social work paradigm. Journal of Social Work Education, 39(1), 57-78.

Fulcher, L. (2003). The working definition of social work doesn't work very well in China and Malaysia. Research on Social Work Practice, 13(3), 376-387. Garber, R. (1997). Social work education in an international context. In M.C. Hokenstad, \& J. Midgley. (Eds.), Issues in international social work (pp. 159-171). Washington, DC: NASW Press.

Genschel, P. (2004). Globalization and the welfare state: A retrospective. Journal of European Public Policy, 11(4), 613-636.

Geyer, M., \& Bright, C. (2000). World history in a global age. In D. Held, \& A. McGrew (Eds.), The Global Transformation Reader: An Introduction to the Globalization Debate (pp. 61-67). Malden, MA: Blackwell Publishers Inc.

Gray, M., \& Fook, J. (2004). The quest for a universal social work: Some issues and implications. Social Work Education, 23(5), 625-644.

Hare, I. (2004). Defining social work for the $21^{\text {st }}$ century: The International Federation of Social Work's revised definition of social work. International Social Work, 47(3), 407-424.

Hartman, A. (1990). Our global village. Social Work, 35(4), 291-292.

Haug, E. (2005). Critical reflections on the emerging discourse on international social work. International Social Work, 48 (2), 126-135. 
Healy, L. M. (2001). International social work: Professional action in an interdependent world. New York, NY: Oxford University Press, Inc.

Healy, L. M. (1986). The international dimension in social work education: Current efforts, future challenges. International Social Work, 29, 135-147. Held, D., \& McGrew, A. (2007). Introduction: Globalization at risk? In D. Held \& A. McGrew (Eds.), Globalization Theory: Approaches and Controversies. Malden, MA: Polity Press.

Hokenstad, M.C., Khinduka, S.K., \& Midgley, J. (1992). The world of international social work. In M. C. Hokenstad, S. K. Khinduka, \& J. Midgley (Eds.), Profiles in international social work (pp. 1-11). Washington, D.C.: NASW Press.

Hokenstad, M. C., \& Midgley, J. (2004). Lessons from other countries: Current benefits and future opportunities. In M.C. Hokenstad \& J. Midgley (Eds.), Lessons from abroad: Adapting international social welfare innovations (pp. 1-12). Washington, DC: NASW Press.

larskaia-Smirnova, E., \& Romanov, P. (2002). "A salary is not important here": The professionalization of social work in contemporary Russia. Social Policy \& Administration, 36(2), 123-141.

Ife, J. (2000). Localized needs and a globalized economy: Bridging the gap with social work practice. Canadian Social Work, 2(1), 50-64.

International Federation of Social Workers (n.d.). International policy statement on globalization and the environment. Retrieved November 12, 2006 from http://www.ifsw.org/en/p38000222.html 
Irving, Z., \& Payne, M. (2005). Globalization: Implications for learning and teaching. In H. Burgess \& I. Taylor (Eds.), Effective Learning \& Teaching in Social Policy \& Social Work (pp. 153-167). New York, New York: RoutledgeFalmer.

Jones, J. B., \& Chandler, S. (2001). Connecting personal biography and social history: Women casino workers and the global economy. Journal of Sociology and Social Welfare, 28(4), 173-193.

Keigher, S. M. (1998). The sickening implications of globalization. Health \& Social Work, 23(2), 153-158.

Kondrat, M. E., \& Ramanathan, C. S. (1996). International perspectives and the local practitioner: An exploratory study of practitioner perception of and attitudes toward globalization. Social Development Issues, 18(2), 1-17.

Leighninger, L., \& Midgley, J. (1997). United States of America. In N. Mayadas, T. Watts, \& D. Elliot (Eds.), International Handbook on Social Work Theory and Practice (pp. 9-28). Westport, CT: Greenwood Press.

Link, R. J., \& Healy, L. M. (2005). Introduction to the collection. In R. J. Link, \& L. M. Healy (Eds.), Teaching international content: Curriculum resources for social work education (pp. v-xii). Alexandria, VA: CSWE.

Lyons, K., Manion, K., \& Carlsen, M. (2006). International perspectives on social work: Global conditions and local practice. New York, NY: Palgrave MacMillan. 
Martinez-Brawley, E. E. (2005). Introduction: The complex scenario of social integration: Harmonisation and convergence in social work education and practice. Portularia, 5 (1), 17-28.

Midgley, J. (2005). Jim Midgley on globalization and social development.

Retrieved on $9 / 28 / 05$ from

http://socialwelfare.berkeley.edu/faculty/midglely.htm

Midgley, J. (1997). Social welfare in global context. Thousand Oaks, CA: Sage Pub., Inc.

Mohan, B. (2005). New internationalism: Social work's dilemmas, dreams, and delusions. International Social Work, 48(3), 241-250.

Morley, C. (2004). Critical reflection in social work: A response to globalization? International Journal of Social Welfare, 13, 297-303.

Nagy, G. \& Falk, D. (2000). Dilemmas in international and cross-cultural social work education. International Social Work, 43(1), 49-60.

Otte, C. (1997). Germany. In N. Mayadas, T. Watts, \& D. Elliot (Eds.), International Handbook on Social Work Theory and Practice (pp. 122143). Westport, CT: Greenwood Press.

Polack, R. J. (2004). Social justice and the global economy: New challenges for social work in the $21^{\text {st }}$ century. Social Work, 49(2), 281-290.

Prigoff, A. (2000). Economics for social workers: Social outcomes of economic globalization with strategies for community action. Belmont, CA: Wadsworth/Thomson Learning. 
Pugh, R., \& Gould, N. (2000). Globalization, social work, and social welfare. European Journal of Social Work, 3(2), 123-138.

Ramanathan, C. S., \& Link, R. (1999). Future visions for global studies in social work. In C. S. Ramanathan \& R. Link (Eds.), All Our Futures: Principles and Resources for Social Work Practice in a Global Era (pp. 219-236). Belmont, CA: Wadsworth Publishing.

Reichert, E. (2003). Social work and human rights: A foundation for policy and practice. New York: Columbia University Press.

Reisch, M. (2000). Social workers and politics in the new century. Social Work, 45(4), 293-297.

Reisch, M., \& Jarman-Rohde, L. (2000). The future of social work in the United States: Implications for field education. Journal of Social Work Education, $36(2), 201-214$.

Rossell, T. (1996). Realities of global interdependence in Europe. In L. Healy (Ed.), Realities of global interdependence: Challenges to social work education (pp. 45-47). Alexandria, VA: CSWE Press.

Rotabi, K., Gammonley, D., Gamble, D., \& Weil, M. (2007). Integrating globalization into the social work curriculum. Journal of Sociology \& Social Welfare, 34(2), 165-185.

Rowe, W., Hanley, J., Repetur Moreno, E., \& Mould, J. (2000). Voices of social work practice: International reflections on the effects of globalization. Canadian Social Work, 2(1), 65-86. 
Saunders, E. (2006, February). Social work education in China: A revolutionary new discipline. Paper presented at the Annual Program Meeting of the Council on Social Work Education, Chicago, IL.

Sewpaul, V., \& Jones, D. (2005). Global standards for the education and training of the social work profession. International Journal of Social Welfare, 14, 218-230.

Shera, W., \& Bogo, M. (2001). Social work education and practice: Planning for the future. International Social Work, 44(2), 197-210.

Society for International Cooperation in Social Work (n.d). Welcome to www.socialwork.de. Retrieved November 1, 2007, from www.socialwork.de

Sowers, K., \& Rowe, W. (2007). Social work practice and social justice: From local to global perspectives. Belmont, CA: Thomson Brooks/Cole.

Steger, M. B. (2003). Globalization: A very short introduction. NY, NY: Oxford University Press, Inc.

Stromquist, N. P. (2002). Education in a globalized world: The connectivity of economic power, technology, and knowledge. New York: Rowman \& Littlefield Publishers.

Tikly, L. (2001). Globalisation and education in the postcolonial world: Towards a conceptual framework. Comparative Education, 37(2), 151-171.

Tripodi, T., \& Potocky-Tripodi, M. (2007). International social work research: Issues and prospects. New York, NY: Oxford University Press. 
Ulrich, S. (2006). International social work best practices curriculum for schools of social work. Unpublished doctoral dissertation, University of Louisville, Kent School of Social Work, Louisville.

United Nations Development Programme (1999). Human development report. New York: Oxford University Press.

United Nations Education, Scientific, and Cultural Organization. (2004). Higher education in a globalized society: UNESCO education position paper. Paris, France: Author.

Vaira, M. (2004). Globalization and higher education organizational change: A framework for analysis. Higher Education, 48, 483-510.

van Wormer, K. (2005). Concepts for contemporary social work: globalization, oppression, social exclusion, human rights, etc. Social Work \& Society, 3(1), 1-10.

Watkins, J., \& Pierce, D. (2005). Social work education: A future of strength or peril. Advances in Social Work, 6(1), 24-32.

Watts, T. (1997). An introduction to the world of social work. In N. Mayadas, T. Watts, \& D. Elliot (Eds.), International Handbook on Social Work Theory and Practice (pp. 1-6). Westport, CT: Greenwood Press.

Webb, S. A. (2003). Local orders and global chaos in social work. European Journal of Social Work, 6(2), 191-204.

Wright, E. (2005, Fall). Feeling at home on foreign soil: Cultural commonalities. International Social Work: A Russian Journey. (Available from the Kent School of Social work, University of Louisville, Louisville, KY 40292) 
Yip, K. (2005). A dynamic Asian response to globalization in cross-cultural social work. International Social Work, 48(5), 593-607.

Yip, K. (2004). A Chinese cultural critique of the global qualifying standards for social work education. Social Work Education, 23(5), 597-612.

Young, P., \& Burgess, H. (2005). Dancing on a moving carpet: The changing context. In H. Burgess \& I. Taylor (Eds.), Effective Learning \& Teaching in Social Policy \& Social Work (pp. 1-12). New York, New York: RoutledgeFalmer. 
APPENDIX A SURVEY 
Welcome to the International Survey on Globalization and Social Work Education!

Please answer every question on each page until the end of the survey.

\section{Section I: Understanding Globalization}

For the purpose of this research, a suggested definition of globalization is the following:

Globalization is the growing interdependence of systems around the world.

1. With many different ways to define globalization, please provide your own definition here:

2. Globalization is experienced in many different ways around the world. Please provide a description and example(s) of each of the following aspects of globalization:

a. Cultural:

b. Economic:

c. Environmental:

d. Political:

e. Social:

\section{f. Technological:}

g. Other:

Please continue to the next page. 


\section{Section II: Globalization and Social Work Education}

1. Is the social work program at your school responding to globalization? Yes No

If yes, please provide examples:

2. Are globalization topics included in courses at your school or your classes? Yes No

If yes, please provide examples:

3. What percentage of the required social work courses includes globalization topics? $\%$

4. What percentage of the elective social work courses includes globalization topics? $\%$

5. What percentage of the courses you are teaching includes globalization topics? $\%$

6. What percentage of your social work students are interested in globalization? $\%$

7. Are there challenges to teaching about globalization and social work? Yes No If yes, please provide examples:

8. Does globalization have an effect on your teaching methods?

Yes No If yes, please provide examples:

9. Will globalization influence the future of social work education?

Yes No If yes, please provide examples:

Please continue to the next page. 


\section{Section III: Globalization and Social Work Education Attitudes Scale}

Please circle the number after each item that best represents your attitude about the statement.

1=Strongly Disagree, 2=Disagree, 3=Neither Disagree nor Agree, 4=Agree, 5=Strongly Agree.

1. Globalization is a critical concern for social work education.
Strongly Disagree----- 1
23
4
5 -----Strongly Agree

2. Social work students need to understand how global issues affect local communities.
Strongly Disagree----- 1
$\begin{array}{lll}2 & 3 & 4\end{array}$
5 -...--Strongly Agree

3. Social workers should be concerned about globalization around the world.
Strongly Disagree----- 1
23
4
5 -----Strongly Agree

4. Social work students need to learn about globalization to work with diverse groups.
Strongly Disagree----- 1
2
34
5 -----Strongly Agree

5. Schools of social work should include international content across their curriculum.
Strongly Disagree----- 1
23
4
5 -----Strongly Agree

6. Future social workers need to have a global perspective of their profession.
Strongly Disagree----- 1
2
34
5 -----Strongly Agree

7. Social work educators must be informed about globalization to be relevant to students.
Strongly Disagree-.-.- 1
23
4
5 -----Strongly Agree

8. Today's social work students should be fluent in more than one language.
Strongly Disagree----- 1
23
4
5 -.---Strongly Agree

9. The subject of globalization should be a required topic in all social work classes.
Strongly Disagree----- 1
2
34
5 -----Strongly Agree

10. Global problems are only important for social work graduates in other countries.
Strongly Disagree--.-- 1
23
4
5 -----Strongly Agree

Please make comments or explain your responses to these statements in the space below:

Please continue to the next page. 


\section{Section IV: Professional Background}

1. What are your areas of qualifications? Please list degrees or diplomas and titles.

(For example: Bachelor's in Psychology, Master's in Social Work, Licensed Social Worker).

2. How many years have you taught in social work?

years

(To nearest $1 / 2$ year, i.e. 5.5 years)

3. How many courses are you teaching currently?

4. What social work course areas are you teaching currently and/or have taught in the past? Please check all that apply:

\section{CURRENT}

Field Practicum

Human Behavior

Policy

Practice

Research

Theory

Other
PAST

Field Practicum

Human Behavior

Policy

Practice

Research

Theory

Other

If Other is checked, please list courses:

5. At what level(s) have you taught social work courses? Please check all that apply:

Bachelor's

Master's

Doctorate

Specialist

Other

If Other is checked, please list levels:

6. How do you spend your professional time? Please provide a total estimate in percentages.

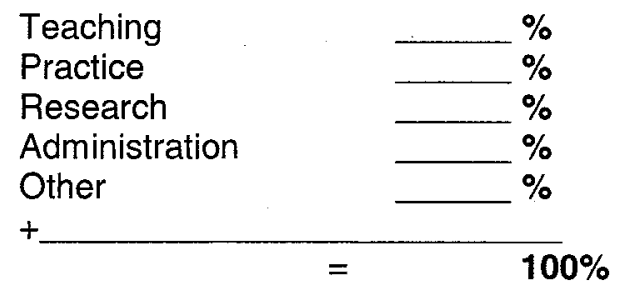

\begin{tabular}{llc} 
Example: & Teaching & $45 \%$ \\
& Practice & $20 \%$ \\
& Research & $15 \%$ \\
& Administration & $10 \%$ \\
& Other (Writing articles) & $10 \%$ \\
\hline & & $100 \%$
\end{tabular}

If Other is checked, please list activities:

Please continue to the next page. 


\section{Section IV Continued: Professional Background}

1. What is your main area of interest in social work? (For example: children, alcohol and drugs, elderly, HIV/AIDS).

2. Do you prefer a macro (large systems) or micro (small systems) approach to social work?

Please check only one:

Macro

Micro

3. How many years have you practiced in the field of social work? years

5.5 years)

(To nearest $1 / 2$ year, i.e.

4. Have you worked with people from cultural or language backgrounds that are different than your own?

Yes

No

If yes, please describe your experience(s):

5. Are you involved in any professional international activities?

Yes

No

If yes, please describe activities:

6. Which resources do you use to learn about globalization? Please check all that apply.

Radio

Television

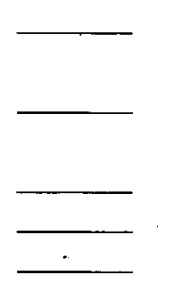

Internet

Videos

Books
Newspapers

Magazines
Scholarly journals Conferences

Workshops
Academic exchanges Community meetings

Travel Other None of these

If Other is checked, please list resources:

7. Which resources would you prefer to use to learn about globalization and social work? Please check all that apply.

Radio

Newspapers

Television

Magazines

Internet

Scholarly journals

Videos

Conferences

Books

Workshops

Academic exchanges Community meetings

Travel

Other

None of these

If Other is checked, please list resources: 


\section{Section V: Personal Background}

1. What is the country where you currently live?

2. Do you currently live in the same country where you were born?

Yes No If no, please list the country where you were born.

3. Have you traveled outside of the country where you currently live?

Yes No If yes, please list all countries where you have traveled and dates of travel:

4. What is the longest length of time you have traveled abroad? Please list approximate time. (For example: 0 days, 2 weeks, 1 month, 3 years).

5. Please list all languages you speak:

6. What are your family's ethnic, cultural, and religious backgrounds? Please list below: (For example: Han Chinese, Bavarian, African American, Buddhist, Muslim, Russian Orthodox).

7. From the following categories, what best represents your level of socioeconomic status? Please check only one:

Low Middle High

8. What is your gender?

Female Male

9. In what year were you born?

Please continue to the next page. 


\section{Section VI: Comments or Questions}

Please provide any comments or questions about globalization and social work education here:

YOU HAVE COME TO THE END OF THIS SURVEY.

THANK YOU FOR YOUR PARTICIPATION!

\begin{tabular}{l} 
If you are interested in further research on this topic, please provide contact information below: \\
Name: \\
Email: \\
Postal Address: \\
\\
\hline
\end{tabular}


APPENDIX B

SURVEY TRANSLATIONS 


\section{全球化与社会工作教育：国际性对比研究}

2006 年 12 月 12 日

尊砤的社会工作教育者, 你们好:

佊被邀请参加由美国路易维尔大学肯特社会工作学院资助、在读博士研究 生 Elaine Wright 主持的一项科研项目。此项研究的目的是探究世界范围内的全 球化现象对社会工作教育的影呴。我们将对您所提供的信息与从其他国家收集 的社会工作教育者的答案进行对比分析。

针对此项研究的调查问卷大概需要㷊三十分钢时间来完成。通过填写该调 查问卷, 您表示自愿参加此项研究。对于使您感党不便的问题您可以拒绝回答。 您可以拒绝或随时终止对此项研究的参与，而您不会因此而损失由于参与此项 研究而将享受的任何利益。尽管此项研究的成果末必直接使愁受益, 但您的参 与将在今后令其他人受益。参与此项研究不存在任何已知风险。

来自资助方、 the Human Subjects Protection Program Office (HSPPO)、 the Institutional Review Board (IRB) 以及其他笿管机构的相关人员将对这些记录 进行检查。在所有其他方面, 此数据将在法律许可范围内进行保密存放。此数 据将被保存在肯特社会工作学院的安全地方。如果此数据被发表, 愁的身份将 不会被暴露。

如果您对此项研究怀有任何疑问或不满，请拨打电话（1-502-852-6922）或 发送电子邮件（tom.lawson@Iouisville.edu）与首席调研员 Thomas R. Lawson

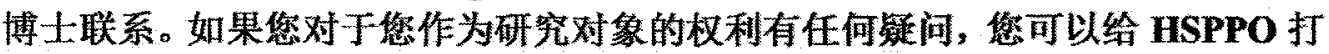
电话 (1-502-852-5188), 与 IRB 的成员就您作为研究对象的任何权利问题进行

私下讨论。此外, 如果愁对此项研究有任何疑问或无法联系到研究人员, 您也 可以拨打上述电话号码。IRB 是由来自大学、科研机构以及与上述所有机构毫 无联系的同一社区普通人士所组成的一个独立委员会。该委员会已经电阅过此 项研究。

如果您对此项研究或研究人员怀有任何疑问或不满，而且您不愿透漏您的 姓名, 佨可以拨打电话 1-877-852-1167。这个电话由不在路易维尔大学工作的人 员接听, 而且是二十四小时服务电话。

此致 
欢迎您参与国际范围内关于全球化与社会工作教育的调㓦!

请回答这份谓查问卷中的船问题。

\section{第一部分 对全球化的理解}

根据此论调查的目的, 暂且将全球化定义如下:

全球化是指在世界范围内，各种机制越来越趋向于相互依赖。

1. 对全球化的定义有很多种, 请将你个人对全球化的理解写在下洎空白处:

2. 在世界范围内诸多领域均存在全球化现象。请就全球化在以下几方面的表现加以描述或 举例说明。

a. 文化方面

b. 经济方面

c. 环境方面

d. 政治方面

e. 社会方面

f. 技术方面

g. 其他方面

转下页 


\section{第二部分：全球化与社会工作教育}

1. 你们学校的社会工作课程是否受到全球化趋势的影唃?

是_—否_— 如果是, 请举例说明:

2. 在你们学校或你所教摱的社会工作课程中是否包括全球化这一话題? 是一

否 如果是, 请举例说明:

3. 在社会工作必修课程中全球化话题所占百分比是多少? $\%$

4. 在社会工作选修课程中全球化话题所占百分比是多少? $\%$

5. 在你所教授的社会工作课程中全球化话题所占百分比是多少? $\%$

6. 在你所教授的社工专业学生中对全球化话题感兴趣的学生所占百分比是多少? $\%$

7. 教授有关全球化及社会工作的课程是否存在挑战?

是

否 如果是, 请举例说明:

8. 全球化现象对你的教学方法是否有影响?

是.

否 如果是, 请举例说明:

9. 全球化是否会对社会工作教骨的末来产生影响?

是 否 如果是, 请举列说明: 


\section{第三部分：对全球化与社会工作教育态度量表}

阅读完下列陈述后，请圈出最能代表你的态度的数字。

1=强烈反对，2=反对， 3=既不反对也不同意， 4=同意， 5=完全同意

1. 全球化对社会工作教育至关重要。
强烈反对- - 1
23
4 5-完全同意

2. 社会工作专业的学生应该了解全球化事件如何会影唃到本地社团。
强烈反对-- 1
23
45 - - 完全同意

3. 社会工作者应该关注世算范围内的全球化问题。
强烈反对-1
23
34
5一完全同意

4. 社会工作专业的学生要想同来自不同种族猆景的因体协作需要了解有关全球化的知识。 强烈反对-1 123045 -

5. 社会工作学院应该在其课程设犆中包括国际化内容。
强烈反对-一1
23
4
5-一完全同意

6. 未来的社会工作者篮要在白已的专业领域用全球化的视角看待问题。
强烈反对- - 1
23
45 -一完全同意

7. 社会工作教育者对于与学生相头的全球化知识必须充分了解。
强烈反对-1
23
4 5-一完全同意

8. 当今社会的社会工作专业学生应该能能熟练运用不只一门语言。
强烈反对-1
23
4 5-一完全同意

9. 所有的社会工作专业课程均应将全球化话题设为一门必修课程。

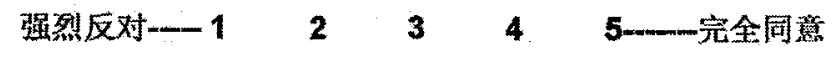

10. 全球化问题只对其他国家的社会工作专业毕业生有重要意义。
强烈反对-1
23
4
5-一完全同意

请在下面空白处对以上陈述加以评论或对你的看法做出解释:

转下页 
1. 你在什么领域具备专业资格? 请列出你的学位、文㶵及头衔。 (例如; 心理学学士，社会工作硕士，持有社会工作者执照）

2. 你从事社会工作教育的时间是多少年? 年

(精确到半年, 如 5.5 年)

3. 你目前教授几门课程?

4. 你目前或曾经教挼过明些社会工作课程? 请在以下选项中进行选择:

目前

社会工作实习指昌

人类行为

社会政策

社会工作实践

调查统计学

理论

其他
曾经

社会工作实习指导

人类行为

社会政策

社会工作实践

调查1统计学

理论

其他

如果选择其他, 请将所讲授的课程列出:

5. 你针对何种程度的学生讲授社会工作课程? 请在以下选项中进行透择:

本科生 硕士研究生

博士研究生 专业人士

其他

如果选择其他, 请列出学生程度:

6. 你投入到专业领域的时间是如何分配的? 请估算成百分比。

\begin{tabular}{|c|c|c|c|c|}
\hline 讲课 & $\%$ & 例如 & 诽课 & $45 \%$ \\
\hline 实践 & $\%$ & & 实践 & $20 \%$ \\
\hline 科研 & $\%$ & . & 科研 & $15 \%$ \\
\hline 行政 & $\%$ & & 行政 & $10 \%$ \\
\hline 其他 & $\%$ & & 其他 & $10 \%$ \\
\hline+ & $=100 \%$ & & & $=100 \%$ \\
\hline
\end{tabular}

如果选择其他,请将其他工作列出: 


\section{第四部分 (续)：专业背景}

1. 在社会工作领域你最感兴趣的方面是什么?（例如：儿童, 酷酒和吸瑇, 老年人, HIV 携带者( 艾滋病患者):

2. 在社会工作中，你更原意用宏观方法还是徽观方法解决问趋? 请选择其一： 宏观 微㹸

3. 你在社会工作领域积累了几年的实践经验? 年

（精确到半年，姐 5.5 年）

4. 你是否曾经与语言和文化背景均与你不同的人一起工作过? 是 如果是, 请简单描述一下你的经历:

露

5. 你是否参与过任何国际性的社会工作活动? 是 否 如果是，请简单措述一下该活动：

6. 你通过以下哪些渠通了解全球化的相关信急? 请在以下选项中进行选择：

\begin{tabular}{|c|c|c|}
\hline 广播 & 搌纸 & 学术交流 \\
\hline 电视 & 舞志 & 社区会议 \\
\hline 互联网 & 学术期刊 & 旅游 \\
\hline 承像 & 会议 & 其他 \\
\hline 㧍籍 & 睤讨会 & 以上都不是 \\
\hline
\end{tabular}

如果选择其他, 请列出其他紫道:

7. 你更喜欢通过丵些渠造了解有关全球化和社会工作的信息? 请在以下选顼中进行选择:

\begin{tabular}{|c|c|c|}
\hline 广播 & 报纸 & 学术交流 \\
\hline 电视。 & 染志 & 社区会议 \\
\hline 互联网 & 孪术期刊 & 旅游 \\
\hline 录像 & 会议 & 其䄬 \\
\hline 书籍。 & 磁讨全 & 以上都不是 \\
\hline
\end{tabular}

如果选择其他, 请列垃基他渠道:

转下页 


\section{第五部分：个人背景}

1. 你目前在哪个国家居住?

2. 你目前店住的国家是否你的出生国? 是 是 如果不是, 请在此写出你的出生国

3. 除了你目前居住的国家外，你是否还去过其他国家? 是 否 如果是，请列出你曾经去过的国家及旅行时间;

4. 你出国时间最长的一次是多长时间? 请写数大權时间。 （例如： 0 天，2周，一个月，3年）

5.请将你所掌层伯语言列在下面:

6. 你的种族、文化和宗教背景是什么?

（例如：汉族，巴伐利亚人，非裔美国人，佛教，穆斯标，东正教）

7. 请选择最能代表你的社会经济地位的一项: 低 中 高

8. 你的性别是什么? 女 男

9. 你的出生年份? 


\section{第六部分：评论或问题}

请就全球化与社会工作教育进行评论或提出问题:

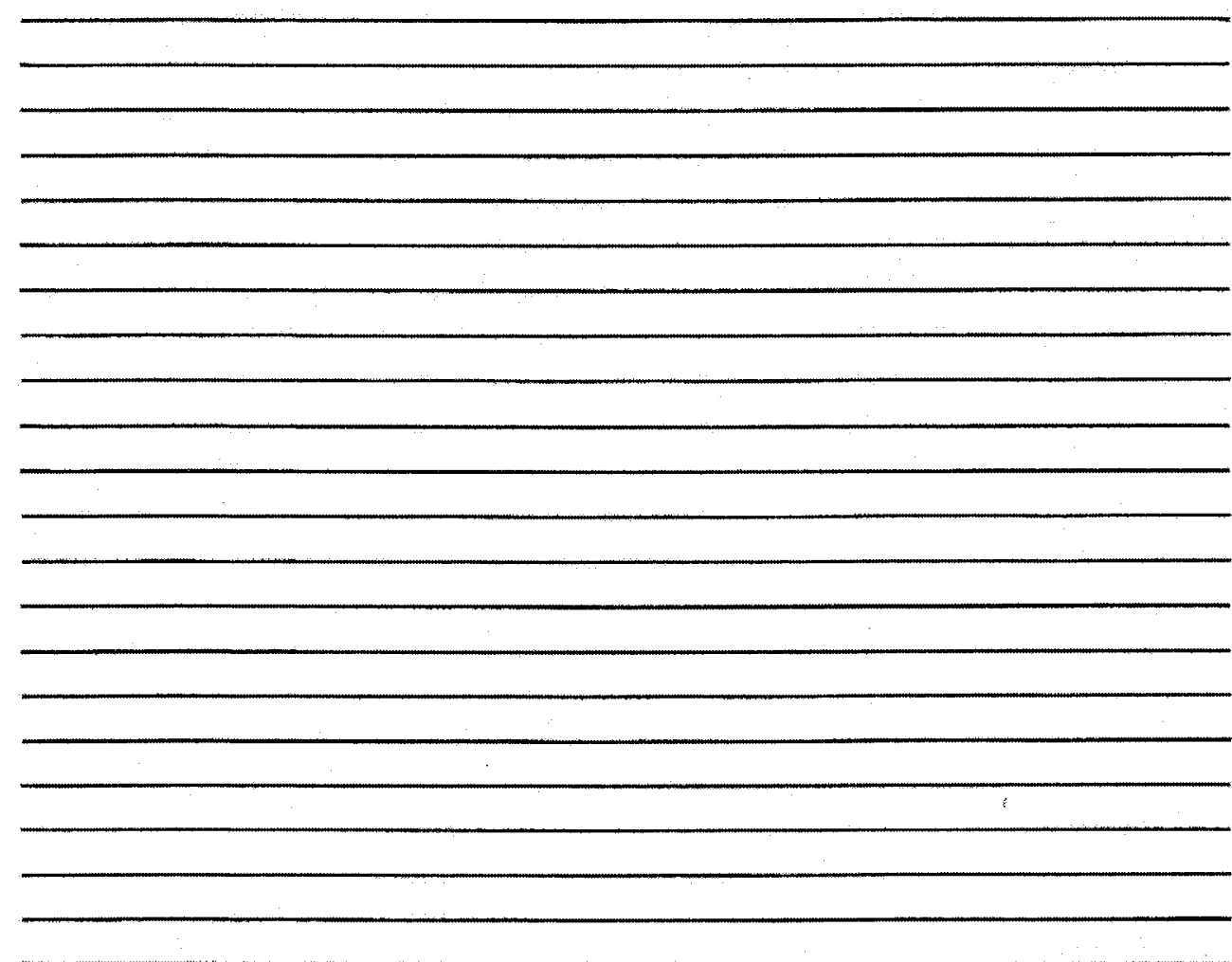

调查问卷至此结束。

感谢您的参与!

如果您对此话题的进一步研究感兴趣, 请留下华的联系方式:

姓名:

电子信箱:

通信地址: 


\section{Globalisierung und Sozialarbeits-Ausbildung: Eine internationale Vergleichs-Analyse}

$12 / 12 / 06$

Sehr geehrte Damen und Herren,

Sie sind eingeladen, an einer Forschungsstudie teilzunehmen, die von der Doktorandin Elaine Wright mit Unterstützung der Kent School of Social Work der University of Louisville durchgeführt wird. Der Zweck dieser Studie ist, den Einfluss von Globalisierung auf die Sozialarbeits-

Ausbildung rund um die Welt zu erforschen. Die gesammelte Information wird verglichen mit den Antworten von Ausbildern der Sozialarbeit in Schulen der Sozialarbeit anderer Länder.

Die Beantwortung des Fragebogens für diese Studie dürfte etwa dreißig Minuten dauern. Durch das Ausfüllen des Fragebogens zeigen Sie an, dass Sie freiwillig an dieser Untersuchung teilnehmen. Sie können die Beantwortung einer Frage ablehnen, wenn Sie sich dabei nicht wohlfühien. Sie können sich jederzeit verweigern oder die Teilnahme abbrechen, ohne Verlust irgendwelcher Vorteile, zu denen Sie sonst berechtigt sind. Obwohl die Ergebnisse dieser Untersuchung nicht unbedingt von direktem Nutzen für Sie sein werden, Ihre Teilnahme könnte für andere in der Zukunft hilfreich sein. Für Ihre Teilnahme an dieser Forschungsstudie gibt es keine uns bekannten Risiken.

Individuen des Sponsors, dem Human Subjects Protection Program Office (HSPPO), dem Institutional Review Board (IRB) und andere Ordnungsbehörden können die Unterlagen einsehen. Ansonsten werden die Daten den gesetzlichen Bestimmungen entsprechend vertraulich gehalten. Sie werden an einem sicheren Ort an der Kent School of Social Work aufbewahrt. Sollten die Daten publiziert werden, wird dabei Ihre Identität nicht veröffentlicht.

Sollten Sie irgendwelche Fragen, Bedenken oder Beschwerden zu dieser Forschungsstudie haben, bitte wenden Sie sich an Dr. Thomas R. Lawson, Principal Investigator, unter der Telefon Nr. 001-502-852-6922 oder über Email: tom.lawson@louisville.edu. Wenn Sie irgendwelche Fragen bezüglich Ihrer Rechte als Forschungs-Subjekt haben, bitte rufen Sie beim HSPPO an, Telefon Nr.: 001-502-852-5188, um ganz persönlich jede Frage Ihrer Rechte als ForschungsSubjekt mit einem Mitglied des IRB zu besprechen. Sie können diese Nummer auch anrufen, wenn Sie irgendwelche anderen Fragen bezüglich der Forschung haben oder vom Forschungspersonal niemanden erreichen können. Das IRB ist eine unabhängige Kommission, zusammengesetzt aus Mitgliedern der Universität, Personal der Institutionen wie auch aus Personen der Gemeinde, die mit diesen Institutionen nicht verbunden sind. Das IRB hat diese Studie bereits überprüft.

Wenn Sie Bedenken oder Beschwerden über diese Forschung oder dem Forschungspersonal haben und Ihren Namen nicht nennen möchten, rufen Sie 001-877-852-1167 an. Diese Nummer steht 24 Stunden zur Verfügung und wird von Personen bedient, die nicht an der University of Louisville arbeiten.

Hochachtungsvoll

Unterzeichnet vom Principal Investigator Unterzeichnet vom Co-Investigator Dr. Thomas R. Lawson Elaine Wright 
Willkommen zur internationalen Untersuchung über Globalisierung und Sozialarbeits-Ausbildung

Bitte beantworten Sie jede Frage auf jeder Seite bis zum Ende der Untersuchung.

\section{Sektion I: Globalisierung verstehen}

Zum Zweck dieser Untersuchung ist eine vorgeschlagene Definition von Globalisierung folgende: Globalisierung ist die wachsende Interdependenz von Systemen rund um die Welt.

1. Es gibt viele verschiedene Arten, Globalisierung zu definieren. Zeigen Sie bitte Ihre eigene Definition auf:

2. Globalisierung wird rund um die Welt auf verschiedene Art und Weise erfahren. Bitte geben Sie eine Beschreibung und Beispiele von jedem der folgenden Aspekte von Globalisierung:

a. Kulturell:

b. Wirtschaftlich:

c. Umweltbezogen:

d. Politisch:

e. Sozial:

f. Technologisch:

g. Andere:

Bitte auf der nächsten Seite fortsetzen. 


\section{Sektion II: Globalisierung und Sozialarbeits-Ausbildung}

1. Reagiert die Sozialarbeits-Ausbildung an Ihrer Fachhochschule auf Globalisierung?

ja_ nein

Wenn ja, bitte geben Sie Beispiele:

2. Sind Globalisierungsthemen in Veranstaltungen Ihrer Fachhochschule oder in Ihren Seminaren eingeschlossen?

ja__nein

Wenn ja, bitte geben Sie Beispiele:

3. Wie viel Prozent der Sozialarbeits-Pflichtveranstaltungen beinhalten Globalisierungsthemen? $\%$

4. Wie viel Prozent der Sozialarbeits-Wahlpflichtveranstaltungen beinhalten Globalisierungsthemen? $\%$

5. Wie viel Prozent der von Ihnen selbst gelehrten Veranstaltungen beinhalten Globalisierungsthemen?

6. Wie viel Prozent der Sozialarbeits-Studenten sind an Globalisierung interessiert?

7. Denken Sie, dass es eine Herausforderung darstellt Globalisierung und Sozialarbeit zu lehren?

Wenn ja, bitte geben Sie Beispiele:

ja_nein

8. Hat Globalisierung einen bestimmten Effekt auf Ihre Lehr Methoden?

ja_nein

Wenn ja, bitte geben Sie Beispiele:

9. Wird Globalisierung die Zukunft der Sozialarbeits-Ausbildung beeinflussen?

ja nein

Wenn ja, bitte geben Sie Beispiele:

Bitte auf der nächsten Seite fortsetzen. 


\section{Sektion III: Globalisierung und Sozialarbeits-Ausbildung Einstellungs-Skala}

Bitte bei jeder Aussage jene Ziffer einkreisen, die Ihrer Einstellung zum Statement am meisten entspricht

1=starke Ablehnung, 2=Ablehnung, 3,=weder Ablehnung noch Zustimmung, 4=Zustimmung, $5=$ starke Zustimmung

1. Globalisierung ist ein wichtiges Thema in der Sozialarbeits-Ausbildung.
starke Ablehnung---- 12
3.4
5 ---- starke Zustimmung

2. Sozialarbeitsstudenten müssen verstehen, wie globale Probleme lokale Gemeinden beeinflussen.

$$
\text { starke Ablehnung---- } 122 \quad 3 \quad 4 \quad 4 \quad 5 \text {---- starke Zustimmung }
$$

3. Sozialarbeiter auf der ganzen Welt sollten sich mit Globalisierung befassen.

$\begin{array}{llllll}\text { starke Ablehnung--- } 1 & 2 & 3 & 4 & 5 \text {---- starke Zustimmung }\end{array}$

4. Sozialarbeitsstudenten müssen etwas über Globalisierung lernen, um mit verschiedenartigen Gruppen arbeiten zu können.

$$
\text { starke Ablehnung---- } 122 \quad 3 \quad 4 \quad 4 \quad 5 \text {---- starke Zustimmung }
$$

5. Fachhochschulen für Sozialarbeit sollten internationale Inhalte quer durch ihr Curriculum enthalten.

$$
\begin{array}{lllll}
\text { starke Ablehnung---- } 1 & 2 & 3 & 4 & 5
\end{array}
$$

6. Zukünftige Sozialarbeiter müssen eine globale Perspektive ihrer Profession haben.

$$
\begin{array}{llllll}
\text { starke Ablehnung---- } 1 & 2 & 3 & 4 & 5 \text {---- starke Zustimmung }
\end{array}
$$

7. Ausbilder für Sozialarbeit müssen über Globalisierung informiert sein, um für die Studenten kompetent zu sein.

$$
\text { starke Ablehnung---- } \begin{array}{lllll}
1 & 2 & 3 & 4 & 5
\end{array}
$$

8. Heutige Sozialarbeitsstudenten sollten mehr als nur eine Sprache fließend sprechen.

$$
\text { starke Ablehnung---- } 122 \quad 3 \quad 4 \quad 4 \quad 5 \text {---- starke Zustimmung }
$$

9. Das Thema Globalisierung sollte in allen Sozialarbeitsseminaren ein verpflichtender Inhalt sein.

$$
\begin{array}{lllll}
\text { starke Ablehnung---- } 1 & 2 & 3 & 4 & 5
\end{array} \text {---- starke Zustimmung }
$$

10. Globale Probleme sind nur für Sozialarbeiter in anderen Ländern wichtig.

starke Ablehnung---- $122 \quad 3 \quad 4 \quad 5$---- starke Zustimmung

Bitte ergänzen, kommentieren oder erklären Sie Ihre Antworten zu diesen Statements:

Bitte auf der nächsten Seite fortsetzen. 


\section{Sektion IV: Professioneller Hintergrund}

1. Was sind die Gebiete Ihrer Qualifizierung? Bitte listen Sie auf Grade, Diplome, Titel.

(Z.B. Diplom in Psychologie, Master in Social Work, Dr. in Ökonomie, etc.)

2. Seit wie vielen Jahren lehren Sie in der Sozialarbeit/Sozialpädagogik?

Jahre

(bitte möglichst genau, z.B. 5,5 Jahre)

3. Wie viele Seminare/Kurse lehren Sie zurzeit?

4. In welchen Sozialarbeitsgebieten lehren Sie gegenwärtig und/oder haben in der Vergangenheit gelehrt? Bitte alle zutreffenden ankreuzen:

\section{GEGENWÄRTIG}

Praktikum

Menschliches Verhalten

Politik

Praxis/Methoden

Forschung

Theorie

Anderes

\section{VERGANGENHEIT}

Praktikum Menschliches Verhalten

Politik

Praxis/Methoden

Forschung

Theorie

Anderes

Falls „Anderes“ angekreuzt, bitte benennen Sie die Veranstaltungen:

5. Auf welchen Ebenen haben Sie Sozialarbeit gelehrt? Bitte alle zutreffenden ankreuzen:

Bachelor

$$
\text { Master }
$$

Doktorat

Spezialisten

Andere

Falls „Andere" angekreuzt, bitte welche:

6. Wie verteilt sich Ihre berufliche Zeit? Bitte geben Sie eine Gesamteinschätzung in Prozenten.

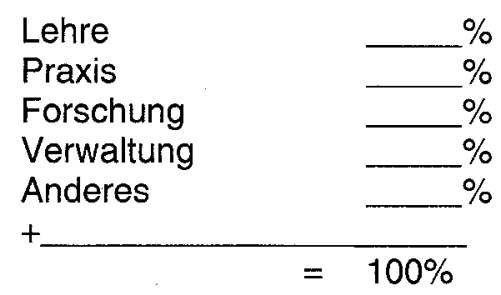

Beispiel:

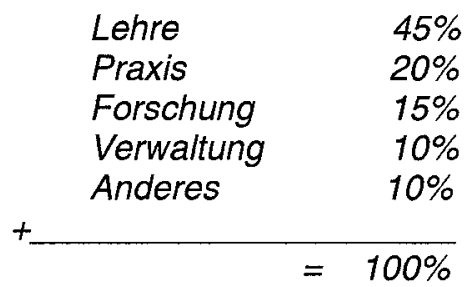

Falls „Anderes“ angekreuzt, bitte benennen Sie die Aktivitäten:

Bitte auf der nächsten Seite fortsetzen. 


\section{Sektion IV Fortsetzung: Professioneller Hintergrund}

1. Was ist Ihr hauptsächliches Interessensgebiet in der Sozialarbeit? (z.B.: Kinder, Alkohol und Drogen, Altenarbeit, HIV/AIDS).

2. Bevorzugen Sie in der Sozialarbeit die Makro-Ebene (große Systeme) oder die Mikro-Ebene (kleine Systeme)?

Bitte nur eines ankreuzen:

Makro__ Mikro

3. Wie viele Jahre haben Sie auf dem Gebiet der Sozialarbeit praktiziert?

$$
\text { (bitte möglichst genau, z.B. 5,5 Jahre) }
$$

4. Haben Sie mit Menschen gearbeitet, deren kultureller oder sprachlicher Hintergrund von dem Ihrigen verschieden ist?

Ja Nein

Wenn ja, bitte beschreiben Sie Ihre Erfahrungen:

5. Sind Sie in irgendwelchen professionellen internationale Aktivitäten involviert?

Wenn ja, bitte beschreiben Sie die Aktivitäten:

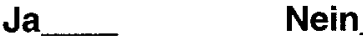

6. Welche Ressourcen benutzen Sie, um über Globalisierung etwas zu erfahren?

Bitte alle zutreffenden ankreuzen:

$\begin{array}{llll}\text { Radio } & & \text { Zeitungen } & \\ \text { Fernsehen } & \text { Magazine } & \text { Akademischen Austausch } \\ \text { Internet } & \text { Fachzeitschriften } & - & \text { Gemeinde Versammlungen } \\ \text { Videos } & \text { Konferenzen } & \text { Reisen } \\ \text { Bücher } & \text { Workshops } & - & \text { Anderes } \\ \text { Keines von allen }\end{array}$

Falls „Anderes“ angekreuzt, bitte geben Sie die Ressourcen an:

7. Welche Ressourcen würden Sie bevorzugen, um etwas über Globalisierung und Sozialarbeit zu erfahren. Bitte alle zutreffenden ankreuzen:

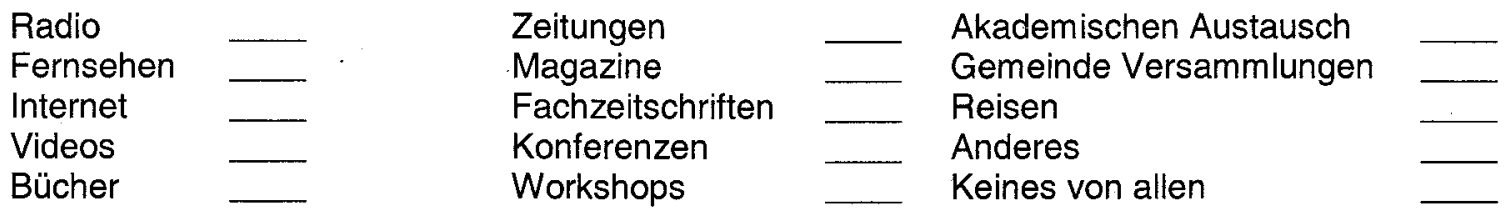

Falls „Anderes“ angekreuzt, bitte geben Sie die Ressourcen an:

Bitte auf der nächsten Seite fortsetzen. 


\section{Sektion V: Persönlicher Hintergrund}

1. In welchem Land leben Sie gegenwärtig?

2. Leben Sie gegenwärtig im gleichen Land, in dem Sie geboren wurden? Ja

Nein

Falls Nein, bitte geben Sie Ihr Geburtsland an:

3. Sind Sie außerhalb des Landes gereist, in dem Sie gegenwärtig leben? Ja

Nein

Wenn Ja, bitte geben Sie alle Länder an, die Sie bereist haben und die Daten Ihrer Reisen:

4. Was ist die längste Zeit, die Sie im Ausland verbracht haben? Bitte geben Sie die ungefähre Zeit an. (z.B.: 0 Tage, 2 Wochen, 1 Monat, 3 Jahre)

5. Bitte geben Sie alle Sprachen an, die Sie sprechen:

6. Was ist der ethnische, kulturelle und religiöse Hintergrund Ihrer Familie?

(z.B.: Han Chinese, Bayerisch, African American, Buddhist, Moslem, Russisch Orthodox).

7. Welche der folgenden Kategorien repräsentiert am besten Ihren sozioökonomischen Status?

Bitte nur eines ankreuzen:

Niedrig

Mittel

Hoch

8. Was ist Ihr Geschlecht:

Weiblich

Männlich

9. In welchem Jahr sind Sie geboren?

Bitte auf der nächsten Seite fortsetzen. 


\section{Sektion VI: Kommentare und Fragen}

Bitte.kommentieren Sie hier oder stellen Fragen zu Globalisierung und Sozialarbeits-Ausbildung:

SIE SIND AM ENDE DIESER UNTERSUCHUNG ANGEKOMMEN. WIR DANKEN IHNEN FÜR IHRE TEILNAHME.

Wenn Sie am weiteren Verlauf der Untersuchung zu diesem Thema interessiert sind, geben Sie uns bitte eine Kontakt-Information:

Name:

Email:

Postalische Adresse: 


\section{Глобализация и Образование в Области Социальной Работы: Международный Сравнительный Анализ}

$12 / 12 / 06$

Уважаемый социальный педагог,

К Вам обращается кандидат на получение докторской степени Элейн Райт с предложением принять участие в ее научном исследовании, проводимом при спонсорской поддержке факультета социальной работы им. Кента Луисвилльского университета. Целью данного исследования является изучение влияния процесса глобализации на образование в области социальной работы во всем мире. Полученная информация будет сопоставлена с результатами опроса социальных педагогов, работающих на факультетах социальной работы в других странах.

Ответы на вопросы анкеты, являющейся частью данного исследования, займут около тридцати минут. Принимая участие в анкетировании, Вы тем самым подтверждаете Ваше добровольное согласие на участие в проводимом научном исследовании. Вы вправе отказаться отвечать на любой из вопросов, который вызывает у Вас неловкость или стеснение. Вы можете прекратить или приостановить Ваше участие в любой момент без потери каких-либо преимуществ, на которые в ином случае Вы могли бы рассчитывать. Хотя результаты данного исследования не могут представлять ценность непосредственно для Вас, они могут принести пользу для других людей в будущем. Ваше участие в данном научном исследовании ни в коем случае не представляет для Вас никакого риска.

Представители спонсорской организации, Департамент программ по защите участников исследований (HSPPO), Ревизионный совет учреждения (IRB) и другие регулирующие органы могут провести инспекцию данных отчетов. Полученные данные не подлежат разглашению во всех остальных случаях, предусмотренных законом. Эти данные будут надежно храниться на факультете социальной работы им. Кента. В случае их опубликования Ваша анонимность гарантируется.

Если у Вас возникнут какие-либо вопросы, сомнения или несогласие в отношении данного научного исследования, Вы можете обратиться к руководителю исследования доктору Томасу Р. Лоусону по телефону 1 (код страны) 502-852-6922, или написать на его электронный адрес tom.lawson@louisville.edu. В случаe возникновения вопросов, касающихся Ваших прав как участников исследования, Вы можете позвонить в HSPPO по телефону 1-502-852-5188 и в конфиденциальном порядке обсудить вопрос Ваших прав как участников исследования с представителем Ревизионного совета учреждения (IRB). Вы также можете позвонить на этот номер, если Вам потребуются ответы на другие вопросы, связанные с исследованием, или же Вы не сможете дозвониться до руководства научного исследования. Ревизионный совет учреждения (IRB) представляет собой независимый комитет, состоящий из представителей университетского сообщества, сотрудников учреждений, а также круга лиц, не имеющих отношения к данным учреждениям. IRB провел анализ данного исследования.

Если у Вас есть сомнения или претензии к самому исследованию или его руководству, или же Вы не желаете указывать в анкете свое имя, Вы можете позвонить на номер 1-877-8521167. Это круглосуточная телефонная линия, по которой Вы можете получить ответы от людей, не являющимися сотрудниками Луисвилльского университета.

С уважением, 


\section{Добро пожаловать на страницы международной анкеты на тему}

«Глобализация и образование в области социальной работы»!

\section{Раздел I: Понятие «глобализация»}

В соответствии с целью данного исследования, предлагается следующее определение термина «глобализация»:

Глобализация это растущая взаимная зависимость систем во всем мире.

1. Наряду с множеством существующих определений понятия «глобализация», дайте ниже свое собственное определение:

2. Глобализация в мире проявляется в различных областях. Опишите и приведите пример(ы) проявления глобализации в каждой из приведенных ниже областей:

а. Культура:

б. Экономика:

в. Окружающая среда:

г. Политика:

д. Общество:

е. Технологии:

ж. Другие:

Продолжение на следующей станице. 


\section{Раздел II: Глобализация и образование в области социальной работы}

1. Учитывает ли программа подготовки социальных работников на Вашем факультете проблему глобализации? Да __ Нет

Если да, приведите примеры:

2. Отражены ли темы глобализации в курсах дисциплин на Вашем факультете или на занятиях? Да _ Н Нет

Если да, приведите примеры:

3. Какой процент обязательных дисциплин для подготовки социальных работников включает темы глобализации? $\%$

4. Какой процент дисциплин по выбору для подготовки социальных работников включает темы глобализации? $\%$

5. Какой процент преподаваемых Вами дисциплин для подготовки социальных работников включает темы глобализации? $\%$

6. Какой процент обучаемых Вами студентов, специализирующихся в области социальной работы, проявляет интерес к глобализации? $\%$

7. Существуют ли определенные сложности в преподавании темы глобализации и социальной работы? Да _ Нет

Если да, приведите примеры:

8. Оказывает ли влияние проблема глобализации на Ваши методы преподавания?

Да Нет

Если да, приведите примеры:

9. Повлияет ли процесс глобализации на подготовку социальных работников в будущем? Да__Нет

Если да, приведите примеры:

\section{Продолжение на следующей станице.}




\section{Раздел III: Глобализация и шкала оценки отношения к образованию в области социальной работы}

В конце каждого пункта обведите номер, который в наибольшей степени отражает

Ваше отношение к данному утверждению.

1=Абсолютно не согласен, 2=Не согласен, 3=Не уверен, 4=Согласен, $5=$ Полностью согласен.

1. Глобализация является актуальной проблемой, стоящей перед образованием в области социальной работы.

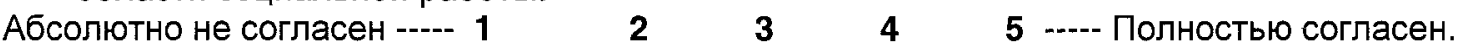

2. Студентам, специализирующимся в области социальной работы, необходимо ясное понимание того, каким образом глобальные проблемы влияют на сообщества людей, проживающих в отдельных регионах.

Абсолютно не согласен ---- $1 \quad 2 \quad 2 \quad 3 \quad 4 \quad 4 \quad 5$---- Полностью согласен

3. Социальные работники должны проявлять интерес к процессу глобализации, происходящему в мире.

Абсолютно не согласен --- $\quad 1 \quad 2 \quad 2 \quad 3 \quad 4 \quad 5$-.-- Полностью согласен 4. Студентам, специализирующимся в социальной работе, необходимо расширять свои знания о глобализации для работы с различными социальными группами.

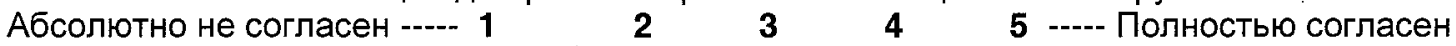

5. Факультеты социальной работы должны учитывать международный опыт в своих учебных планах.

Абсолютно не согласен ---- $1 \quad 2 \quad 2 \quad 3 \quad 4 \quad 50$-.-- Полностью согласен

6. Будущим социальным работникам необходимо стремиться к международным перспективам в своей профессии.

Абсолютно не согласен -.-- $1 \quad 2 \quad 3 \quad 4 \quad 4 \quad 5$---- Полностью согласен 7. Социальные педагоги должны быть хорошо осведомлены о проблеме глобализации с тем, чтобы быть компетентными в глазах студентов.

Абсолютно не согласен ---- $1 \quad 2 \quad 3 \quad 3 \quad 4 \quad 5$-.-- Полностью согласен 8. Современные студенты, специализирующиеся в области социальной работы, должны владеть одним или несколькими иностранными языками.

Абсолютно не согласен ---- $1 \quad 2 \quad 2 \quad 3 \quad 4 \quad 5 \quad$---- Полностью согласен

9. Проблема глобализации должна стать обязательной темой на всех занятиях для студентов социальной работы.

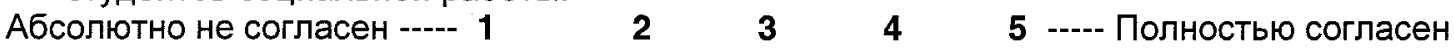
10. Глобальные проблемы представляют важность только для аспирантов социальной работы в других странах.

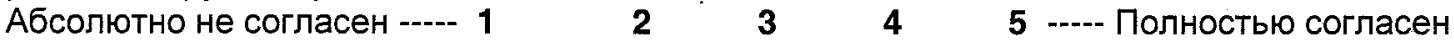

Прокомментируйте или объясните ниже Ваши ответы на предыдущие высказывания:

Продолжение на следующей станице. 


\section{Раздел IV: Профессиональный опыт}

1. В каких областях Вы имеете квалификацию? Перечислите Ваши степени или дипломы, а также звания.

(Например: бакалавр психологии, магистр социальной работы, лицензированный социальный работник).

2. Сколько лет Вы преподаете социальную работу?

лет

(с точностью до ближайших полгода, например 5.5 лет)

3. Сколько дисциплин Вы преподаете в настоящий момент?

4. К каким направлениям деятельности в области социальной работы относятся дисциплины, которые Вы преподаете в настоящий момент и/или преподавали в прошлом? Отметьте соответствующие:

\section{В НАСТОЯЩИЙ МОМЕНТ}

Производственная практика

Социальное поведение

Политика

Практика

Научная работа

Теория

Другие

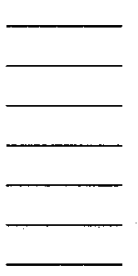

\section{В ПРОШЛОМ}

Производственная рактика

Социальное поведение

Политика

Практика

Научная работа

Теория

Другие

В случае варианта «Другие», перечислите наименования дисциплин:

5. Студентам какого(их) уровня(ней) Вы преподаете дисциплины по специальности «Социальная работа»? Отметьте соответствующие:

Бакалавр __ Магистр __ Аспирант __ Специалист __ Другие

В случае варианта «Другие», перечислите уровни:

6. Каким образом Вы используете Ваше рабочее время? Укажите суммарную оценку в процентном выражении.

Преподавание

Практика

Научная работа

Руководство

Другие

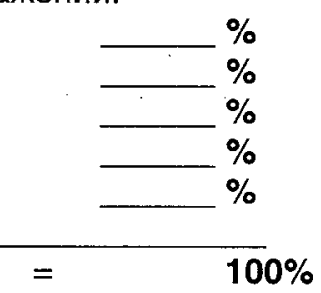

Например:

Преподавание

Практика

$45 \%$

Научная работа

Руководство

$10 \%$

Другие (Написание статей) $\quad 10 \%$

$+$

$=$

$100 \%$

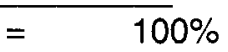

В случае варианта «Другие», перечислите виды деятельности: 


\section{Продолжение Раздела IV: Профессиональный опыт}

1.Какова сфера Ваших профессиональных интересов в области социальной работы? (Например: дети, алкоголь и наркотики, пожилые люди, ВИЧ инфицированные/больные спИДом).

2. Вы отдаете предпочтение макро (крупные системы) или микро (малые системы) подходу к социальной работе? Отметьте только один вариант: Макро Микро

3. Сколько лет Вы работаете в области социальной работы? лет (с точностью до ближайших пол года, например 5.5 лет)

4. Вам приходилось работать с людьми из другой культурной или языковой среды, отличной от Вашей?

Да Нет

В случае ответа «Да», опишите Ваш опыт:

5. Участвуете ли Вы в какой-либо профессиональной международной деятельности?

Да Нет

В случае ответа «Да», опишите Вашу деятельность:

6. Какие возможности Вы используете для расширения знаний о глобализации? Укажите все возможные варианты.

$\begin{array}{llll}\text { Радио } & & \begin{array}{l}\text { Газеты } \\ \text { Журналы } \\ \text { Телевидение } \\ \text { Интернет }\end{array} \\ \text { Видео } & - & \begin{array}{l}\text { Научн. издания } \\ \text { Конференции } \\ \text { Книги }\end{array} & \\ \text { Семинары } & \end{array}$

Академич. обмены Встречи с людьми Поездки Другие Ни один из них

В случае варианта «Другие», перечислите возможности:

7. Какие возможности Вы предпочитаете использовать для расширения знаний о глобализации? Укажите все возможные варианты.

Радио

Телевидение

Интернет

Видео

Книги

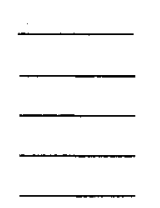

Газеты

Журналы

Научн. издания

Конференции

Семинары
Академич. обмены Встречи с людьми Поездки Другие Ни один из них

В случае варианта «Другие», перечислите возможности:

Продолжение на следующей станице. 


\section{Раздел V: Личный опыт}

1. В какой стране Вы проживаете в настоящий момент?

2. В настоящий момент Вы проживаете в той стране, где родились? Да Her

В случае ответа «Нет», укажите страну Вашего рождения.

3. Выезжали ли Вы за пределы страны, в которой Вы проживаете в настоящий момент?

Да Нет

В случае ответа «Да», перечислите все страны, в которых Вы побывали и сроки их посещения:

4.Укажите самый длительный период пребывания за рубежом. Укажите приблизительные сроки пребывания. (Например: 0 дней, 2 недели, 1 месяц, 3 года).

5. Назовите все языки, которыми Вы владеете:

6. Каково этническое, культурное и религиозное происхождение Вашей семьи? Перечислите ниже: (Например: китаец, баварец, афро-американец, буддист, мусульманин, русский православный).

7. Какой из ниже приведенных уровней социально-экономического статуса соответствует Вам в большей степени? Укажите только один вариант:

Низкий Средний Высокий

8. Укажите Ваш пол?

Женский Мужской

9. В каком году Вы родились?

\section{Продолжение на следующей станице.}




\section{Раздел VI: Вопросы или комментарии}

Приведите ниже Ваши комментарии или вопросы, касающиеся глобализации и образования в области социальной работы:

КОНЕЦ АНКЕТЫ

\section{СПАСИБО ЗА ВАШЕ УЧАСТИЕ!}

Если Вам интересно исследование по данной теме, Вы можете оставить свои контактные данные:

Имя:

Электронный адрес:

Почтовый адрес: 


\section{APPENDIX C}

CONSENT PREAMBLE AND IRB APPROVAL 
RAVMOND A. KENT

\section{Globalization and Social Work Education: An International Comparative Analysis}

\section{$12 / 12 / 06$}

Dear Social Work Educator:

You are being invited to participate in a research study conducted by Elaine Wright, Doctoral Candidate, and sponsored by the Kent School of Social Work at the University of Louisville. The purpose of this study is to explore the impacts of globalization on social work education around the worid. The information collected will be compared with responses from social work educators at social work schools in other countries.

The questionnaire for this study should take about thirty minutes to complete. By completing this questionnaire, you are indicating your voluntary agreement for participation in this research. You are free to decline to answer any questions that make you feel uncomfortable. You may refuse or discontinue to participate at any time without loss of benefits to which you are otherwise entitled. Though the results of this research may not benefit you directly, your participation may be helpful to others in the future. There are no known risks for your participation in this research study.

Individuals from the sponsor, the Human Subjects Protection Program Office (HSPPO), the Institutional Review Board (IRB), and other regulatory agencies may inspect these records. In all other respects, the data will be held in confidence to the extent permitted by law. The data will be kept in a secure location at the Kent School of Social Work. Should the data be published, your identity will not be disclosed.

If you have any questions, concerns, or complaints about the research study, please contact Dr. Thomas R. Lawson, Principal Investigator, at 1(country code)-502-852-6922 or by email at tom.lawson@louisville.edu. If you have any questions about your rights as a research subject, you may call the HSPPO at 1-502-852-5188 to discuss, in private, any questions about your rights as a research subject with a member of the IRB. You may also call this number if you have other questions about the research or cannot reach the research staff. The IRB is an independent committee composed of members of the University community, staff of the institutions, as well as people from the community not connected with these institutions. The IRB has reviewed this study.

If you have concerns or complaints about the research or research staff and you do not wish to give your name, you may call 1-877-852-1167. This is a 24-hour phone line answered by people who do not work at the University of Louisville.

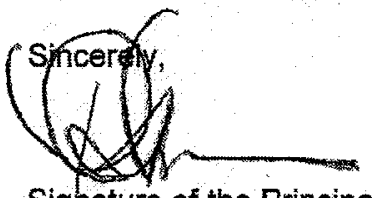

Signature of the Principal Investigator

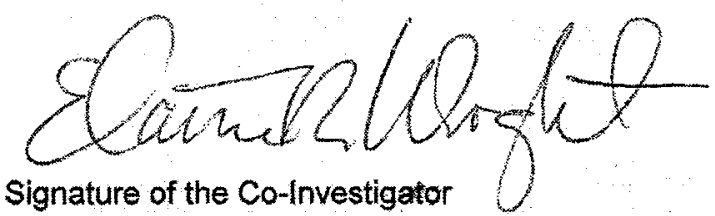

Date Written: 12/9/06 


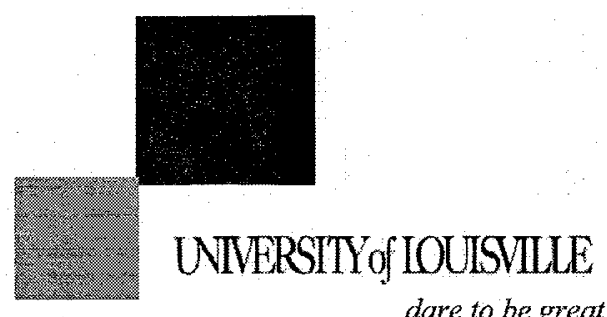

January 8, 2007

Dr. Thomas R. Lawson

(Elaine Wright)

Kent School of Social Work

University of Louisville

Louisville, KY 40292
HUMAN SUBJECTS PROTECTION PROGRAM OFFICE

University of Louisville MedCenter One, Suite 200 501 E. Broadway

Louisville, Kentucky $40202-1798$

Office: $\quad 502-852-5188$

Fax: $\quad 502-852-2164$

RE: $\quad 680.06 /$ Globalization and Social Work Education: An International Comparative Analysis

Dear Doctor Lawson:

The above study has been received by the Human Subjects Protection Program Office. It has been determined by the chair of the Institutional Review Board that the study is exempt according to 45 CFR 46.101 (b) 2 since the research involves the use of educational tests (cognitive, diagnostic, aptitude, achievement), survey procedures, interview procedures or observation of public behavior, unless: (i) information obtained is recorded in such a manner that human subjects can be identified, directly or through identifiers linked to the subjects; and (ii) any disclosure of the human subjects' responses outside the research could reasonably place the subjects at risk of criminal or civil liability or be damaging to the subjects' financial standing, employability, or reputation. The study is exempt only if information that could identify subjects is not recorded.

This study was also reviewed through 45 CFR 46.117 (c), which means that an IRB may waive the requirement for the investigator to obtain a signed informed consent form for some or all subjects if it finds that the research presents no more than minimal risk of harm to subjects and involves no procedures for which written consent is normally required outside of the research context.

The purpose of this study is a comparative analysis of the impacts of globalization on social work education as described by social work educators in China, Germany, Russia and the USA.

Since this study has been found to be exempt, no additional reporting, such as submission of Progress Reports for continuation reviews, is needed. Please note: before you use the submitted Preamble with subjects, please be certain to include the Principal Investigator's name and contact information in the letter. Best wishes for a successful study. Please send all inquires and electronic revised/requested items to our office email address at hsppofc@louisville.edu.

Sincerely,

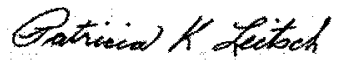

Patricia K. Leitsch, Ph.D., Chair,

Social/Behavioral/Educational Institutional Review Board

PKL/Crn 


\section{CURRICULUM VITAE}

\section{ELAINE R. WRIGHT, MSSW, PHD}

P.O. Box 4954, Louisville, KY 40204

elaine.r.wright@gmail.com

(502) 634-2579

\section{PROFESSIONAL INTERESTS}

Globalization, immigrants and refugees, human rights advocacy, international social work, social work education, sustainable communities, and youth empowerment.

\section{EDUCATION}

Doctorate of Philosophy in Social Work - December 2007, GPA 4.0/4.0

Dissertation - Globalization and Social Work Education: An Initial International Inquiry

Kent School of Social Work, University of Louisville, Louisville, Kentucky

Master's of Science in Social Work - May 1998, GPA 3.9/4.0

Policy \& Administration Emphasis, Children \& Families Setting

Kent School of Social Work, University of Louisville, Louisville, Kentucky

Bachelor's of Social Work - May 1995, GPA 3.5/4.0

Brescia University, Owensboro, Kentucky 


\section{PROFESSIONAL EXPERIENCE}

University of Louisville, Louisville, KY

- Research Assistant, Kent School of Social Work $\quad$ 6/2007 to 8/2007

Conducted research on sex offenders and community responses to sex offenses/offenders, correctional programming evaluation, and institutional violence. Created and maintained databases while collecting data from multiple sources for analysis.

University of Louisville, Louisville, KY

-Graduate Assistant, Kent School of Social Work

$5 / 2002$ to $5 / 2006$

Aided in implementation of international social work program activities. Assisted in facilitation of student and faculty exchanges. Collaborated on research about global issues and the social work profession. Presented information about international learning opportunities on campus, in the community, at national conferences, and abroad.

\section{University of Louisville, Louisville, KY}

-Lecturer, Kent School of Social Work $5 / 2003$ to $5 / 2005$ Instructed graduate students about macro practice and research issues, settings, techniques, and knowledge base. Supervised the development, implementation, and assessment of 12 graduate research projects. Created an environment for scholarly inquiry and professional development. Served on curriculum and advanced research practice committees. Courses taught at the Kent School of Social Work: SW 669 Advanced Research Practice II (Spring 2005), SW 668 Advanced Research Practice I (Fall 2004), SW 691 Advanced Macro Practice I (Fall 2003), SW 698 Children in Out of Home Care II (Teaching Assistantship Summer 2003). 
Eckerd Youth Alternatives, Elizabethtown, NC

-Social Services Coordinator, Camp E-Tik-Etu 8/2001 to 3/2002

Provided leadership of social services department for a residential wilderness treatment program for high-risk youth. Participated in strategic and budget planning with management team. Supervised multidisciplinary service plans and training of staff for integration of program goals and client/community concerns.

\section{Eckerd Youth Alternatives, Elizabethtown, NC}

-Family Worker, Camp E-Tik-Etu

$8 / 1999$ to $7 / 2001$

Responsible for case management and crisis intervention services of individuals and groups in all treatment phases from intake to transition and aftercare. Secured family and agency support necessary for the optimum experience of clients. Conducted home visits for assessment, support, and problem-solving sessions. Implemented a community parent skills training group.

YMCA of Greater Louisville, Louisville, KY

-Day Camp Counselor, Camp Piomingo 6/1999 to 8/1999

Assisted in implementation of wilderness day camp program for youth.

Collaborated with day camp director on daily and weekly program activities.

Responsible for supervision of special needs children and application of appropriate behavior management techniques.

\section{YMCA of Greater Louisville, Louisville, KY}

-International Project Coordinator

$1 / 1999$ to $5 / 1999$

Managed Wider Horizons employment training and peace/reconciliation project.

Developed program materials and services for $50+$ community volunteers and 20 at-risk youth from the Republic of Ireland and Northern Ireland. Organized youth work activities and weekly group sessions. Participated in grant writing and program evaluation. 
Catholic Charities, Louisville, KY -Orientation Program Coordinator 9/1998 to $12 / 1998$

Coordinated cultural orientation services for newly arrived refugee children and adults. Organized culturally and linguistically appropriate presentations and group discussions. Responsible for recruitment, training, and supervision of volunteers for children's program. Collaborated with educational consultant on orientation curriculum. Collected data and prepared reports to determine orientation needs and meet grant obligations.

YMCA of Greater Louisville, Louisville, KY -Project Consultant/Scheme Leader, Safe Place Services 5/1998 to 8/1998 Conducted public awareness campaign of Safe Place Services to 1000 youth in Lisburn and Belfast, Northern Ireland. Assisted in supervision of children's program at drop-in shelter. Provided crisis intervention on-site and via telephone.

\section{CONTINUING EDUCATION/PROFESSIONAL TRAININGS}

Birth Doula Workshop (DONA International - 2002)

Intermediate Grant Writing (University of Louisville - 2007)

Introduction to Grant Writing (University of Louisville - 2007)

Solution Focused Brief Therapy (Eckerd Youth Alternatives - 2001)

Therapeutic Crisis Intervention (Eckerd Youth Alternatives - 1999, 2000, 2001)

Working with Abused Families (Eckerd Youth Alternatives - 2001)

Working with Victims of Human Trafficking (Louisville OIA - 2007)

\section{PROFESSIONAL AFFILIATIONS}

Council on Social Work Education, Member (2002-Present)

International Association of Schools of Social Work, Member (2006-Present)

International Federation of Social Work, Member (2006-Present)

National Association of Social Work, Member (1996-Present) 


\section{HONORS AND AWARDS}

Academic Scholarship, Rhodes College (1991)

Golden Key International Honor Society (2006-Present)

Graduate Assistantships, University of Louisville (1995-1998, 2002-2007)

International Center Study Abroad Scholarship, University of Louisville (2005)

Outstanding Social Work Student, Brescia University (1995)

Outstanding Social Work Student, University of Louisville $(1998,2007)$

Recognition of Service Award, Kentucky Cabinet for Families \& Children (2003)

\section{ACADEMIC LEADERSHIP}

Brescia Broadcast, Editor (1994-1995)

Brescia Student Social Work Association, President (1993-1995)

Kent School of Social Work Student Association, Vice-President (1995-1996)

\section{RECENT COMMUNITY SERVICE}

Americana Community Center (2005)

Community Farm Alliance (2003-2006)

Living Lands and Waters (2006)

Louisville Science Center (2003-2004)

Squallis Puppeteers (2005-Present)

YMCA of Louisville International Services Committee (1997-Present)

\section{INTERNATIONAL EXPERIENCE}

Canada (1990, 1997), China (2006), England (1999), France (2006), Germany $(1996,2003,2004)$, Hungary $(2003,2004)$, India $(2005)$, Ireland $(1998,1999)$, Italy (1996), Mexico (1995, 2001), Northern Ireland (1998, 1999), Russia (2005, 2006), Scotland (1999), South Africa (2004), Spain (1988), Wales (1999) 


\section{PRESENTATIONS}

Lawson, T., Gamble, J. Jewell, J., \& Wright, E. (2007, March 27). China today: Coming to terms with their growing social problems. Presentation to members and guests. The Veritas Society, Bellarmine University, Louisville, Kentucky.

Wright, E. (2007, February 1). A social worker's journey around the globe. Presentation to students, faculty, and staff. Eckerd Youth Alternatives, Elizabethtown, North Carolina.

Lawson, T., Jewell, J., Kamlager, C., \& Wright, E. (2007, January 24). China today: Coming to terms with their growing social problems. Presentation to members and guests. The Asia Institute, Inc., Louisville, Kentucky.

Wright, E. (2006, September 12). Social work education: An international overview. Presentation to students and faculty. Belgorod State University, Belgorod, Russia.

Wright, E. (2006, July 7). Social work education: An international overview. Presentation to visiting Chinese faculty and administrators. Kent School of Social Work, Louisville, Kentucky.

Wright, E. (2006, June 26). Social work education: An international overview. Presentation to students and faculty. Chongqing Social Work Vocational. College, Chongqing, China.

Wright, E. (2006, June 20). Social work education: An international overview. Presentation to students and faculty. Wuhan Vocational and Technical College, Wuhan, China. 
Wright, E. (2003, May 29). Social work doctoral education in the United States. Presentation to visiting German students and faculty. Kent School of Social Work, Louisville, Kentucky.

Wright, E. (2003, June 11). Wilderness therapy and outdoor programs. Presentation to visiting German students and faculty. Kent School of Social Work, Louisville, Kentucky.

\section{MANUSCRIPTS IN PREPARATION}

Wright, E. \& Faul, A. The Environment and Social Work: An International Study of Student Attitudes and Practices.

Wright, E. The Environment in Social Work. A Qualitative Content Analysis 